JORGE RODOLFO BEINGOLEA GARAY

\title{
ANÁLISE DE DESEMPENHO DE UMA REDE DE SENSORES SEM FIO BASEADO NO PADRÃO \\ ZIGBEE/IEEE 802.15.4
}

São Paulo

2007 


\section{JORGE RODOLFO BEINGOLEA GARAY}

\section{ANÁLISE DE DESEMPENHO DE UMA REDE DE SENSORES SEM FIO BASEADO NO PADRÃO \\ ZIGBEE/IEEE 802.15.4}

Dissertação apresentada à Escola

Politécnica da Universidade de São

Paulo para obtenção do Título de

Mestre em Engenharia Elétrica

São Paulo 


\section{JORGE RODOLFO BEINGOLEA GARAY}

\section{ANÁLISE DE DESEMPENHO DE UMA REDE DE SENSORES SEM FIO BASEADA NO PADRÃO \\ ZIGBEE/IEEE 802.15.4}

Dissertação apresentada à Escola

Politécnica da Universidade de São

Paulo para obtenção do Título de

Mestre em Engenharia Elétrica.

Área de concentração:

Sistemas Eletrônicos.

Orientador:

Prof. Dr. Sergio Takeo Kofuji.

São Paulo 
Este exemplar foi revisado e alterado em relação à versão original, sob responsabilidade única do autor e com a anuência de seu orientador.

São Paulo,.... de de 2007.

Assinatura do autor:

Assinatura do orientador:

\section{FICHA CATALOGRÁFICA}

Garay, Jorge Rodolfo Beingolea

Análise de desempenho de uma rede de sensores sem fio baseada no padrão ZIGBEE/IEEE 802.15.4 / J. R. Beingolea Garay. - São Paulo, 2007.

p. 107.

Dissertação (Mestrado) - Escola Politécnica da Universidade de São Paulo. Departamento de Engenharia de Sistemas Eletrônicos.

1.Wireless 2.Dispositivos eletrônicos 3.Avaliação de desempenho (Arquitetura) 4.Redes de computadores 5.Energia I.Universidade de São Paulo. Escola Politécnica. Departamento de Engenharia de Sistemas Eletrônicos II.t. 


\section{AGRADECIMENTOS}

Ao meu Pai Jorge Enrique Beingolea a quem ainda devo um abraço de despedida, onde ele estiver que saiba que eu lhe amo e sempre lhe ame. A minha mãe Luisa Garay de Beingolea por ter sido a minha melhor amiga, por ter me apoiado sempre e ter sido o motor de meu sucesso.

Ao meu orientador Dr. Sergio Takeo Kofuji, quem pacientemente soube levar nossas diferenças no percorrer deste mestrado, pelas oportunidades e por ter sido um bom amigo quando foi necessário. Ao mesmo tempo pelas muitas discussões que ajudaram na elaboração desta dissertação e dos artigos publicados ao longo deste mestrado.

Ao Conselho Nacional de Desenvolvimento Científico e Tecnológico - CNPq pelo financiamento deste trabalho.

Aos meus colegas do grupo PAD e HumaLab pelo apoio, tem sido todos imprescindíveis. 


\section{RESUMO}

As Redes de Sensores Sem Fio (RSSF) caracterizam-se por suas limitações computacionais e escassos recursos de energia, que limitam seu desempenho em determinados ambientes. O padrão Zigbee, baseado nas especificações da norma IEEE 802.15.4, constitui uma alternativa de solução às limitações existentes. Entre seus objetivos o padrão aumenta a automia dos nós sensores e proporciona confiabilidade em transmissões de baixa velocidade através de tecnicas eficientes de gerenciamento de recursos. Embora o padrão Zigbee/802.15.4 seja em teoria a melhor opção para o desenvolvimento de novas tecnologias de nós sensores, faz-se necessário uma avaliação das diferentes características do padrão e seu comportamento em RSSF. Especificamente a avaliação é realizada nas primeiras três camadas: Física, de Enlace e de Rede.

Embora vários estudos sobre o padrão tenham sido realizados, a maioria baseada em simulações ou análise matemática. Faz-se necessária, a realização de experimentos em ambientes reais (Internos e Externos) que possam permitir a obtenção de resultados que auxiliem no desenvolvimento de novos hardwares e aplicações para as novas RSSF baseadas no padrão Zigbee.

$\mathrm{Na}$ realização dos experimentos consideramos cenários Internos e Externos, foram avaliadas as características que as RSSFs ZigBee/802.15.4 apresentam nestes ambientes de avaliação. Nos experimentos realizados se incluem a aplicação dos modelos BeaconEnabled e Beacon-Disabled propostos pelo 802.15.4 e adotados pelo padrão ZigBee.

O trabalho também apresenta resultados de alcance de sinal de um nó sensor para os dois cenários de avaliação, o qual inclui as distâncias máximas de separação dos nós na rede com o objetivo de atingir maiores áreas de cobertura. Ao mesmo tempo é realizada uma análise das topologias malha, estrela e seu impacto nos diferentes ambientes de avaliação.

Finalmente é implementada uma ferramenta para medir o impacto no consumo de energia do nó nos diferentes eventos de comunicação. 


\begin{abstract}
A Wireless sensors network (WSN) have limited energy and computational capabilities that difficult the performance in some environments. Considering these limitations the Zigbee standard was created based in the specifications of the norm IEEE 802.15.4. Between their objectives of this standard is to increase the autonomy of sensors and provides trustworthiness of transmissions of low speed through efficient techniques of resource management. Although the Zigbee/802.15.4 standard is in theory the best option for the development to new technologies of sensors nodes, is necessary an evaluation of the different characteristics of the standard and its behavior in wireless sensors network. Specifically the evaluation is carried out in the first three layers; Physical, Link and Network, measuring its performance on an architecture of sensors nodes developed on the characteristics of the Zigbee standard. Although some studies on the standard have been carried out, they are all based on simulation or mathematical analysis then is necessary to perform experiments in real environments. These experiments could allow the acquirement of results that assist in the development of new hardware and applications for the new wireless sensors network based on the Zigbee standard.
\end{abstract}

To realize the experiments we consider indoor and outdoor environments, were evaluated the features that WSNs ZigBee/802.15.4 show in those environments. Were included on the experiments the application of the models Beacon-Enabled e Beacon-Disabled proposed by 802.15 .4 and adopted by ZigBee standard.

This work too contains results of signal coverage of a sensor node for the two scenarios of evaluation. This result includes the separation distance between nodes in a net with the aim cover big areas. At the same time is realized an analysis of the net topologies mesh and star, and their impact at different environments of evaluation.

Finally is developed a tool to measure the impact of energy consumption of the node on the different communication events. 


\section{Lista de Figuras}

2.1 Representação de Uma RSSF . . . . . . . . . . . . . . . . . . . . . 6

2.2 Diagrama de Blocos de um Nó Sensor . . . . . . . . . . . . . . . . . . 6

2.3 Modelo de camadas de uma RSSF . . . . . . . . . . . . . . . . 11

2.4 Bandas de Operação de Freqüência Fonte(802.15.4 2003) . . . . . . . . . . 13

2.5 Diagrama de blocos da transformação de sinal . . . . . . . . . . . . . . 14

2.6 Modulação QPSK e OQPSK . . . . . . . . . . . . . . . . . 15

2.7 Modelo de camadas IEEE 802.15.4 segundo modelo OSI. Fonte (802.15.4,

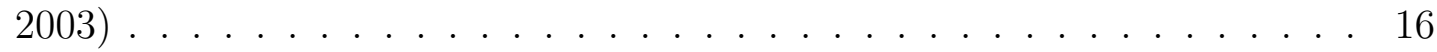

2.8 Formato do frame MAC. Fonte $(802.15 .4,2003) \ldots \ldots \ldots$. . . . . 17

2.9 Frame do $A C K \ldots \ldots \ldots \ldots$

2.10 Frane de Dados com o Campo Command Type. Fonte $(802.15 .4,2003)$. . . 19

2.11 Estrutura do frame Beacon (Beacon Frame). Fonte $(802.15 .4,2003)$. . . . 20

2.12 Transmissão ao Coordenador. Beacon-Enabled (a) e Beacon-Disabled (b) . 21

2.13 Transmissão a partir do Coordenador. Beacon-Enabled (a) e BeaconDisabled (b) . . . . . . . . . . . . . . . . . . 22

2.14 Transmissão Beacon-Enabled na RSSF . . . . . . . . . . . . . . 23

2.15 Beacon transmitido pelo coordenador sengundo intervalos de tempo. . . . . 23

2.16 Transmissão Beacon-Disabled na RSSF . . . . . . . . . . . . . . . 24

2.17 ACK enviados ao coordenador pelos nós da rede . . . . . . . . . . . . . . 24

2.18 Modelo OSI para o Padrão ZigBee. Fonte (Zigbee, 2005) . . . . . . . . . . 25

2.19 Freqüências e Taxas de Transmissão . . . . . . . . . . . . . . . . . . 26

2.20 Modelos de rede . . . . . . . . . . . . . . . . . . . . . . 28

2.21 Diagrama de Blocos do Surge-Telos . . . . . . . . . . . . . . . 30

2.22 Formato do pacote Surge-Telos . . . . . . . . . . . . . . . . . 31 
3.1 Análise de RSSI no NS-2 segundo variações do tamanho do pacote de dados em ambientes internos e externos. Fonte (Petrova et al., 2006) . . . . . . . 33

3.2 Modulo PAN4450. Fonte (Hyncica et. al. 2006) . . . . . . . . . . . . . 34

3.3 Bancada de testes e Distribuição dos geradores de Tráfico e o Coordenador da rede. Fonte $($ Lee, 2005) . . . . . . . . . . . . . . 36

3.4 Nó sensor Z-Wave (módulo de teste). Fonte (Ferrari et al., 2007) . . . . . . 37

4.1 Diagrama de blocos da montagem para medida de Consumo de Energia . . 40

4.2 Interface do Programa Medidor de tensão da bateria $\ldots$. . . . . . . . . . . 41

4.3 Diagrama de Blocos do Filter-Log.nc . . . . . . . . . . . . . . . 42

4.4 TmoteSky . . . . . . . . . . . . . . . . . . . 43

4.5 Diagrama de Blocos do Modulo TmoteSky. Fonte (Chipcon, 2006) . . . . . 44

4.6 Mica2dot . . . . . . . . . . . . . . . . . . . . 44

4.7 Cenário para a realização dos experimentos - Ambiente Interno . . . . . . 45

4.8 Cenário para a realização dos experimentos - Ambiente Externo .... 47

4.9 Código para configuração do Time-Rate . . . . . . . . . . . . . . . . 48

4.10 Bancada de testes para análise de RSSI (HP8565E) . . . . . . . . . . . . . 49

4.11 Diagrama de Conexão do HP4156A com os nós sensores . . . . . . . . . . . 49

4.12 Disposição inicial dos nós . . . . . . . . . . . . . . . . . . 50

4.13 Onda Construtiva e Onda Destrutiva . . . . . . . . . . . . . . . 50

4.14 Disposição dos nós nas bases . . . . . . . . . . . . . . . . . . . 51

4.15 Montagem dos Equipamentos de testes para a análise do RSSI . . . . . . . 53

4.16 Mica2 e SensorBoard - TmoteSky . . . . . . . . . . . . . . . . 54

4.17 TmoteSky com o Sensorboard do Mica2 . . . . . . . . . . . . . . . 54

4.18 Esquematico . . . . . . . . . . . . . . . . . . 55

5.1 Alcance \& Vazão de Dados Ambiente Interno . . . . . . . . . . . . . . . 57

5.2 Intensidade do Sinal Recebido RSSI aos 60m. (imagem extraída do analisador de espectro $\ldots \ldots \ldots \ldots . \ldots . \ldots 58$

5.3 Intensidade do Sinal Recebido RSSI aos $75 \mathrm{~m}$ (imagem extraída do analisador de espectro) . . . . . . . . . . . . . . . . . . 59

5.4 Alcance \& Vazão de Dados - Ambiente Externo . . . . . . . . . . . . . . . 60

5.5 Distribuição da Rede - Topologia Estrela . . . . . . . . . . . . . . . . . . 62 
5.6 Vazão de dados - Topologia Estrela (Ambiente Interno) . . . . . . . . . . . 62

5.7 Vazão de dados - Topologia Estrela (Ambiente externo) . . . . . . . . . . . 63

5.8 Distribuição Aleatória da Rede . . . . . . . . . . . . . . . . . 64

5.9 Vazão de Dados e Área de Cobertura (Distribuição Aleatória) ...... 64

5.10 Distribuição da Rede - Topologia tipo Malha . . . . . . . . . . . . . . . . . 65

5.11 Vazão de Dados e Área de Cobertura (Topologia tipo Malha) . . . . . . . . 65

5.12 ID do Pacote e ID do sensor para o cálculo de Taxa de Perda de Pacotes . 68

5.13 Sincronização nó de borda e nó comum na rede - Sem Antenas Externas . . 69

5.14 Montagem da Antena Externa para o nó sensor . . . . . . . . . . . . . . . 70

5.15 Sincronização nó de borda e nó comum na rede - Com Antenas Externas . 71

5.16 Consumo $(\mathrm{mA})$ Transmissor $\mathrm{T}_{x}$ (TmoteSky) . . . . . . . . . . . . . 72

5.17 Consumo $(\mathrm{mA})$ Receptor $\mathrm{R}_{x}$ (TmoteSky) . . . . . . . . . . . 73

5.18 Consumo $(\mathrm{mA})$ Nó em estado Idle $\mathrm{T}_{x}$ (TmoteSky) . . . . . . . . . . . . . 74

5.19 Consumo (mA) Nó em estado Idle (Rádio Off) . . . . . . . . . . . . . . 74

5.20 Vazão de Dados Beacon-Disabled Beacon-Enabled . . . . . . . . . . . 76

5.21 Cenário de LME - Distribuição 1 . . . . . . . . . . . . . 80

5.22 Cenário LME - Distribuição 2 . . . . . . . . . . . . . . . . . . 80

5.23 Atenuação Obstáculo - Vidro . . . . . . . . . . . . . . . 81

5.24 Atenuação Obstáculo - Divisória de Madeira . . . . . . . . . . . . . . . . . 81

5.25 Atenuação Divisória - Parede . . . . . . . . . . . . . . . 82

5.26 Atenuação Parede - Divisória - Parede . . . . . . . . . . . . . . . . 83

5.27 Atenuação Parede - Divisória - Parede - Divisória . . . . . . . . . . . . . 83

6.1 RSSI - Distância $75 \mathrm{~m}$ ambiente interno. . . . . . . . . . . . . . . 87

6.2 RSSI - Distância 35m ambiente interno. Fonte (PETROVA et. al. 2006) . 88

6.3 RSSI - Distância de separação 80cm ambiente interno. Fonte (FERRARI et. al. 2007) . . . . . . . . . . . . . . . . . . 88

6.4 Vazão - Transmissão Direta e Indireta com beacon. Fonte (J. Lee 2005) . 89 


\section{Lista de Tabelas}

2.1 Operação de Freqüência IEEE $802.15 .4 \ldots$. . . . . . . . . . . . . . . . . 13

3.1 Trabalhos Experimentais . . . . . . . . . . . . . . . 38

5.1 Alcance \& Vazão de Dados. . . . . . . . . . . . . . . . . . . . . . 58

5.2 Alcance \& Vazão de Dados e RSSI. . . . . . . . . . . . . . . . . . . . . . . 59

5.3 Alcance \& Vazão de Dados (valores médios) . . . . . . . . . . . . . 61

5.4 Taxa de Perda de Pacotes - Topologia Estrela (Ambiente Interno). . . . . . 67

5.5 Taxa de Perda de Pacotes - Topologia Estrela (Ambiente Externo). . . . . 67

5.6 Taxa de Perda de Pacotes - Topologia Malha (Ambiente Externo). . . . . . 67

5.7 Taxa de Perda de Pacotes - Topologias Estrela e Malha. . . . . . . . . . . 68

5.8 Sincronização e Consumo de Energia . . . . . . . . . . . . . . 71

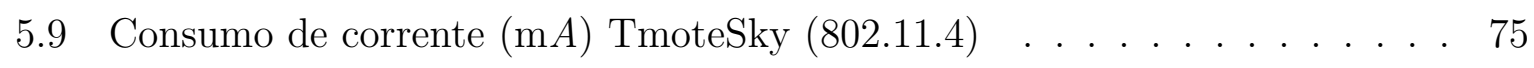

5.10 Perda de Pacotes Beacon-Disabled . . . . . . . . . . . . . 77

5.11 Perda de Pacotes Beacon-Enabled . . . . . . . . . . . . . . 77

5.12 Consumo de Energia do nó na rede. . . . . . . . . . . . . 78

5.13 RSSI - Atenuação segundo obstáculos Potência de saida 10dBm . . . . . . 83

5.14 RSSI - Atenuação segundo obstáculos Potência de saida $17 \mathrm{dBm}$. . . . . . 84

5.15 RSSI - Atenuação segundo obstáculos Potência de saida 10dBm . . . . . . 85

6.1 Trabalhos Experimentais - Alcance do Sinal . . . . . . . . . . . 87

6.2 Trabalhos Experimentais - Alcance do Sinal . . . . . . . . . . . . . 90

6.3 Topologias Estrela e Malha - Áreas de Cobertura. Fonte (Capitulo V) . . . 91

6.4 Distância de separação dos nós da rede segundo a área de cobertura. . . . . 93 


\section{Lista de Abreviaturas e Siglas}

ACK Acknowledgement

API Application Programming Interface

BER Bit ErrorRate

BPSK Binary Phase Shift Keying

CCA Clear Channel Assessment

CRC Cyclic Redundancy Chech

CSMA/CA Carrier Sense Multiple Access with Collision Avoidance

DAQ Data Acquisition

DSSS Direct Sequence Spread Spectrum

DSN Data Sequence Number

FTPS Flooding Time Synchronization Protocol

GPS Global Positioning System

IEEE Institute of Electrical and Electronics Engineers

ISM Industrial, Scientific and Medical

ISO International Organization for Standardization

LQI Link Quality Indicator

LR-WPAN Low-Rate Wireless Personal Area Networks

LWIM Low power Integrated Microsensors

MAC Medium Access Control

MDA Mote Data Acquisition Board

MEMS Micro Electro Mechanical Systems

MIB Mote Interface Board

MFR MAC FooterR

MPDU MAC Protocol Data Unit

MSK Minimum Shift keying 
MTS

NS-2

O-QPSK

OSI

PHR

$\mathrm{PN}$

PPDU

PSDU

RFD

RSSI

RSSF

SAP

SHR

SSCS

USB

SFD

WLAN

SCM

$\mathrm{Vi}$

WPAN
Mote Sensor Board

Network Simulator-2

Offset Quadrature Phase-shift Keying

Open Systems Interconnect

Phy HeaderR

Pseudo-Ruido

Phy Protocol data Unit

Phy Service Data Unit

Reduced Function Device

Receive Signal Strength Indication

Rede de Sensores Sem Fio

Point Access Service

Synchonization HeaderR

Subcamada de Convergência de Serviços Específicos

Universal Serial Bus

Start of Frame Delimiter

Wireless Local Area Network

Schedule Control Module

Virtual Instrument

Wireless Personal Area Network 


\section{Sumário}

1 INTRODUÇÃO

1.1 Contexto e Motivação do Projeto de Pesquisa . . . . . . . . . . . . . . . 2

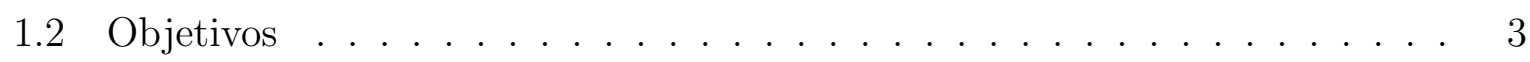

1.2.1 Objetivos Específicos . . . . . . . . . . . . . . 3

1.3 Organização do trabalho . . . . . . . . . . . . . . . . . 4

2 CONCEITOS BÁSICOS

2.1 Redes de Sensores Sem Fio (RSSF) . . . . . . . . . . . . . . 6

2.1.1 Objetivo de uma RSSF e considerações na implementação. . . . . . 7

2.1.2 Características de uma RSSF. . . . . . . . . . . . 8

2.1.3 Aplicações das Redes de Sensores Sem Fio . . . . . . . . . . . . . . 9

2.1.4 Modelo Por Camadas das RSSFs . . . . . . . . . . . . . . . 10

2.2 Conectividade IEEE 802.15.4 e $\quad$ o $\quad$ Padrão

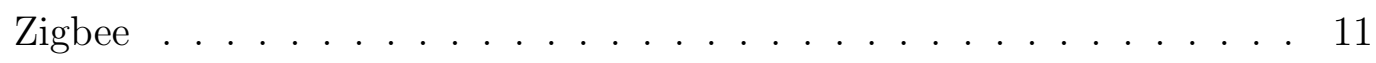

2.2.1 Camada Física . . . . . . . . . . . . . . . . . . . 12

2.2.1.1 Canais IEEE $802.15 .4 \ldots \ldots \ldots \ldots$

2.2.1.2 Modulação IEEE 802.15.4 . . . . . . . . . . . . . . . 14

2.2.2 Camada de Enlace de Dados . . . . . . . . . . . . . . . . . 16

2.2.2.1 Estrutura do Frame MAC . . . . . . . . . . . . . . . 17

2.2.2.2 Estrutura do Quadro de Dados (Data Frame) . . . . . . 17

2.2.2.3 Estrutura do Frame ACK (Acknowledgment Frame) . . . . 18

2.2.2.4 Estrutura do Frame de Comandos MAC (MAC Command Frame $\ldots \ldots \ldots \ldots \ldots$

2.2.2.5 Estrutura do Frame Beacon (Beacon Frame) . . . . . . . . 19 
2.2.3 Os Modelos de Transmissão de Dados . . . . . . . . . . . . . . . . . 20

2.2.3.1 Transmissão ao Coordenador . . . . . . . . . . . . . . 20

2.2.3.2 Transmissão a partir do Coordenador . . . . . . . . . . . . 21

2.2.4 Modelos de Transmissão na RSSF Zigbee . . . . . . . . . . . . . . . 22

2.2.4.1 Transmissão Beacon-Enabled . . . . . . . . . . . 22

2.2.4.2 Transmissão Beacon-Disabled .............. 23

2.3 O Padrão ZigBee . . . . . . . . . . . . . . . . . . . . . . . . 24

2.3.1 Rede de Área Pessoal (WPAN) . . . . . . . . . . . . . . . 25

2.3.2 Conectividade Zigbee . . . . . . . . . . . . . . . . . . . 26

2.3 .3 Aplicações . . . . . . . . . . . . . . . . . . . . . . . 27

2.3.4 Camada de Rede . . . . . . . . . . . . . . . . . . 27

2.3.4.1 Modelos de Rede . . . . . . . . . . . . . . . . . . 28

2.3.4.2 Roteamento na Rede de Sensores Sem Fio . . . . . . . . . 29

3 TRABALHOS CORRELATOS

3.1 Performance Study of IEEE 802.15.4 Using Measurements and Simulations 33

3.2 The ZigBee Experience . . . . . . . . . . . . . . . . . . . . . . . . . . 34

3.3 An Experiment on Performance Study of IEEE 802.15.4 Wireless Networks 35

3.4 Wireless Sensor Networks: Performance Analysis in Indoor Scenarios . . 36

4 METODOLOGIA $\quad 39$

4.1 Soluções Propostas . . . . . . . . . . . . . . . . . . . . . 40

4.1.1 Ferramenta para análise do Consumo de Energia - Descrição da

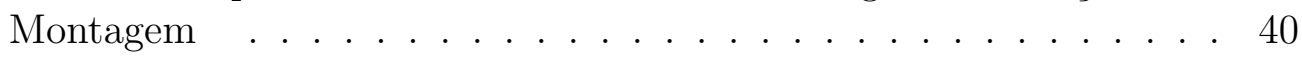

4.1.1.1 Descrição da Interface Vi-Energy Para Coleta dos Dados 41

4.2 Ferramenta para Filtragem dos Logs de dados . . . . . . . . . . . . . . . 42

4.3 Hardware Empregado nos Experimentos . . . . . . . . . . . . . . 43

4.4 Cenários de Avaliação . . . . . . . . . . . . . . . . . . . . 45

4.4 .1 Cenário de Avaliação Ambiente Interno . . . . . . . . . . . . . . . 45

4.4 .2 Cenário de Avaliação Ambiente Externo . . . . . . . . . . . . . . . 46

4.5 Configuração do Hardware para Avaliação . . . . . . . . . . . . . . . . . . 47 
4.5.1 Considerações Finais na Distribuição da rede nos Cenários de Avaliação. . . . . . . . . . . . . . . . . . . . . 50

4.5.2 Configuração do Hardware para a Análise do RSSI . . . . . . . . . 51

4.5.3 Montagem da Placa de Sensores (Sensorboard) do Mica2 para o TmoteSky ........................ 53

5 RESULTADOS DOS EXPERIMENTOS 56

5.1 Camada de Rede . . . . . . . . . . . . . . . . . . . . 57

5.1 .1 Análise em Ambiente Interno (Alcance Do Sinal) . . . . . . . . . . 57

5.1.2 Análise em Ambiente Externo (Alcance Do Sinal) . . . . . . . . . . 60

5.1.3 Análise das Topologias e Densidade da Rede . . . . . . . . . . . . . 61

5.2 Camada de Enlace . . . . . . . . . . . . . . . . . . . . 75

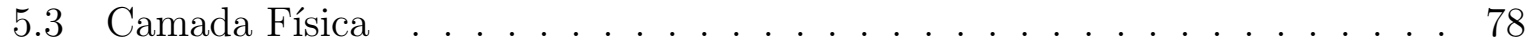

6 Conclusões e Trabalhos Futuros $\quad 86$

6.1 Contribuições Reais do Trabalho e Trabalhos Futuros . . . . . . . . . . . . 92

6.1.1 Trabalhos Futuros . . . . . . . . . . . . . . . 94

APÊNDICE A - Código Fonte dos Programas Desenvolvidos 102

$\begin{array}{ll}\text { APÊNDICE B - Código Fonte } V i & 107\end{array}$ 


\section{Capítulo 1}

\section{INTRODUÇÃO}

Um dos maiores desafios nas redes ad-hoc e nas redes de sensores sem fio (RSSF) é desenvolver técnicas de comunicação que resultem em baixo consumo de energia. A norma IEEE 802.15.4 (802.15.4, 2003) propõe o uso de técnicas de gerenciamento de energia e modulação em quadratura de fase O-QPSK. Isso permite uma maior taxa de transmissão de pacotes em um tempo menor diminuindo o consumo de energia do nó. Ao mesmo tempo se propõe alcançar maiores distâncias de cobertura através de topologias Estrela (Star), Malha (mesh), peer-to-peer (802.15.4, 2003; ZIGBEE, 2005).

A criação de soluções para melhorar o desempenho das RSSF tem estimulado a atenção de pesquisadores com o objetivo de desenvolver novas técnicas de comunicação entre os elementos da rede, e dessa forma garantir a existência da mesma por um tempo maior. Entre estas soluções se tem a criação e uso de eficientes protocolos de roteamento que permitam maximizar as características dos padrões de comunicação para RSSFs. O presente trabalho de pesquisa busca avaliar as características de eficiência do padrão Zigbee (ZIGBEE, 2005) em uma Rede de Sensores sem Fio nas três primeiras camadas: camada física, camada de enlace e a camada de rede. Para tanto, são realizadas análises dos modelos de transmissão adotados pelo padrão Zigbee/802.15.4, modelos BeaconEnabled e Beacon-Disabled e seu impacto no consumo de energia da rede; é também realizada uma análise das topologias malha e estrela nos diferentes ambientes de avaliação. Este estudo procura ajudar aos desenvolvedor de hardware de RSSF quanto às 
especificações da norma IEEE 802.15.4 e o padrão Zigbee e os parâmetros de eficiência que o dispositivo desenvolvido deverá atingir durante seu funcionamento, tanto em ambientes internos como em ambientes externos. Finalmente, é realizada uma análise do nível de Intensidade do Sinal Recebido segundo as características do ambiente de propagação.

\subsection{Contexto e Motivação do Projeto de Pesquisa}

Cada vez mais o número de usuários de redes é maior e mais exigente, porque dependem em maior medida das tecnologias existentes para o seu trabalho. Nas RSSFs essa situação não é diferente, havendo necessidade de conhecer os parâmetros de eficiência que o hardware produto dos diferentes padrões deverá fornecer. Novos padrões de comunicação são criados com o objetivo de aumentar o desempenho das comunicações em diferentes ambientes e aplicações. Estes padrões são representados através de um modelo em camadas, o qual mostra ser útil quando se deseja fazer um estudo detalhado de cada uma das camadas propostas. Assim sendo, essa mesma forma de divisão por camadas facilita a avaliação de desempenho de uma RSSF. A adoção do modelo de camadas resulta em um estudo detalhado da norma IEEE 802.15.4 e o padrão Zigbee. Estudos analíticos e simulações foram realizados tentando caracterizar o desempenho do padrão IEEE 802.15.4 (CALLAWAY et al., 2002) (ZHENG; LEE, 2004), aliás, uma grande quantidade de esforços têm sido empregados na caracterização da eficiência de energia e otimização da pilha Zigbee para RSSF (BOUGARD et al.,2005) (AL-KARAKI; KAMAL, 2004) (SADAGOPAN; KRISHNAMARCHARI; HELMY, 2003) (HEINZELMAN; CHANDRAKASAN; BALAKRISHNAN, 2000). Em (MISIC, J. V.; MISIC, V. B.; SHAFI, 2004) são apresentados estudos de simulações e medidas com produtos IEEE 802.15.4 com principal interesse na descoberta de métricas, úteis para o desenvolvimento de redes de sensores para ambientes internos e ambientes externos. Timmons e Scalon (2004) apresentam análises matemáticas do desempenho do IEEE 802.15.4 em relação às redes de sensores para aplicações médicas. Lee (2005) realizou uma série de análises de desempenho através de vários experimentos práticos, incluindo os efeitos de 1) transmissão direta e indireta 2) mecanismos CSMA-CA 3) tamanho do payload da dados 4) modo beacon habilitado. Embora existam vários estudos do IEEE 802.15.4 com resultados obtidos através de simulações e alguns outros trabalhos 
experimentais publicados recentemente, estes não utilizam todas as métricas necessárias para determinar a eficiência da norma IEEE 802.15.4 e o padrão ZigBee em diferentes aplicações como uma Rede de Sensores Sem Fio.

Desde sua criação o grupo Humanlab no Laboratório de Sistemas Integráveis da EPUSP vem trabalhando na área de RSSF produzindo resultados através de pesquisas em aplicações de segurança sobre curvas elípticas para RSSF (ASCAMA, 2005). Estudos de caracterização e desempenho de uma RSSF são realizados em (CABRINI, 2006) utilizando as arquiteturas de hardware do Mica2 e Mica2dot que operam na faixa de freqüência dos $900 \mathrm{MHz}$.

Este trabalho procura dar continuidade às contribuições existentes em RSSF realizando um estudo de desempenho das principais características de um novo padrão de comunicações chamado ZigBee e sua aplicação em RSSF. O estudo é realizado através da aplicação de métricas de desempenho como: vazão de dados, taxa de perda de pacotes, consumo de energia, impacto das topologias estrela e malha nos diferentes ambientes de avaliação, modelos de transmissão e a caracterização dos cenários de avaliação segundo as características de RSSI.

\subsection{Objetivos}

O objetivo principal do presente trabalho é avaliar o desempenho de uma Rede de Sensores Sem Fio (RSSF) baseada no uso do padrão de comunicações Zigbee e a norma IEEE 802.15.4 nas primeiras três camadas: camada física, camada de enlace e a camada de rede.

\subsubsection{Objetivos Específicos}

- realizar um estudo objetivo de uma RSSF baseada no padrão de comunicações Zigbee e a norma IEEE 802.15.4 nas três primeiras camadas utilizando a arquitetura de hardware do nó sensor TmoteSky;

- realizar uma comparação dos valores obtidos durante a avaliação de desempenho da RSSF com os valores obtidos na literatura existente o qual inclui valores de 
referência do Mica2dot nos experimentos de Alcande do Sinal;

- realizar análise de impacto do sistema de comunicação da RSSF Zigbee baseados no consumo de energia do nó na rede;

- caracterização dos ambientes de propagação (interno e externo) em função do Nível de Intensidade do Sinal Recebido.

\subsection{Organização do trabalho}

Esta dissertação está dividida em seis capítulos. Neste capítulo foram apresentados: o contexto em que se insere o trabalho, as motivações para o seu desenvolvimento e os seus objetivos. No Capítulo 2 é abordado o marco teórico para a sustentação da proposta de trabalho. No Capítulo 3 são expostos diferentes trabalhos correlatos. No Capítulo 4 é apresentada a metodologia empregada neste trabalho de pesquisa, as métricas para a avaliação de desempenho, as ferramentas de hardware e software empregadas e os aspectos da implementação também são discutidos nesse capítulo. No capítulo 5 são apresentados os resultados dos experimentos realizados. Finalmente, no Capítulo 6 são realizadas as discussões dos resultados e as conclusões. 


\section{Capítulo 2}

\section{CONCEITOS BÁSICOS}

O capítulo apresenta uma breve introdução às RSSFs, suas características e aplicações. Em seguida é apresentado o padrão ZigBee (ZIGBEE, 2005) descrito como padrão aberto pelo IEEE através da norma IEEE 802.15 .4 (802.15.4, 2003) e suas aplicações em redes de sensores sem fio de baixo consumo de energia.

Inicialmente temos uma breve introdução à documentação do IEEE 802 descrita na norma IEEE 802.15.4 nas camadas física, de enlace e uma breve introdução às principais características do padrão Zigbee. 


\subsection{Redes de Sensores Sem Fio (RSSF)}

As RSSF (Figura 2.1) são um tipo especial de rede ad-hoc, compostas por dispositivos de hardware reduzido, de pouca capacidade computacional individual e baixo custo, com capacidade de realizar atividades de sensoriamento e processamento de dados através de conexões sem fio. Devido às suas limitações computacionais, um nó sensor dificilmente consegue processar e realizar trabalhos de sensoriamento de forma individual e ao mesmo tempo de forma eficiente, mas em grande número os nós sensores têm a capacidade de realizar grandes tarefas através de técnicas de colaboração e gerenciamento de recursos (energia).

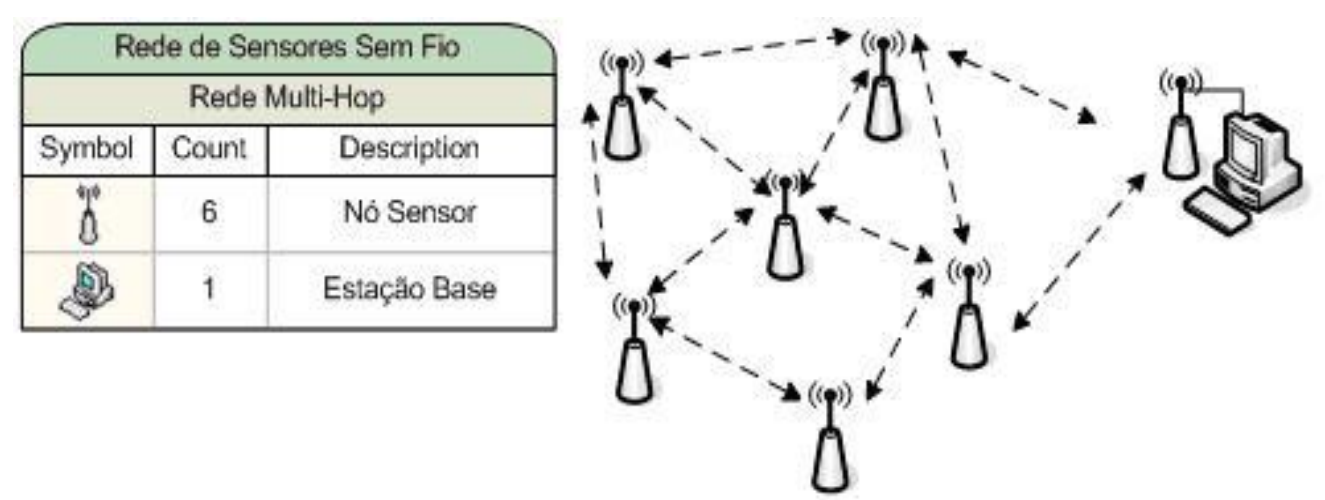

Figura 2.1: Representação de Uma RSSF

Os nós sensores são constituídos fisicamente por uma unidade de processamento, sensores e uma unidade de comunicação (Figura 2.2).

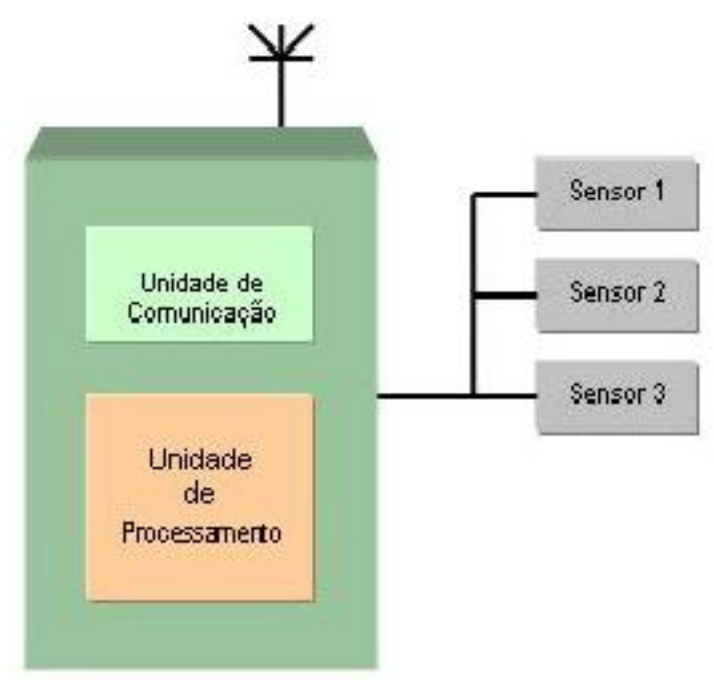

Figura 2.2: Diagrama de Blocos de um Nó Sensor 
O sensor e a unidade de processamento são os encarregados de coletar e processar a informação capturada e a unidade de comunicação de transportar-la até a estação base, onde se encontra o observador (administrador) da rede (figura 2.1), armazenamento e processamento dos dados para sua posterior visualização. A forma pela qual os dados serão enviados dependerá basicamente do protocolo de roteamento Multihop empregado.

\subsubsection{Objetivo de uma RSSF e considerações na implementação.}

O principal objetivo de uma RSSF é coletar as informações do ambiente monitorado e prover essas mesmas informações ao observador via uma interface sem fio (PEREIRA, 2003). Partindo dessa premissa, precisa-se da escolha de um protocolo eficiente que considere as limitações de energia, potência de transmissão e características do hardware do nó sensor. Afim de que essa tarefa ocorra de forma eficiente, uma avaliação antes da escolha definitiva do protocolo deverá ser feita. Outro caso é o tipo de canal de comunicação que será utilizado pelo protocolo, consideração que deverá ser realizada tomando em conta a arquitetura de hardware do nó sensor, o tipo de dados que transportará e a aplicação. Todos estes parâmetros de roteamento, comunicação e desempenho deverão considerar o impacto que cada um deles terá sobre o consumo de energia, recurso limitado no nó sensor (a troca de baterias num nó sensor é praticamente inviável, seja pelo tamanho da rede ou pela localização dos nós no ambiente observado). Diversos protocolos implementados no nível da camada MAC tentam resolver tais problemas através de mecanismos de consumo de energia gerenciáveis (CORREIA et al., 2005) (RAGHUNATHAN et al., 2002).

O objetivo da avaliação das novas arquiteturas de nós sensores e os novos padrões de comunicação segundo seu desempenho é determinar o tipo de plataforma a ser usado considerando a aplicação que terá e o tipo de ambiente a ser monitorado pela RSSF. Embora o ambiente de avaliação não seja o mais adequado, as ferramentas utilizadas (software e hardware) para uma interpretação eficiente dos valores coletados deverão oferecer um índice de confiabilidade maior. 


\subsubsection{Características de uma RSSF.}

As RSSFs, segundo sua composição, podem ser homogêneas ou heterogêneas. Para o primeiro caso os nós sensores possuem a mesma constituição física e as mesmas funções, já para o segundo caso, os nós da rede podem possuir notáveis diferenças em características não só de hardware, mas também de funcionamento e comunicação.

As RSSF possuem características próprias, além de herdar algumas outras das redes adhoc:

- Recursos Computacionais Limitados: devido às restrições de tamanho os nós sensores possuem limitados recursos de hardware, pelo qual geralmente o processamento da informação coletada pelos mesmos não pode ser processada de forma individual, e sim pela rede em seu conjunto;

- Escalabilidade: uma das principais características das RSSFs é a possibilidade de ter um grande número de nós sensores devido às demandas da aplicação, recurso ou ambiente a ser monitorado. Aliás, é evidente que os protocolos de comunicação empregados devem ter as características necessárias para permitir a escalabilidade da rede;

- Topologia Dinâmica e Tolerância a Falhas: esta é uma característica importante da rede, pois diante da perda de nós por situações relacionadas ao ambiente monitorado ou ao esgotamento da bateria, a rede deve ter a capacidade de manter seu correto funcionamento e se reorganizar para evitar a perda de dados e o baixo desempenho da rede. Conforme mencionado anteriormente, as características do meio de comunicação e os algoritmos de controle deverão ser os mais adequados para conseguir resolver problemas de perda de nós e ocorrência de falhas durante o funcionamento da rede (MACEDO et.al., 2005) (CORREIA et al. 2005);

- Baixas taxas de transmissão: em relação às redes convencionais e às redes típicas ad-hoc, as RSSFs possuem baixas taxas de comunicação. Nas RSSF a transmissão da informação coletada não é feita de forma contínua (no caso do monitoramento de vibrações do solo a rede pode estar configurada para responder a partir de um grau de vibração predeterminado e o evento monitorado pode não ser constante). A 
informação só será transmitida no instante que o valor predeterminado seja atingido. É possível que a variação das taxas de transmissão seja também influenciada ou determinada pelo tipo de sistema de rádio, protocolo de comunicação e modulação empregada;

- Sistema de funcionamento colaborativo: na RSSF é necessário o uso de técnicas de processamento e transmissão colaborativas para reduzir o consumo de energia da mesma;

- Comunicação Multihop e Broadcast: em aplicações das redes de sensores é sempre característico o uso de protocolos que permitam a comunicação Multihop (múltiplos saltos), porém, é também utilizaada a comunicação broadcast (Elson, Girod e Estrin, 2002).

\subsubsection{Aplicações das Redes de Sensores Sem Fio}

As RSSFs devido à sua tecnologia de baixo custo e consumo de potência são de grande aplicação em diversas áreas tais como: controle de processos industriais, segurança em centros comerciais, prédios, campos de cultivo, zonas propensas a desastres naturais, acompanhamento de pacientes em zonas hospitalares e segurança em transportes. Atualmente, espera-se alcançar uma tecnologia de nós sensores inteligentes com capacidade de processar grandes quantidades de informação que contribuam para o bom funcionamento de processos industriais, controle de tarefas domésticas, organização de processos e predição de desastres etc.. Alguns dos processos são descritos a seguir:

Ambientes de Alta Segurança: existem ambientes que requerem altos níveis de segurança (PERRIG; STANKOVIC; WAGNER, 2004) (SLIJEPCEVIC et al., 2002) para os quais é necessário criar soluções que permitam um acesso restrito aos usuários, baseados nestes critérios uma rede de sensores que realize um monitoramento e controle dos ambientes e dos usuários que trafegam dentro dele é uma solução bastante viável. A aplicação de sensores de movimento, de som, e os que realizam a identificação das pessoas através de seu tipo sanguíneo são uma realidade;

Monitoramento Ambiental: o monitoramento ambiental de florestas (PORTER et al., 
2005), oceanos (SUKHATME et al., 2007) seria praticamente inviável sem uma rede de sensores. O controle de determinadas variáveis tais como temperatura, umidade, fogo, atividades sísmicas entre muitas outras ajudam os especialistas na área a diagnosticar ou prevenir um problema ou urgência, e também permitem minimizar o impacto ambiental da presença humana;

Aplicação Industrial: o reduzido tamanho do nó sensor torna possível sua implementação nas diversas áreas da produção industrial através de redes de sensores para o controle de variáveis tais como temperatura, pressão, automatização de processos (RUIZHONG et al., 2004), automóveis (HSIN-MU et. al, 2007) etc.;

Aplicação Médica: um dos atuais desafios dos pesquisadores é a incorporação de novas tecnologias para monitoramento de pacientes através de redes de sensores que coletam informações sobre as sinais vitais do indivíduo (SENE et al, 2006) e realizam ações baseados na observação de determinadas variáveis tais como pressão arterial, batimentos cardíacos como em Kang (2007) etc.

A diversidade de aplicações das RSSFs é cada dia maior e como resultado novas arquiteturas de hardware e padrões de comunicação são criadas com o propósito de atingir estas novas demandas.

\subsubsection{Modelo Por Camadas das RSSFs}

As redes de sensores provêem ao usuário um conjunto de serviços e dentro destes serviços funções específicas que permitem a interoperabilidade entre as diferentes etapas de funcionamento da rede. Estas etapas e os serviços que estas redes incluem são representados num modelo de camadas segundo o modelo de referência OSI. Uma rede de sensores está definida em cinco camadas as quais são apresentadas na Figura 2.3: 


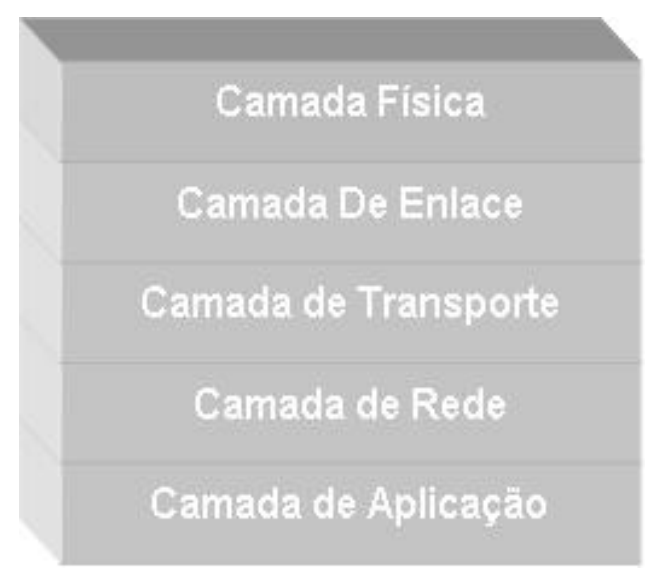

Figura 2.3: Modelo de camadas de uma RSSF

- Camada Física: define o tipo de comunicação empregada numa RSSF, podendo ser Infravermelha, Óptica, Rádio Freqüência e Acústica;

- Camada de Enlace: fornece serviços de comunicação de dados para as camadas superiores, tais como multiplexação do canal, segmentação, modelos de transmissão de dados e parâmetros de qualidade de serviço;

- Camada de Rede: nesta camada se provêm o serviço de roteamento, o qual pode ser definido como o processo pelo qual a rede identifica o destinatário das mensagens e encontra um caminho entre o emissor e o destinatário das mensagens;

- Camada de Aplicação: constituída pelo sistema operacional e as aplicações que servirão de interface entre a rede, o ambiente monitorado e o observador.

\subsection{Conectividade IEEE 802.15.4 e o Padrão Zigbee}

A norma 802.15.4 definida pelo IEEE (Institute of Eletrical and Eletronics Engineers), que descreve as camadas; Física - PHY (Physical) para LR-WPAN (Low Rate Wireless Personal Área Network) e a camada de enlace MAC (Medium Access Control) adotadas no que hoje é o padrão ZigBee propõe resolver as limitações existentes nas RSSF através de técnicas de gerenciamento de energia e modulação em quadratura de fase $O$-QPSK que permite uma maior taxa de transmissão de pacotes. 
Entre as características da norma 802.15.4 sobre as Redes Sem Fio de Área Pessoal e Baixa Taxa de Consumo de Energia (Low-Rate PAN), estão a pouca complexidade de instalação, baixo custo e consumo de potência e velocidades de até $250 \mathrm{Kbps}$. Admitem-se topologias tipo estrela (Star) e malha (mesh) (basicamente, a formação das redes deve de ser tratada na camada de rede que não é especificada no 802.15.4, mas o documento sugere dois tipos de associações (Star Topology e Peer-to-Peer Topology), estruturas do frame com e sem Beacon, com confirmação de recebimento de mensagens.

\subsubsection{Camada Física}

IEEE 802.15.4 oferece duas opções de camada física $(P H Y)$ que combinam com o $M A C$ para permitir um amplo alcance de aplicações em redes sem fio. Inicialmente, as duas camadas físicas baseiam-se em métodos de Espalhamento Espectral por Seqüência Direta (DSSS do inglês Direct Sequence Spread Spectrum), que resultam em baixos custos de implementação digital, e ambas compartilham a mesma estrutura básica de pacotes de baixa redundância (Low-duty-cycle) com operações de baixo consumo de energia. A principal diferença entre as duas camadas está nas bandas de freqüência:

- A camada física a $2.4 \mathrm{GHz}$, especifica a operação na banda $\mathrm{ISM}^{1}$, que praticamente está disponível no mundo todo;

- A camada física a 868/915 MHz, especifica a operação na banda de $865 \mathrm{MHz}$ na Europa e $915 \mathrm{MHz}$ na banda ISM.

A freqüência de operação é variável, 868, 915 e $2450 \mathrm{MHz}$ (1, 10 e 16 canais respectivamente), com modulações $B P S K$ e $O-Q P S K$, tabela 2.1.

${ }^{1}$ Industrial Cientific Medical 
Tabela 2.1: Operação de Freqüência 802.15.4

\begin{tabular}{cccccc}
\hline \hline PHY & Frequency & \multicolumn{2}{c}{ Spreading Parameters } & \multicolumn{2}{c}{ Data Parameters } \\
\hline \multirow{2}{*}{ MHz } & Band & Chip rate (kchip/s) & Modulation & Bit rate (kb/s) & Symbols \\
$868 / 915$ & $868-868.6$ & 300 & BPSK & 20 & Binary \\
& $902-928$ & 600 & BPSK & 40 & Binary \\
2450 & $2400-2483.5$ & 2000 & O-QPSK & 250 & 16 -ary \\
\hline
\end{tabular}

\subsubsection{Canais IEEE 802.15.4}

IEEE 802.15.4 define 27 canais de freqüência em três bandas (802.15.4, 2003)(Figura 2.4). A camada física 868-915 MHz suporta apenas um canal entre os 868 e os $868.6 \mathrm{MHz}$, e dez canais entre os 902.0 e $928.0 \mathrm{MHz}$. Em razão do suporte regional dessas duas bandas de freqüência, é muito improvável que só uma rede utilize os 11 canais. Porém as duas bandas estão suficientemente próximas em freqüência e pode se utilizar um mesmo hardware para ambas redes e assim reduzir custos de manufatura. A camada física a $2.4 \mathrm{GHz}$ suporta 16 canais entre os 2.4 e os $2.4835 \mathrm{GHz}$, com um amplo espaço entre canais ( $5 \mathrm{MHz}$ ).

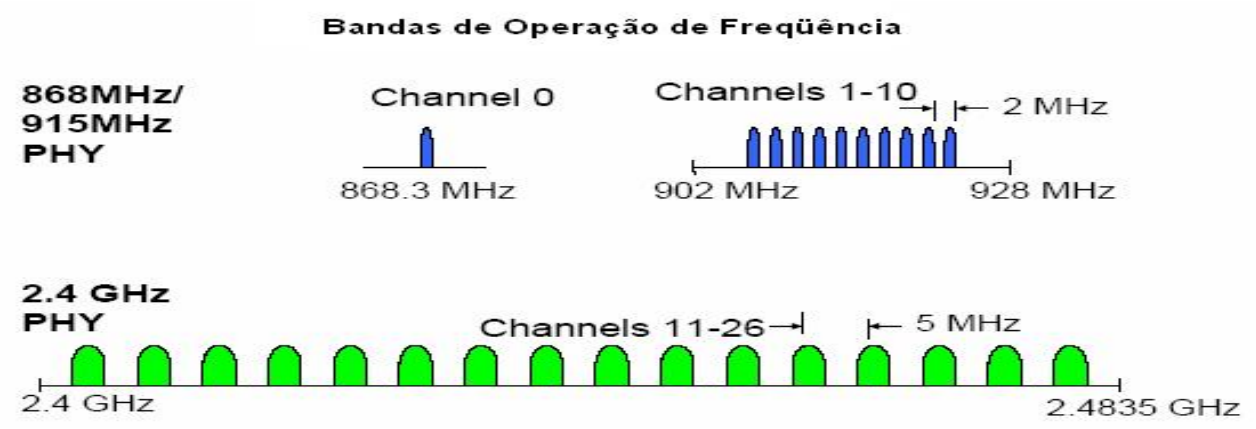

Figura 2.4: Bandas de Operação de Freqüência Fonte(802.15.4 2003)

Normalmente no ambiente doméstico existem múltiplas redes sem fio trabalhando nas mesmas bandas de freqüência, assim como uma interferência não intencionada das diferentes aplicações, a capacidade de re-localização dentro do espectro será um fator importante no êxito das redes sem fio dentro do lar. O padrão foi projetado para realizar uma seleção dinâmica de canais, através de uma seleção específica de algoritmos a qual é de responsabilidade da camada de rede. 
A camada $M A C$ inclui funções de busca que segue passo a passo através de uma lista de canais permitidos pela norma 802.15.4 em busca de um sinal guia, já na camada física existem várias funções de baixo nível, tais como: detecção dos níveis de energia recebidos, indicadores de qualidade do enlace $(L Q I)$, assim como a comutação de canais, o que permite distribuição de canais e agilidade na seleção de freqüências. Essas funções são utilizadas pela rede para estabelecer seu canal inicial de operação e para trocar os canais em resposta a uma pausa muito prolongada.

\subsubsection{Modulação IEEE 802.15.4}

A modulação é a operação pela qual determinada característica de uma onda denominada portadora é modificada em função de outra denominada moduladora, que contém a informação a transmitir. A onda resultante e em condições de ser transmitida é denominada de sinal modulado. No processo de modulação para transmissão sem fio o bitstream digital (Figura 2.5) precisa ser primeiro transformado em sinal analógico (baseband signal) e depois sofrer uma modulação analógica para uma freqüência portadora (carrier).

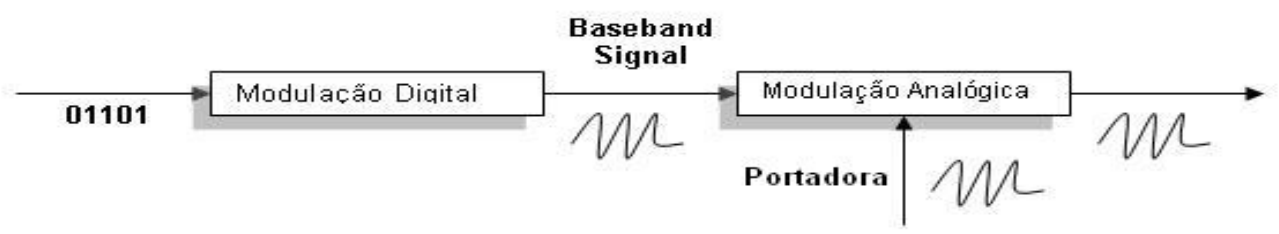

Figura 2.5: Diagrama de blocos da transformação de sinal

A camada $P H Y$ nos 868/915 MHz e a camada $P H Y$ a $2.4 \mathrm{GHz}$ utiliza um método de aproximação simples DSSS (Direct-Sequence Spread-Spectrum) (802.15.4, 2003) (GIACOMIN; VASCONCELOS, 2006). Este método gera um protetor de bit redundante por cada bit a ser transmitido. O bit protetor é chamado de chipping code. No entanto, em termos de sensibilidade de recepção, a camada física 868-915 MHz tem uma vantagem de 6-8 dB devido ao fato que possui velocidades de transmissão mais baixas (Wang, 2006).

As principais características do metodo DSSS são:

1. Identifica os dados para que o receptor possa reconhecê-los como pertencentes a 
determinado transmissor;

2. O código de chip (chipping code) distribui os dados pela largura de banda disponível;

Entre suas vantagens temos:

- O circuito gerador de freqüência (sintetizador) é mais simples, pois não tem necessidade de trocar de freqüência constantemente;

- O processo de espalhamento é simples, pois é realizado através da multiplicação do sinal de informação por um código;

- Garante uma maior capacidade de transmissão.

A modulação utilizada na camada física a $2.4 \mathrm{GHz}$ junto com a técnica $D S S S$ é a modulação O-QPSK (Offset quadrature phase-shift keying). A modulação O-QPSK baseada também no QPSK (Figura 2.6) é uma variação da modulação PSK (phase-shift keying) e é uma forma de modulação do sinal que é enviado em quatro fases numa portadora de $360^{\circ}$ graus.

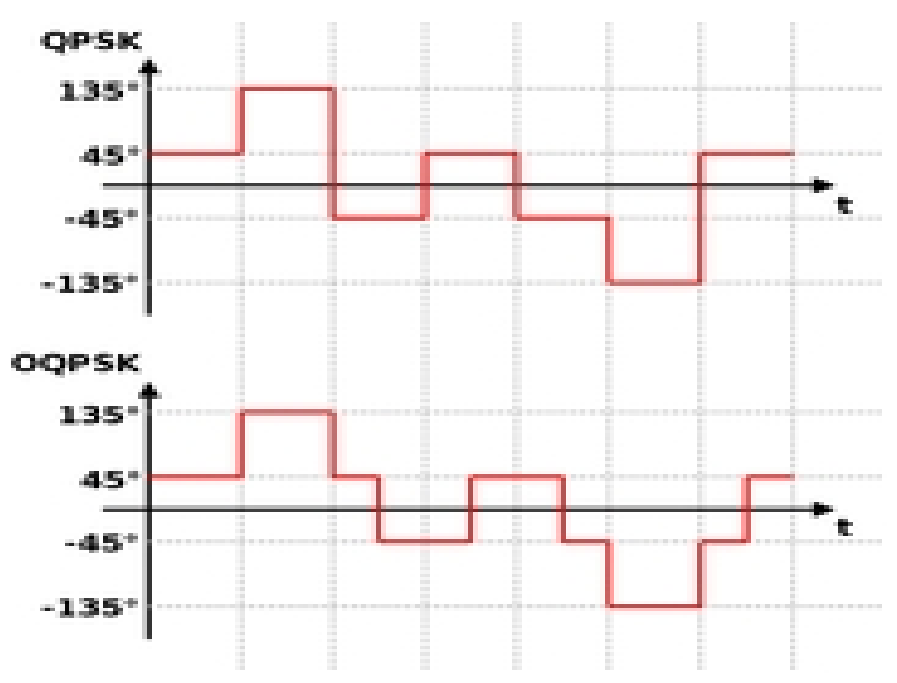

Figura 2.6: Modulação QPSK e $O Q P S K$

Este tipo de modulação adotado pelo IEEE 802.15.4 tem como objetivo a redução das transições de fase do sinal modulado, limitando-as a um máximo de $90^{\circ}$ graus. 


\subsubsection{Camada de Enlace de Dados}

A norma IEEE 802.15.4 divide a camada de Enlace de Dados $(D L L)$ em duas subcamadas, a camada de Controle de Acesso ao Meio (Medium Access Control, MAC) e a subcamada de Controle de Enlaces Lógicos (Logical Link Control, $L L C$ ). O LLC é comum para todas as normas 802, mas a camada $M A C$ depende do hardware e varia segundo implementação desta camada. Na figura 2.7 mostra-se a norma IEEE 802.15.4, segundo o modelo de referência $O S I$.

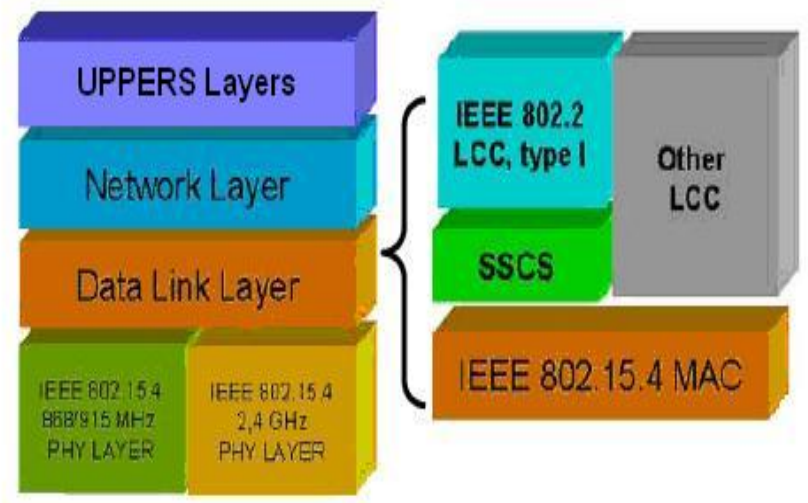

Figura 2.7: Modelo de camadas IEEE 802.15.4 segundo modelo OSI. Fonte (802.15.4, 2003)

As características do $M A C$ IEEE 802.15.4 são: associação-dissociação, reconhecimento de entrega do pacote $A C K$ (Acknowledgment), mecanismos de acesso ao canal, validação de frame, controle de guias (Beacon) e varredura do canal. As subcamadas $M A C$ proporcionam dois tipos de serviços para as camadas superiores que acessam através de Pontos de Acesso a Serviços (SAPs), que são:

- Os serviços de dados $M A C$ para o qual o acesso é por meio da parte comum da subcamada (MCPS-SAP);

- O controle de serviços $M A C$ para o qual o acesso é por meio da camada $M A C$ de controle de identidades (MLME-SAP).

Os dois serviços em menção proporcionam uma interface entre as subcamadas de convergência de serviços específicos $(S S C S)$ ou entre o $L L C$ e as camadas físicas. 


\subsubsection{Estrutura do Frame MAC}

O formato geral dos frames MAC foi projetado para ser muito flexível e para ser facilmente ajustado às necessidades das diferentes aplicações com diversas topologias de rede ao mesmo tempo em que se mantém um protocolo simples (ZHENG; LEE, 2004).

\subsubsection{Estrutura do Quadro de Dados (Data Frame)}

O frame geral do MAC (Figura 2.8) é denominada de PPDU (Phy Protocol data Unit), camada física da Unidade de Dados do Protocolo MAC. O frame começa com um cabeçalho de sincronização (SHR,Synchonization HeaderR), seguido de um cabeçalho da camada física para indicar o comprimento do pacote (PHR, Phy HeaderR), e finalmente, a camada física da unidade de serviço de dados (PSDU, Phy Service Data Unit). Figura 2.8.

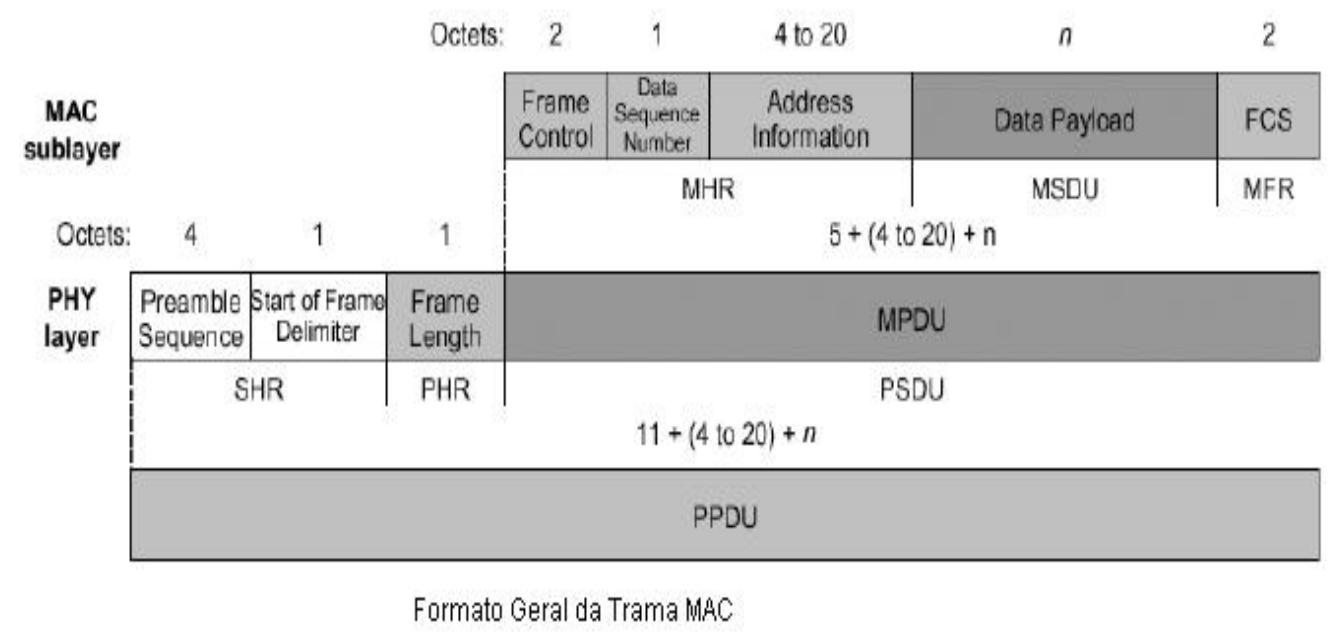

Figura 2.8: Formato do frame MAC. Fonte $(802.15 .4,2003)$

O preâmbulo de 32 bits está desenhado para a aquisição de símbolos e para os tempos de chip, e em alguns casos é utilizada para ajustes bruscos na freqüência. Dentro do cabeçalho da camada física se utilizam 7 bits para especificar a longitude da carga de dados (em bytes). O comprimento do pacote vai de 0 a 127 bytes. O tamanho típico dos pacotes para a maioria das aplicações domésticas, tais como o monitoramento e controle de dispositivos de segurança, iluminação, ar condicionado, e outras aplicações vai de 30 a 60 bytes, porém, outras aplicações como jogos interativos e periféricos de PC requerem 
pacotes maiores. É necessario mencionar que a duração máxima do pacote é de $4.25 \mathrm{~ms}$ para a banda de $2.4 \mathrm{GHz}$, e de $26.6 \mathrm{~ms}$ para a banda de $915 \mathrm{MHz}$, e de $53.2 \mathrm{~ms}$ para a banda de $868 \mathrm{MHz}$.

O frame da unidade de dados do protocolo $M A C$ ( $M P D U, M A C$ Protocol Data Unit), é composta pelo cabeçalho MAC (MHR, MAC HeaderR), Unidade de Serviço de Dados $M A C$ (MSDU, MAC Service Data Unit) e termina com o chek-up do frame (MFR, $M A C$ FooterR). O primeiro campo do frame de cabeçalho $M H R$ é o campo de controle denominado Frame Control. O Frame Control indica o tipo de frame $M A C$ que se pretende transmitir, especifica o formato, o campo de endereço e controla as mensagens $A C K^{2}$ (de confirmação). Basicamente o Frame Control especifica a composição do frame de dados e o seu conteúdo. O DSN (Data Sequence Number) verifica a integridade do frame $M A C$ e é um número de seqüência igual a frame $F C S^{3}$. Os frames $F C S$ ajudam a verificar a integridade dos frames do MAC. O tamanho do endereço Address information pode variar entre 0 e 20 bytes. Por exemplo, um frame de dados pode conter informação da fonte e do destino, já no frame $A C K$ (acknowledgment) de confirmação não existe nenhuma informação sobre endereço nenhum. Esta flexibilidade na estrutura ajuda a incrementar a eficiência do protocolo ao manter os pacotes o mais reduzido possíveis. O Payload é de comprimento variável, porém o frame completo do $M A C$ não deve exceder os 127 bytes de informação. Os dados que o Payload leva dependem do tipo de frame. O protocolo IEEE 802.15.4 tem quatro tipos diferentes de frame $M A C$ : frame de guia, frame de dados, frame $A C K$ e o frame de comandos (só os frames de dados e os frames de guia contêm informações que provêm das camadas superiores; os frames de mensagens $A C K$ e a de comandos $M A C$ originados no $M A C$ são usadas para as comunicações MAC peer-to-peer).

\subsubsection{Estrutura do Frame ACK (Acknowledgment Frame)}

O frame $A C K$ (Figura 2.9) proporciona a troca de informação ativa desde o receptor até o emissor informando que o pacote foi recebido sem erros (o curto pacote do $A C K$ aproveita o tempo do silêncio (quiet time) especificado pela norma imediatamente depois

\footnotetext{
${ }^{2}$ Uma transmissão é considerada com êxito só quando o frame de confirmação $(A C K)$ contém a mesma seqüência de números que a seqüência anterior transmitida

${ }^{3}$ FCS (Frame Check Sequency) é um frame de chekup de 16 bits CRC (Cyclic Redundancy Chech)
} 
da transmissão do pacote de dados).

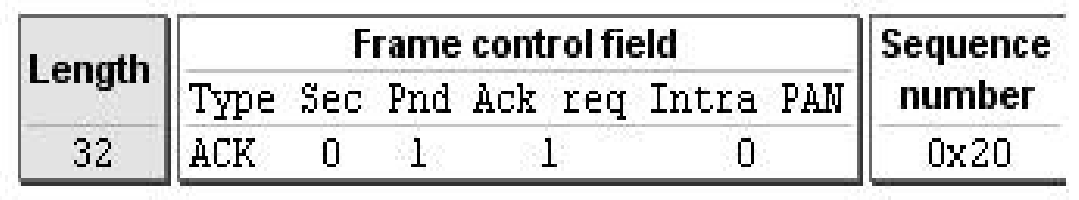

Figura 2.9: Frame do $A C K$

Uma função importante do $M A C$ é a confirmação de recepções com êxito de frames dos nós na rede. As recepções com êxito e as validações de recibo dos dados são confirmadas por meio de frames $A C K$. Quando por alguma razão o dispositivo de recepção não é capaz de receber a informação nesse momento o receptor não envia nenhum frame $A C K$.

\subsubsection{Estrutura do Frame de Comandos MAC (MAC Command Frame)}

O frame de comandos $M A C$ é um mecanismo para o controle ou configuração à distância dos dispositivos nós. Permite que um administrador da rede, centralizado, possa configurar os dispositivos de forma individual sem importar o tamanho da rede. $\mathrm{Na}$ Figura 2.10 pode se ver que só o campo Command Type é adicionado à estrutura do frame de dados.

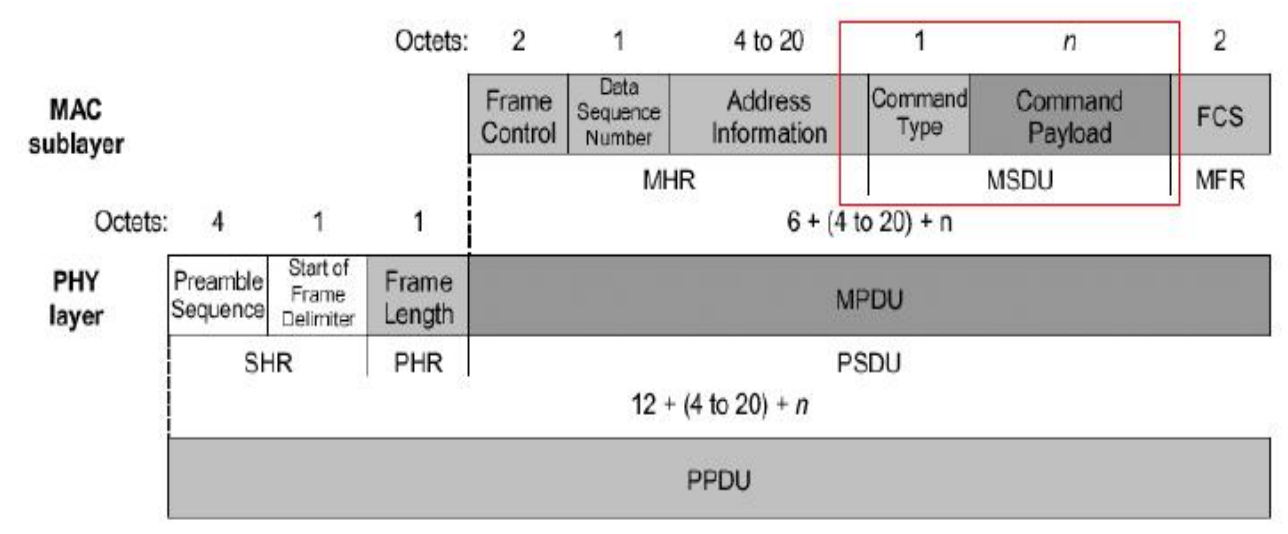

Figura 2.10: Frane de Dados com o Campo Command Type. Fonte (802.15.4, 2003)

\subsubsection{Estrutura do Frame Beacon (Beacon Frame)}

O frame Beacon (sinal guia) (Figura 2.11) agrega um novo nível de funcionalidade na rede. Os dispositivos dos nós podem ser acordados facilmente quando é transmitido um 
sinal de guia ou Beacon. Os frames Beacon são importantes nas redes de tipo malha (mesh) e arvore (cluster tree) para manter todos os nós sincronizados sem precisar que os nós consumam energia da bateria, ouvindo o canal durante períodos longos de tempo.

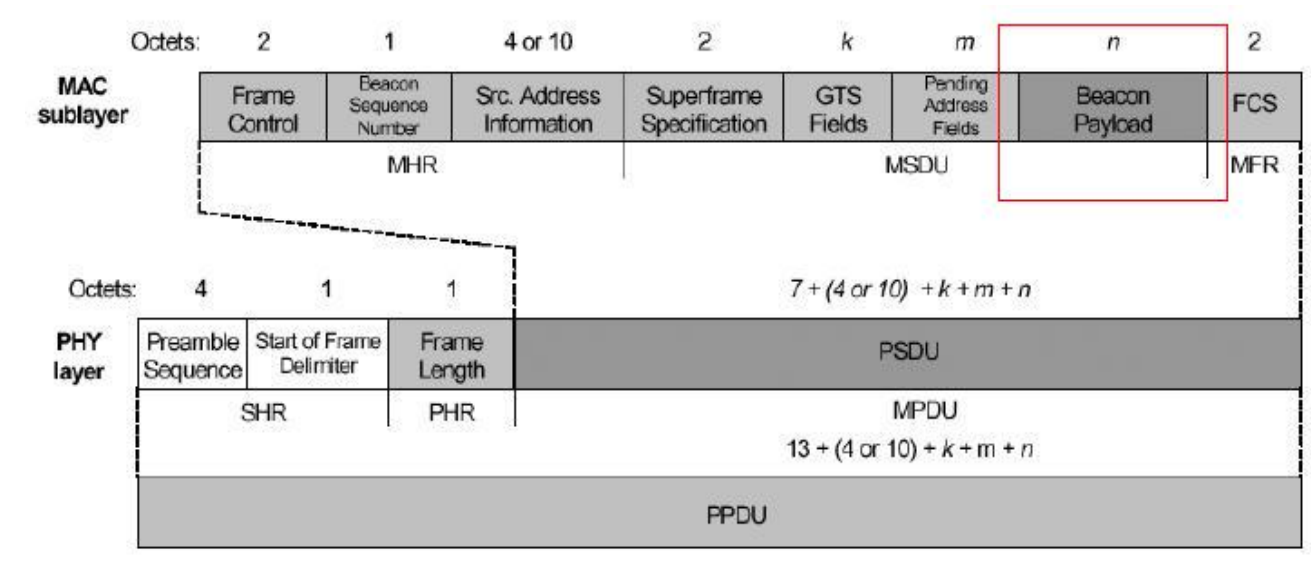

Figura 2.11: Estrutura do frame Beacon (Beacon Frame). Fonte $(802.15 .4,2003)$

\subsubsection{Os Modelos de Transmissão de Dados}

A norma IEEE 802.15.4 considera duas formas ou modelos de transmissão de dados que são: Transmissão ao Coordenador que pode ser; sem beacon (beacon-Disabled) e com beacon (beacon-Enabled), e a Transmissão desde o Coordenador que também pode ser; com beacon (beacon-Enabled) e sem beacon (beacon-Disabled).

\subsubsection{Transmissão ao Coordenador}

Esta transação de dados é o mecanismo para transferir de um nó para um dispositivo coordenador na rede. Numa rede com Beacon-Enabled, quando um dispositivo deseja transferir dados a um coordenador, escuta primeiro o beacon na rede, como é mostrado na Figura 2.12(a); quando é achado o nó sincroniza a estrutura de superframe. No momento apropriado o dispositivo transmite seu frame de dados usando CSMA/CA slotted ao coordenador. O coordenador reconhece a transmissão bem sucedida de dados transmitindo um frame de confirmação. Em uma rede com beacon-Disabled, quando um dispositivo deseja transferir dados, transmite simplesmente seu frame de dados usando $C S M A / C A$ ao coordenador. O coordenador reconhece a recepção bem sucedida dos dados transmitindo um frame de reconhecimento como mostrado na Figura 2.12(b). 


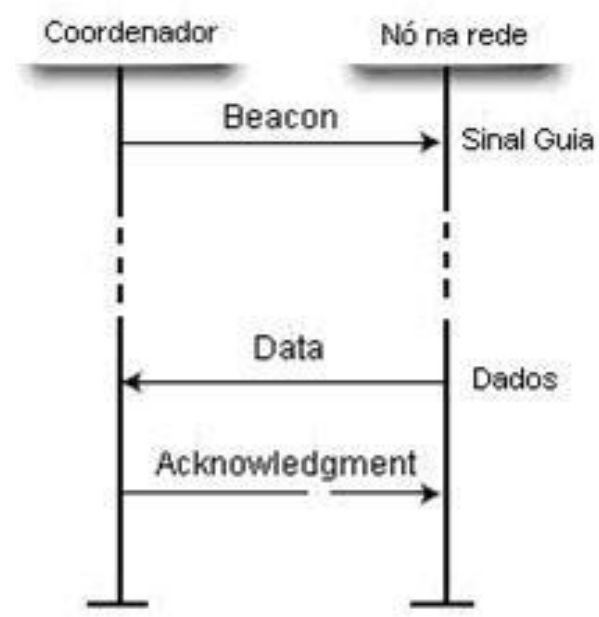

a) Diagrama de transmissäo com BeaconEnabled

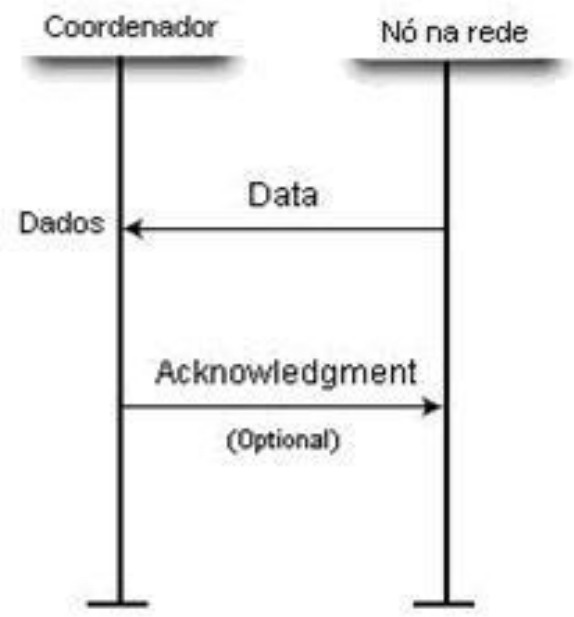

b) Diagrama de transmissäo comBeaconDisabled

Figura 2.12: Transmissão ao Coordenador. Beacon-Enabled (a) e Beacon-Disabled (b)

\subsubsection{Transmissão a partir do Coordenador}

É o mecanismo que permite a transferência de dados de um nó coordenador para um nó da rede(Figura 2.13). Quando o coordenador deseja transmitir dados para um nó na rede indica em um beacon que existe uma mensagem de dados pendente para esse nó. O nó escuta o canal de forma periódica para ver se existe um beacon indicando uma mensagem para ele, e se existir alguma mensagem pendente transmite um comando $M A C$ que pede os dados usando CSMA/CA slotted. O coordenador reconhece a recepção bem sucedida do pedido dos dados transmitindo um frame de confirmação $A C K$. O frame de dados em pendente é transmitido usando $C S M A / C A$ slotted. Finalmente, o nó reconhece a recepção bem sucedida dos dados transmitindo um frame de confirmação de recebimento do pacote. Além do coordenador receber a mensagem de confirmação de recebimento, remove a mensagem da lista das mensagens pendentes do beacon. Esta seqüência é representada na Figura 2.13(a). 


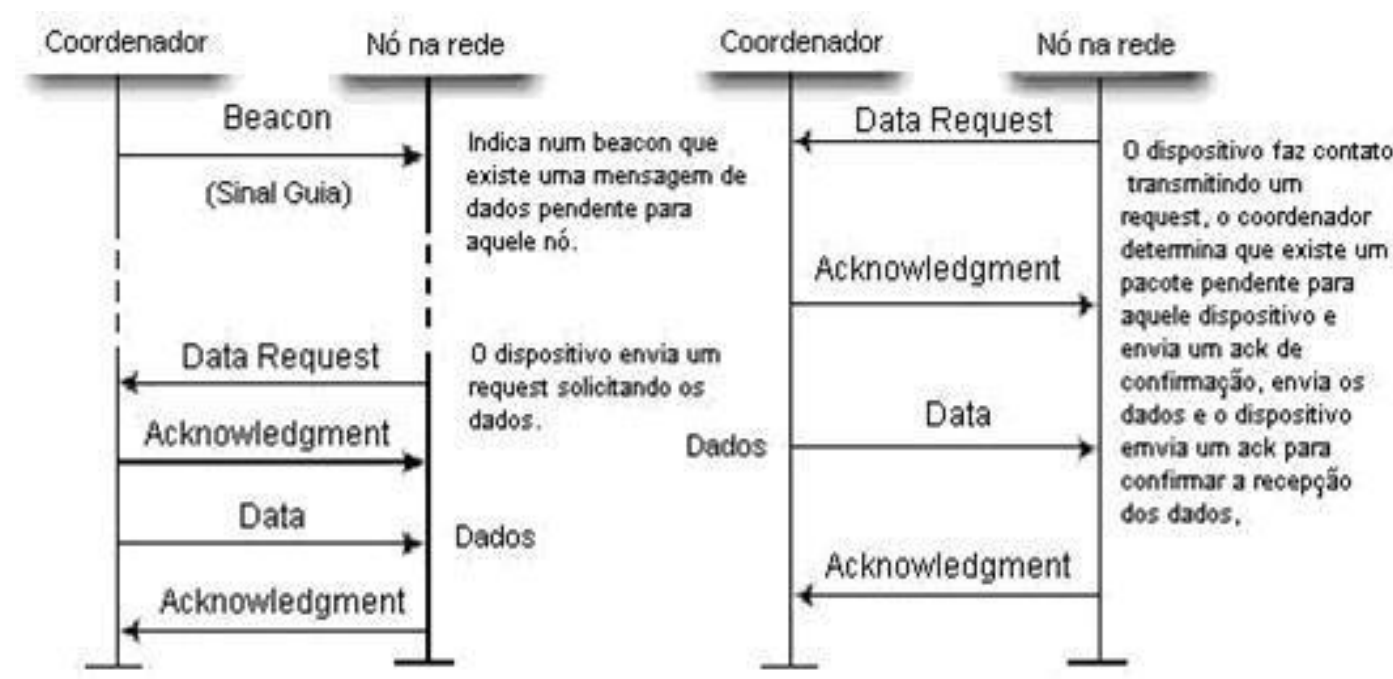

\section{a) Diagrama de transmissäo com Beacon- b) Diagrama de transmissăo comBeacon- Enabled \\ Disabled}

Figura 2.13: Transmissão a partir do Coordenador. Beacon-Enabled (a) e Beacon-Disabled (b)

Na transmissão com Beacon-Disabled, quando um coordenador deseja transferir dados para um dispositivo na rede, primeiramente armazena-se os dados até que o dispositivo apropriado faça o contato e peça os dados. Um dispositivo na rede pode fazer contato transmitindo um comando $M A C$ para pedir os dados, fazendo uso de CSMA/CA para o coordenador. (Figura 2.13(b)) Para o primeiro caso, a comunicação é realizada por um dispositivo comum para o coordenador da rede. No segundo caso a comunicação é feita do coordenador para um dispositivo comum na rede.

\subsubsection{Modelos de Transmissão na RSSF Zigbee}

Nas redes Zigbee não são mencionados de forma específica os modelos de transmissão do IEEE 802.15.4 e sim as transferências com beacon e sem beacon. No entanto, dentro das RSSF estas apresentam um processo mais simples devido às restrições computacionais destes dispositivos.

\subsubsection{Transmissão Beacon-Enabled}

Na transferência de dados com Beacon-Enabled (Figura 2.14) o nó que deseja transmitir dados ao nó coordenador escuta o beacon na rede; quando o beacon é achado o nó 
transmite seu frame de dados usando CSMA-CA slotted ao coordenador. Para este caso, especificamente, o nó coordenador libera um beacon em intervalos de tempo específicos para disponibilizar o canal para uma nova transmissão. (Figura 2.15)

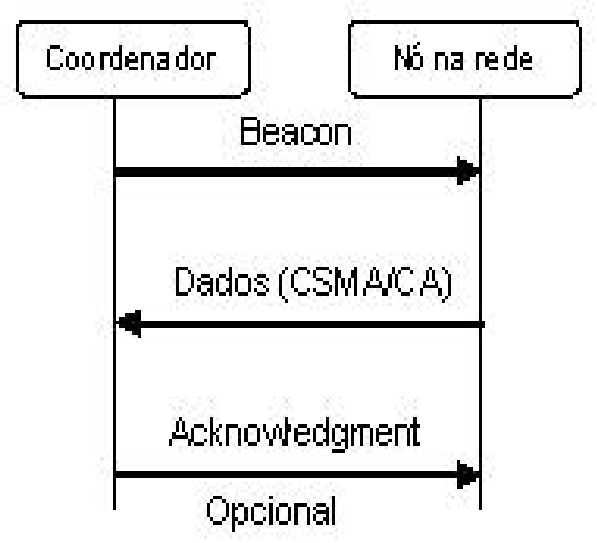

Figura 2.14: Transmissão Beacon-Enabled na RSSF

Na Figura 2.15 é mostrada uma seqüência de transmissão de pacotes de quatro nós da rede e um nó coordenador especificado com ID (00). Observa-se que o envio de um beacon pelo nó coordenador da rede determina o início de uma nova seqüência de transmissão para os nós da rede (coluna do ID de nó, nós $7,6,9,8$ ).

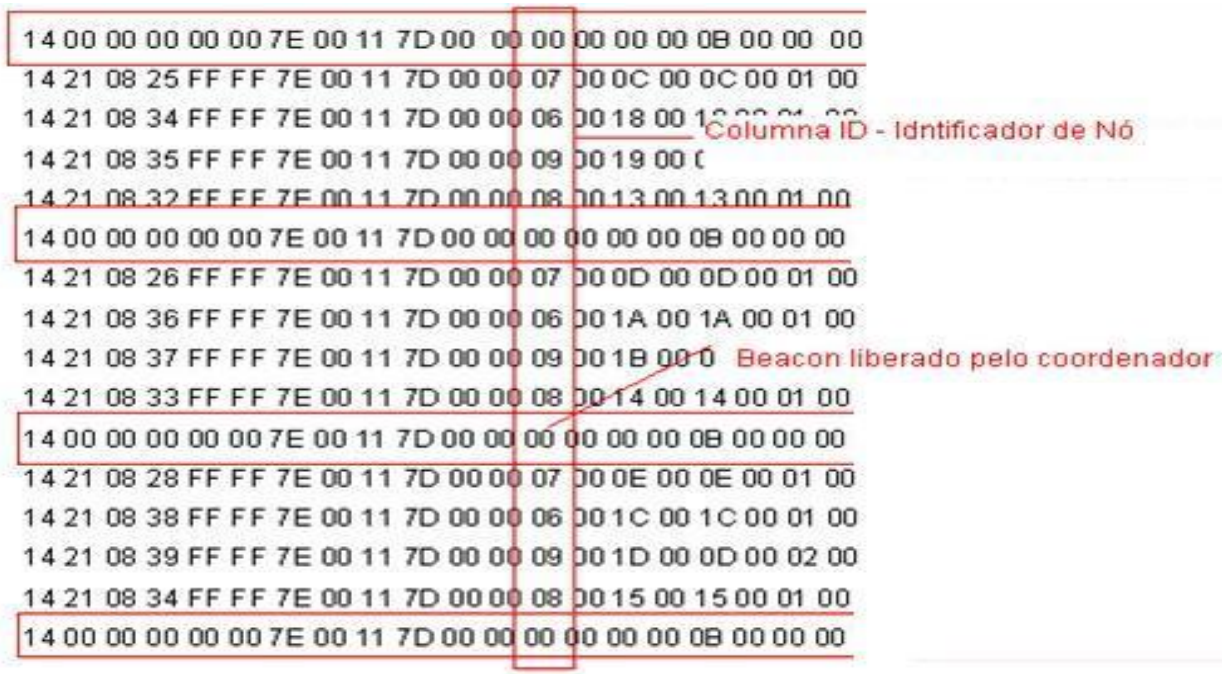

Figura 2.15: Beacon transmitido pelo coordenador sengundo intervalos de tempo.

\subsubsection{Transmissão Beacon-Disabled}

Na transferência de dados com Beacon-Disabled (Figura 2.16) o nó que deseja enviálos transmite simplesmente seu pacote de dados usando $C S M A / C A$ ao coordenador. O 
coordenador reconhece a recepção bem sucedida dos dados, mas, não transmite $\mathrm{ACK}^{4}$ de confirmação, o qual faz com que o nó envie em intervalos de tempo um pedido de confirmação de recebimento ( $A C K$ Request) da integridade dos dados enviados e da disponibilidade do canal para o inicio de uma nova transmissão.

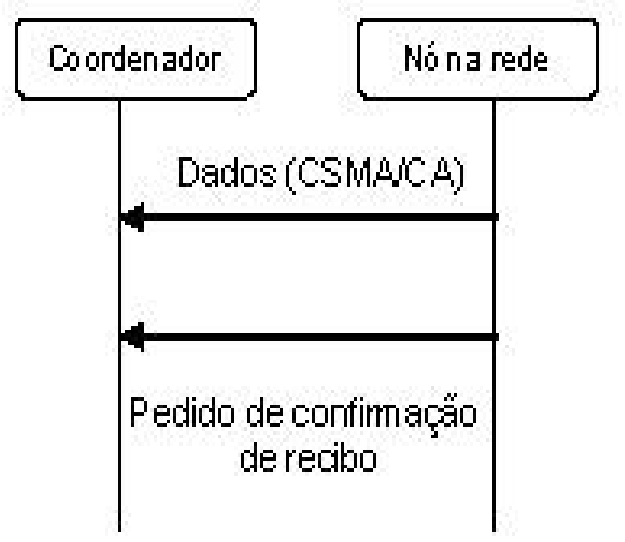

Figura 2.16: Transmissão Beacon-Disabled na RSSF

O envio excessivo do $A C K$ request demanda um tempo maior de atividade do sistema de rádio e acrescenta o consumo de energia do nó sendo confirmado através dos experimentos de consumo de energia.

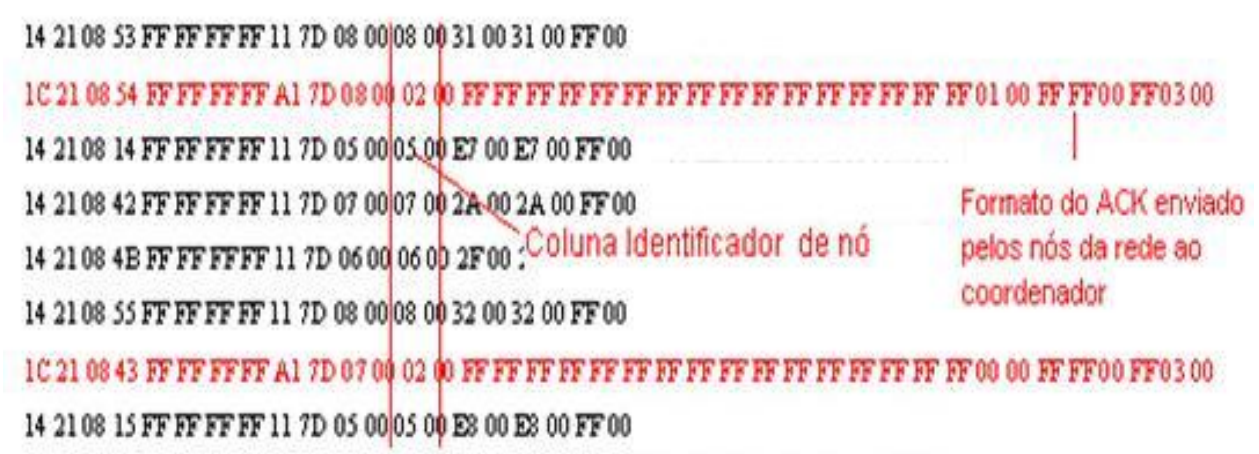

Figura 2.17: ACK enviados ao coordenador pelos nós da rede

\subsection{O Padrão ZigBee}

ZigBee (Zigbee, 2005) é um padrão de hardware e software baseado na recentemente ratificada norma IEEE 802.15 .4 (802.15.4, 2003) tratado nas camadas físicas (PHY) e

\footnotetext{
${ }^{4} \mathrm{O}$ envio de um $A C K$ na RSSF não é um processo comum, com maior razão quando se trata de diminuir os eventos na comunicação para economizar energia.
} 
de controle de acesso ao meio $(M A C)$. A aliança ZigBee ${ }^{5}$ agregou às camadas do IEEE 802.15.4 as especificações das camadas de rede $(N W K)$ e aplicação $(A P L)$ para completar o que é chamado de pilha ou stack ZigBee. (Figura 2.18)

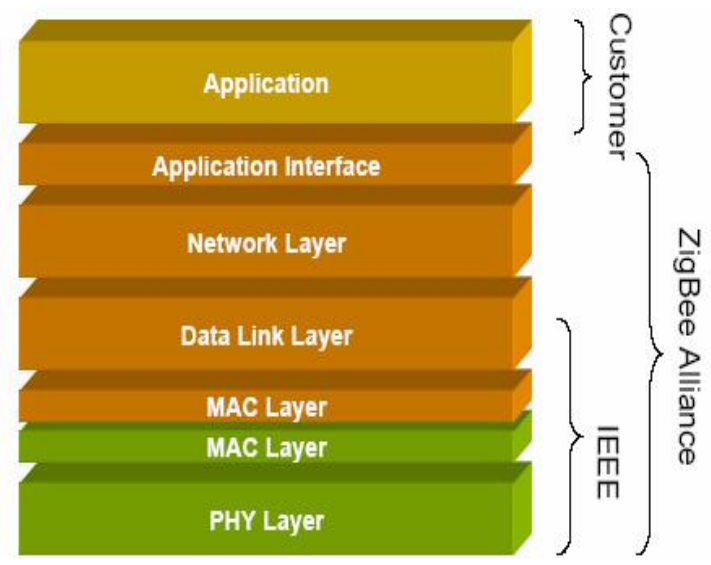

Figura 2.18: Modelo OSI para o Padrão ZigBee. Fonte (Zigbee, 2005)

ZigBee, diferente de outros padrões, é um protocolo que está sendo projetado para suportar um diverso mercado de aplicações que requerem baixo custo e baixo consumo, com baixa transmissão de dados, baixo ciclo de serviço de conectividade etc. A origem deste novo padrão é para permitir a interoperabilidade entre os dispositivos fabricados por companhias diferentes.

\subsubsection{Rede de Área Pessoal (WPAN)}

O padrão Zigbee descreve um protocolo normalizado para a conexão de uma rede de área pessoal ou WPAN, a qual é uma infra estrutura de comunicação de curto alcance que suporta comunicações na área de uma pessoa, especificamente em um raio de $5 \mathrm{~m}$ até os $10 \mathrm{~m}$ e são normalmente utilizadas para conectar vários dispositivos portáteis pessoais sem necessidade de cabos. Este tipo de comunicação se dá fazendo uso de topologias Peer-toPeer que normalmente não requerem altas taxas de transmissão. A comunicação em uma rede $W P A N$ inclui baixo custo de implementação, baixas taxas de consumo de energia e taxas de transmissão que atingem até os 250kbps.

Uma WPAN pode ser composta por dois dispositivos diferentes:

\footnotetext{
${ }^{5} \mathrm{O}$ padrão é resultado do trabalho de mais de 70 companhias associadas para criar e promover o novo padrão ZigBee, agora propriedade de um consórcio que conforma a Aliança ZigBee.
} 
- FFD (Full Function Device): É um dispositivo de função completa, que pode ser usado sobre qualquer topologia. Este dispositivo possui a capacidade de ser Coordenador de Rede e pode se comunicar com qualquer outro dispositivo.

- RFD (Reduced Function Device): É um dispositivo de função reduzida. Limitado a uma topologia em estrela. Não pode ser coordenador de rede e só pode conversar com um coordenador de rede. É de fácil implementação.

O FFD pode operar como coordenador da PAN (Personal Area Network), ou como um dispositivo comum da $P A N$, enquanto que o $R F D$ pode operar apenas como um dispositivo comum da rede.

\subsubsection{Conectividade Zigbee}

O hardware e as redes Zigbee/IEEE 802.15.4 devem permitir uma transferência de dados de até $250 \mathrm{kbps}(802.15 .4,2003)$, com um alcance na transmissão entre 10 a 75 metros(ZIGBEE, 2005). O hardware típico a $2.4 \mathrm{GHz}$ apresenta uma distância de trabalho de até 30 metros dentro de um prédio e mais de 100 metros no ar livre (CHIPCON, 2006).

As bandas de operação de freqüência do padrão Zigbee (Figura 2.19) conjuntamente com as velocidades de transmissão são fornecidas pelo IEEE 802.15.4 e finalmente adotadas pelo padrão Zigbee.

\begin{tabular}{|c|c|c|c|c|}
\hline & Banda & Cobertura & Transmissão & Canais \\
\hline $2.4 \mathrm{Ghz}$ & ISM & Mundo & $250 \mathrm{kbps}$ & 16 \\
\hline $868 \mathrm{MHz}$ & & EUROPA & $20 \mathrm{kbps}$ & 1 \\
\hline $915 \mathrm{MHz}$ & ISM & Américas & $40 \mathrm{kbps}$ & 10 \\
\hline
\end{tabular}

Figura 2.19: Freqüências e Taxas de Transmissão 
Devido ao uso geográfico ser livre, a banda $2.4 \mathrm{GHz}$ é a preferida devido à sua disposição internacional (porém, é também verdade que existem muitas bandas sem licença nas freqüências mais altas). As bandas de $2.4 \mathrm{GHz}$ e $868 / 915 \mathrm{MHz}$ foram escolhidas pela norma IEEE 802.15.4 em relação à suas características de propagação ${ }^{6}$. Segundo experimentos realizados as freqüências 868/915 MHz e $2.4 \mathrm{GHz}$ possuem uma boa penetração através das paredes e dos tetos (GIACOMIN e VASCONCELOS, 2006) porém tem um alcance limitado (considerando que a limitação do alcance é desejável para reduzir as interferências). Portanto, ZigBee é baseado no IEEE 802.15.4, que é um protocolo para PAN (Personal Area Network).

\subsubsection{Aplicações}

Entre as principais aplicações do padrão ZigBee temos:

1. Automação e Controle Predial (segurança, controle de acesso) (Wheeler, 2007);

2. Controle Industrial (gerenciamento de ativos, controle de processos);

3. Periféricos para PC;

4. Controle remoto de produtos eletrônicos;

5. Automação residencial e comercial;

6. Saúde Pessoal (Monitoração de pacientes etc.).

\subsubsection{Camada de Rede}

Nas redes tradicionais a cabo a camada de rede é responsável pela topologia e pela construção e manutenção da mesma, assim como pelos serviços de enlace que incorporam as tarefas necessárias de endereçamento e segurança na rede. Os mesmos serviços existem para as redes sem fio, porém o baixo consumo de energia é um dos maiores desafios destes tipos de redes. As redes ZigBee construídas dentro da norma IEEE 802.15.4, possuem a capacidade de se auto-organizar e auto-manter em funcionamento utilizando técnicas de

\footnotetext{
${ }^{6} \mathrm{~A}$ propagação faz diferença à maneira em que as ondas de rádio atuam no meio ambiente.
} 
gerenciamento dos recursos de energia, o qual será possivelmente uma redução importante no valor total de implementação da rede. Como foi mencionado anteriormente o IEEE 802.15.4 sugere múltiplas topologias para a conexão em rede, entre elas: a topologia em estrela (Star) e a topologia Peer-to-Peer (802.15.4, 2003). Porém, a especificação da camada de rede não faz parte do IEEE 802.15.4 e a topologia a escolher é determinada pelo tipo de aplicação que terá a rede segundo o padrão Zigbee.

\subsubsection{Modelos de Rede}

O padrão ZigBee, baseado nas recomendações do IEEE 802.15.4, considera uma topologia de rede muito mais abrangente chamada Malha $\left(m e s h^{7}\right)$, este tipo de topologia parece ser ideal quando se deseja alcançar maiores áreas de cobertura (KWANG et. al, 2006). Mesmo que o padrão Zigbee considere a topologia tipo malha muito mais abrangente inclui também as topologias em estrela $(S t a r)$ e a topologia Híbrida, sendo cada uma delas possivelmente muito mais eficientes segundo seja a aplicação e a área de cobertura do ambiente monitorado. As topologias de rede adotadas no padrão ZigBee são ilustradas na Figura 2.20.

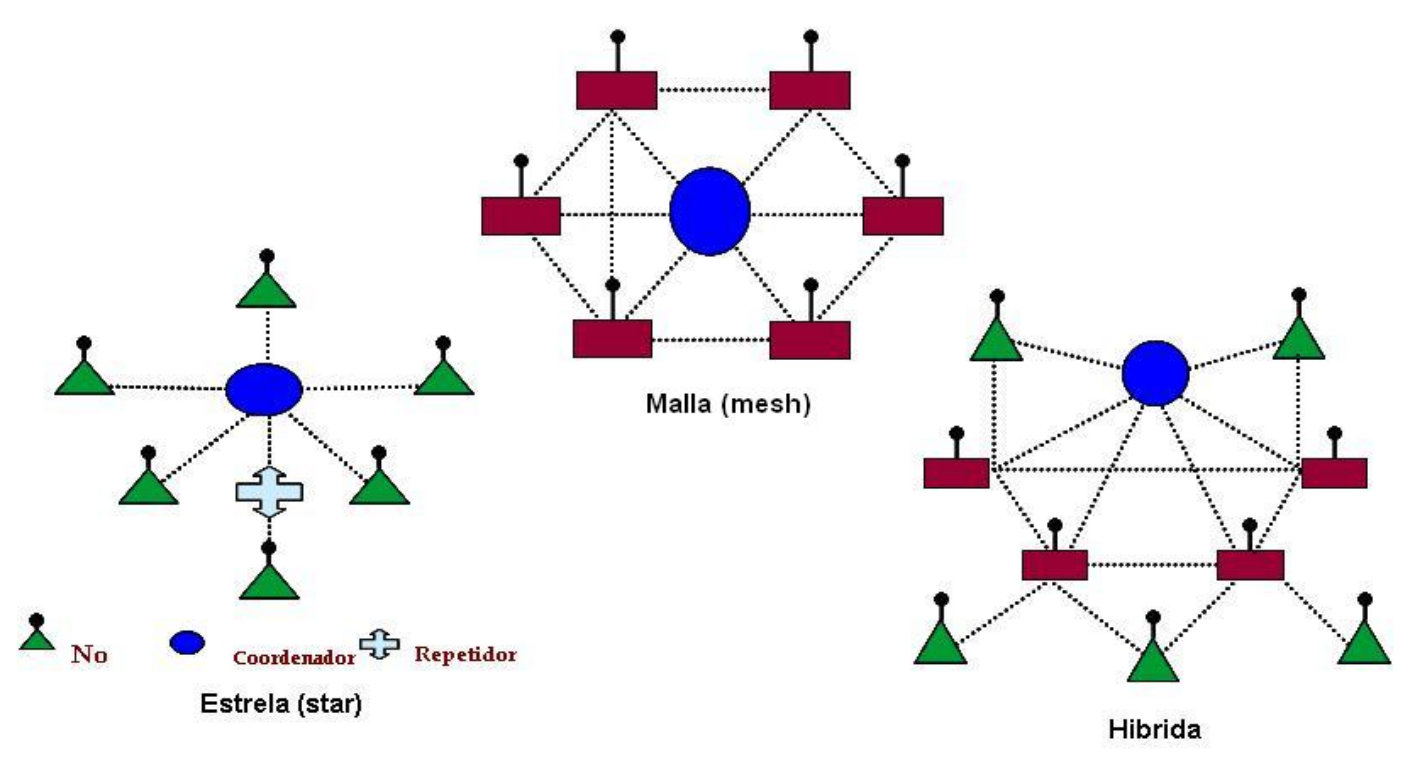

Figura 2.20: Modelos de rede

\footnotetext{
${ }^{7} \mathrm{O}$ termo mesh é usado devido ao fato que os roteadores e o coordenador tem múltiplas trajetórias de comunicação
} 
- Topologia Estrela; Na topologia em estrela, todos os nós são coordenados por um nó FDD (Function Device) o qual é denominado como PAN (Personal Area Network Coordinator) e que controla o acesso ao médio. Os outros dispositivos são os RFD (Reduced Function Device) e suportam uma funcionalidade reduzida e são controladas pelo PAN cordinator, o qual indica os períodos em que é possível transmitir, através de um mecanismo de sinalização.

- Topologia Malha; Nas redes de tipo malha (mesh), os nós atuam como encaminhadores de pacotes de outros nós que não se encontram na área de conexão direta com os seus destinos (LEE et. al., 2006). Na classificação das redes de tipo malha se tem: Rede malha com infra-estrutura e sem infra-estrutura. Na rede malha com infra-estrutura temos nós que realizam tarefas especificas ou prestações de serviços específicos. No entanto, para o caso das redes malha sem infra-estrutura os nós móveis têm os mesmo serviços e se conectam entre eles de forma arbitraria cooperando para formar uma rede (as quais são conhecidas como redes ad-hoc ou manet)(DRAVES; PADHYE; ZILL 2004)

Os componentes integrantes da rede são o coordenador, os roteadores e os dispositivos finais end devices.

- O coordenador: inicia a rede definindo o canal de comunicação usado, gerencia os nós da rede e armazena informações sobre eles;

- Os roteadores: são responsáveis pelo encaminhamento das mensagens entre os nós da rede;

- Os end device: pode ser um dispositivo bem mais simples, só se comunicando com outro nó da rede.

\subsubsection{Roteamento na Rede de Sensores Sem Fio}

O Surge-Telos é um protocolo de roteamento multihop baseado em beacon e CSMA/CA feito sobre as características do IEEE 802.15.4. Próprio para RSSF o Surge-Telos está centrado na conservação de energia do nó sensor e em conseqüência de toda a rede, em sua 
estrutura inclui módulos de programação para o chip CC2420 (Figura 2.21) na camada física. O protocolo em menção permite a transmissão Beacon-Enabled e Beacon-Disabled descrito no IEEE 802.15.4 e adotado pelo padrão Zigbee, pode ser implementado segundo sejam as necessidades da aplicação.

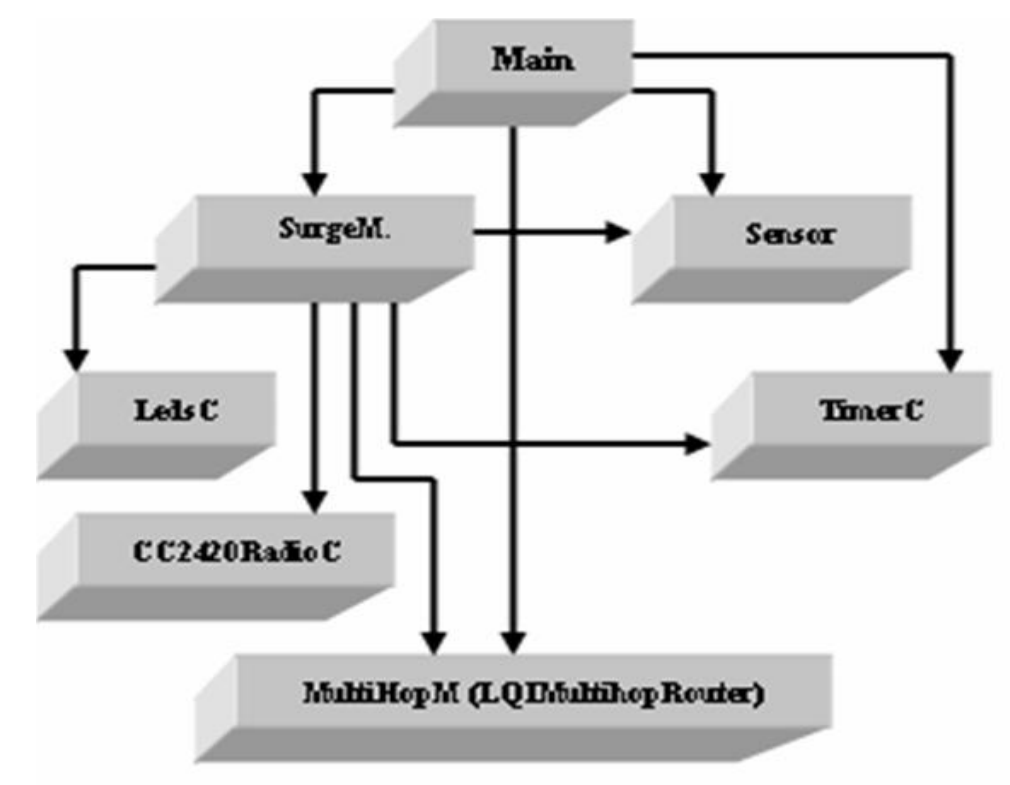

Figura 2.21: Diagrama de Blocos do Surge-Telos

O tamanho do pacote do Surge-Telos é para este caso de 30 bytes (Figura 2.22) e devido ao fato de seu código ser aberto o tamanho do pacote pode ser alterado segundo as demandas da aplicação. O campo len (length) indica o tamanho total do pacote, o campo dsn indica o número de sequência do pacote e é reservado, o campo addr indica o endereço de destino do pacote, o campo Source é a origem do último salto do pacote, o campo HopCnt indica o número de saltos do pacote até seu destino final e o campo Reading os valores do sensor ativo. 


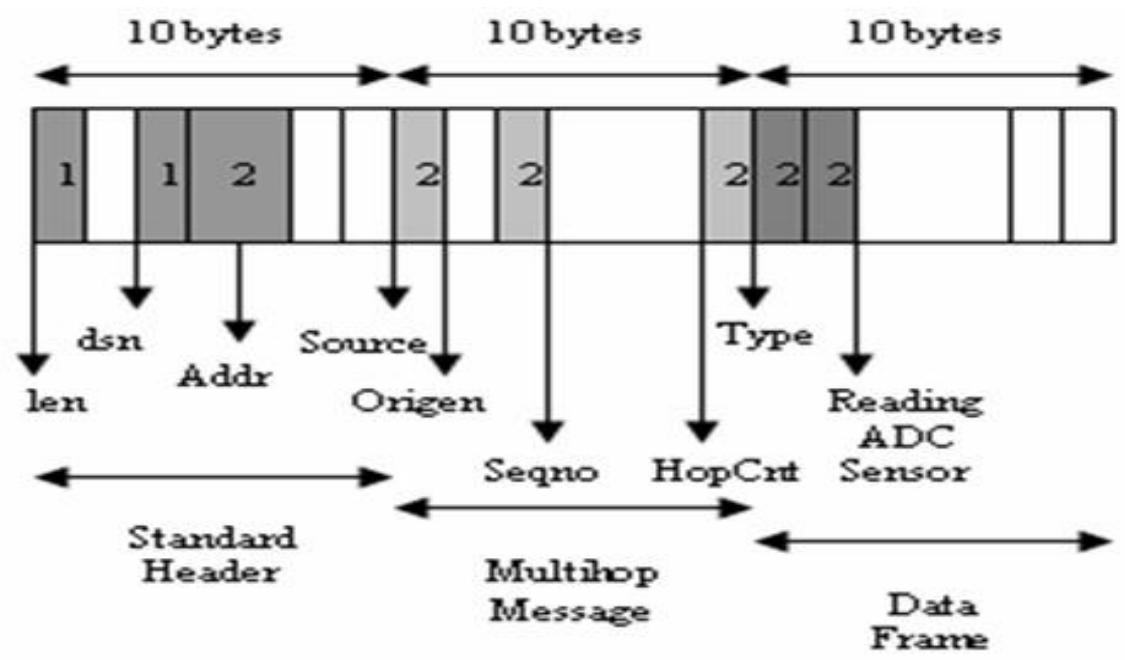

Figura 2.22: Formato do pacote Surge-Telos

O protocolo em menção está incluído dentro do conjunto de aplicações que proporciona o Sistema Operacional (S.O) TinyOs 2.0, que considera em seus módulos de programação aplicações desenvolvidas sobre as especificações da norma IEEE 802.15.4 e o padrão Zigbee. O S.O. em menção é um dos mais usados para aplicações de RSSF. No entanto existem muitos outros S.O., tais como: Contiki (DUNKELS; GRÖNVALL; VOIGT, 2004), YATOS (ALMEIDA et al., 2004), T2 (LEVIS et al., 2005), Mantis (BHATTI et al., 2005) entre outros. 


\section{Capítulo 3}

\section{TRABALHOS CORRELATOS}

Estudos analíticos e simulações foram realizados com o intuito de caracterizar o desempenho do IEEE 802.15.4 como em (CALLAWAY et al, 2002), aliás, da mesma forma em Zheng e Lee (2006) desenvolveu-se uma aplicação no simulador NS-2 para analisar as principais características do IEEE 802.15.4.

Timmons e Scalon (2004) apresentaram análises matemáticas do desempenho do IEEE 802.15.4 em relação às redes de sensores para aplicações médicas. Anastasi et al. (2004) investiga o desempenho dos Motes Mica2 e Mica2Dot através de estudos experimentais, o estudo faz uma análise dos principais elementos que caracterizam o desempenho de uma rede de sensores sem fio.

Lee (2005) realiza estudos experimentais com dispositivos IEEE 802.15.4 em ambientes reais utilizando topologia em estrela. Em (COX; MILENKOVIC; JOVANOV, 2005) apresenta-se a programação de um protocolo FTPS (Flooding Time Synchronization Protocol) desenvolvido explicitamente com o objetivo de fazer uma avaliação sobre o tempo que leva um nó sensor para se sincronizar na rede ZigBee. Finalmente, um dos trabalhos experimentais mais recentes é o realizado por Ferrari et. al. (2007) utilizando uma tecnologia proprietária chamada Z-wave. As avaliações são realizadas em um ambiente interno. 


\subsection{Performance Study of IEEE 802.15.4 Using Measurements and Simulations}

O trabalho realizado em Petrova et. al. (2006) tem como objetivo a avaliação de desempenho do IEEE 802.15.4. Ao mesmo tempo os autores realizam um estudo sobre a coexistência de dispositivos projetados sobre a norma 802.11 (Bluetooth) e a norma IEEE 802.15.4 através de medições em um mesmo ambiente de propagação, analisando as interferências e seu impacto na transferência de dados para os dois casos. Na realização dos experimentos são utilizadas como métricas de desempenho: a vazão de dados, o nível de RSSI, o PER (Packet error rate). Entre os pontos mais relevantes deste trabalho encontrase a realização dos experimentos em ambientes internos (Indoor) e externos (Outdoor) utilizando um modulo de rádio da chipcon CC2420EB. O modulo é programado para medir o PER segundo a variação de distâncias. Os resultados de RSSI atingem o valor de $-47 \mathrm{dBm}$ em ambientes internos e de $-37.5 \mathrm{dBm}$ para ambientes externos (Figura 3.1). Na realização dos experimentos de RSSI é criada uma relação com a taxa de PER nos diferentes ambientes de avaliação.
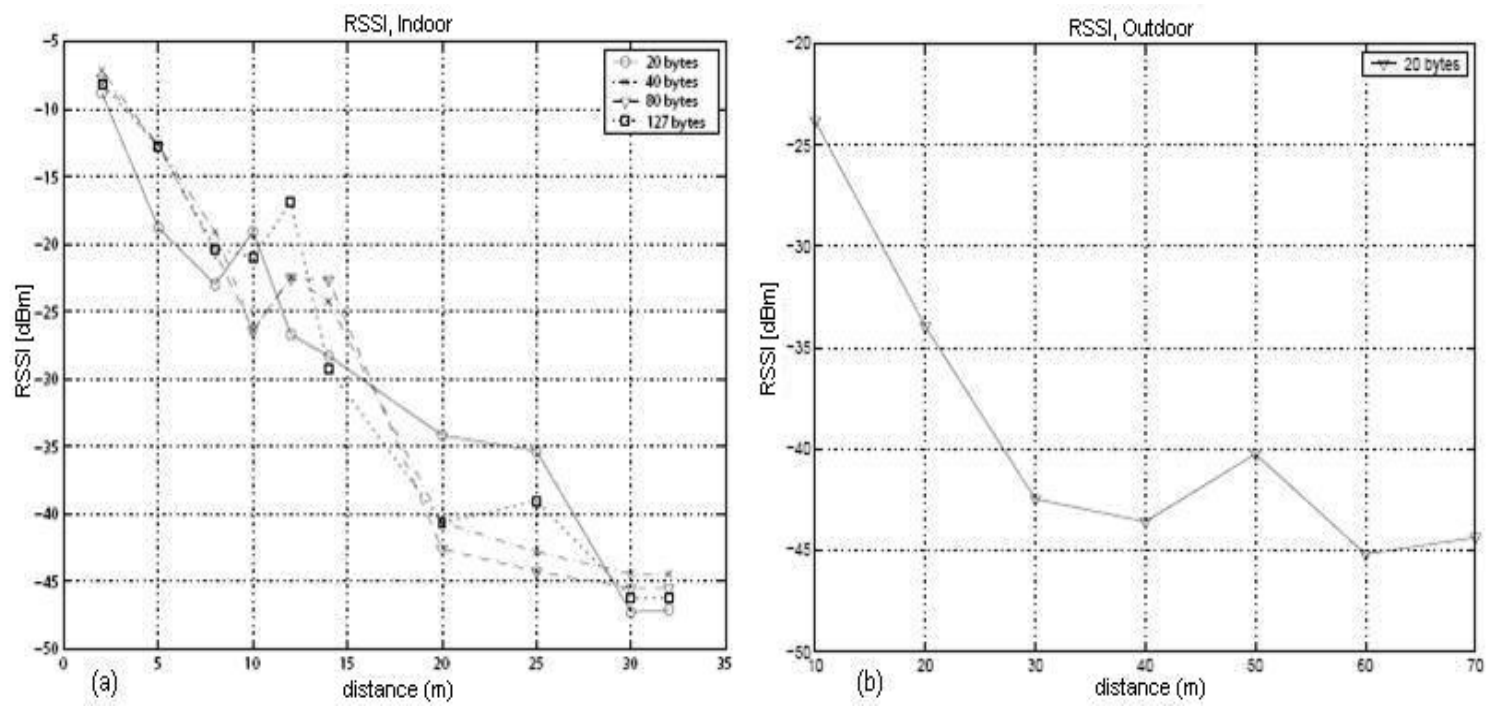

Figura 3.1: Análise de RSSI no NS-2 segundo variações do tamanho do pacote de dados em ambientes internos e externos. Fonte (Petrova et al., 2006)

Os resultados mostrados para ambos ambientes indicam um alcance do sinal de $35 \mathrm{~m}$ para o funcionamento da rede em ambientes internos, e de até $70 \mathrm{~m}$ para ambientes externos.

O trabalho apresenta originalidade e consideran-se relevante as técnicas utilizadas na 
realização dos experimentos de desempenho, alguns dos quais são adotados em nosso estudo. No entanto, apesar do trabalho apresentar resultados e técnicas originais através da utilização de módulos hardware como: chips de rádio programados utilizando a pilha do IEEE 802.15.4 e o nó sensor Telos para a realização dos experimentos de transferência de dados (vazão), não é especificado o número de nós utilizado nos experimentos, as distâncias de separação entre eles, as características do ambiente de propagação segundo os níveis de RSSI e o consumo de energia dos dispositivos IEEE 802.15.4 em cada uma das análises realizadas, parâmetros considerados importantes nos experimentos de desempenho e que são aplicados em nosso estudo.

\subsection{The ZigBee Experience}

O trabalho realizado por Hyncica et. al. (2006) realiza um interessante estudo do desempenho de alguns módulos de rádio ZigBee. O relevante deste estudo é a realização das análises em um ambiente interno (Indoor) com o objetivo de caracterizar a estrutura do ambiente segundo os níveis de RSSI. Os autores utilizam como indicadores de desempenho: A qualidade do Enlace segundo o cenário de propagação, o número de pacotes transmitidos, pacotes recebidos e o tempo de resposta.

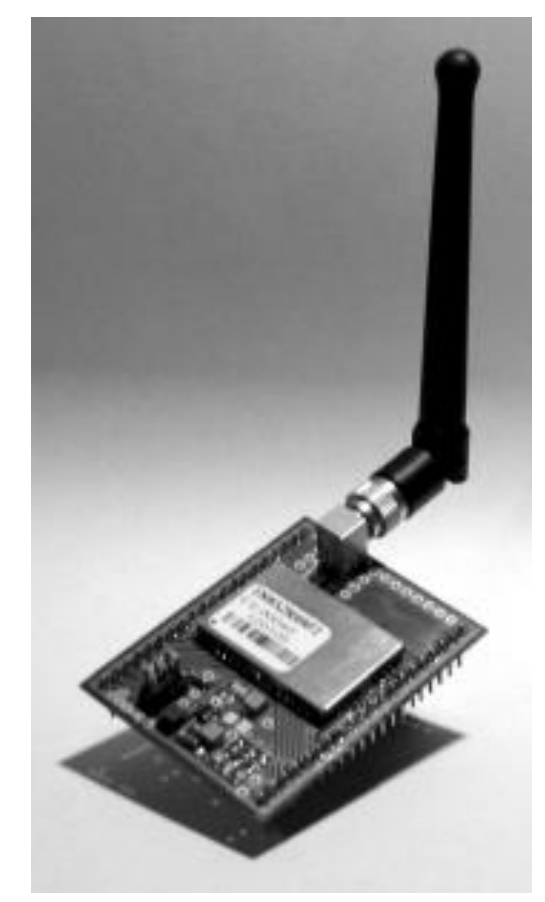

Figura 3.2: Modulo PAN4450. Fonte (Hyncica et. al. 2006) 
Na programação dos módulos ZigBee é utilizada a pilha de protocolos SMAC proporcionada pela Freescale a qual utiliza um payload com tamanho máximo de 125 bytes (dos quais são utilizados 32 bytes). Os resultados dos experimentos apresentam um alcance dos módulos ZigBee de até 44m (ambiente interno) com um valor máximo de RSSI que varia entre os $-68 \mathrm{dBm}$ e $-70 \mathrm{dBm}$ e um alcance efetivo por cada nó de $12 \mathrm{~m}$

O trabalho (HYNCICA et. al., 2006) realiza um estudo dos parâmetros mais significativos na transmissão em um ambiente interno. Os resultados das análises auxiliam na realização de novos experimentos sobre o padrão ZigBee, os quais são aplicados em nosso estudo na caracterização do ambiente de propagação segundo os níveis de RSSI.

\subsection{An Experiment on Performance Study of IEEE 802.15.4 Wireless Networks}

Este é um dos primeiros estudos de desempenho do IEEE 802.15.4. o trabalho realizado pro Lee (2005) consiste no estudo experimental das camadas física e de enlace do IEEE 802.15.4. No qual se realiza uma análise dos modelos de transmissão Direta e Indireta, utilizando como métricas a vazão de dados e valores de RSSI para cada modelo de transmissão. Como resultado o trabalho evidencia a eficiência do modelo de Transmissão Direta com uma vazão de $153.02 \mathrm{Kbps}$ sobre os $65.69 \mathrm{Kbps}$ do modelo de Transmissão Indireta. Lee (2005) cria uma interessante relação da vazão obtida nos modelos de transmissão com os níveis de RSSI, sendo de -34.35 dBm para o primeiro modelo (Direta) e de $-40.87 \mathrm{dBm}$ para o segundo.

No estudo dos mecanismos do CSMA/CA se calcula o erro na transmissão, expressada na formula seguinte (3.1):

$$
\text { ReffData }=\frac{\text { Ndata } *(L M S D U) d a t a}{\text { Tend }- \text { Tstart }}
$$

Os experimentos do CSMA/CA são realizados pelo autor através dos tipos de transmissão com Beacon e sem Beacon. Para esta análise o tamanho do payload do MSDU é determinado em 20 bytes. Finalmente é criada uma relação entre os mecanismos do 
CSMA/CA, os tipos de transmissão com e sem Beacon e a variação do payload de dados que inicia com 20 bytes, 60 bytes e termina com 102 bytes.
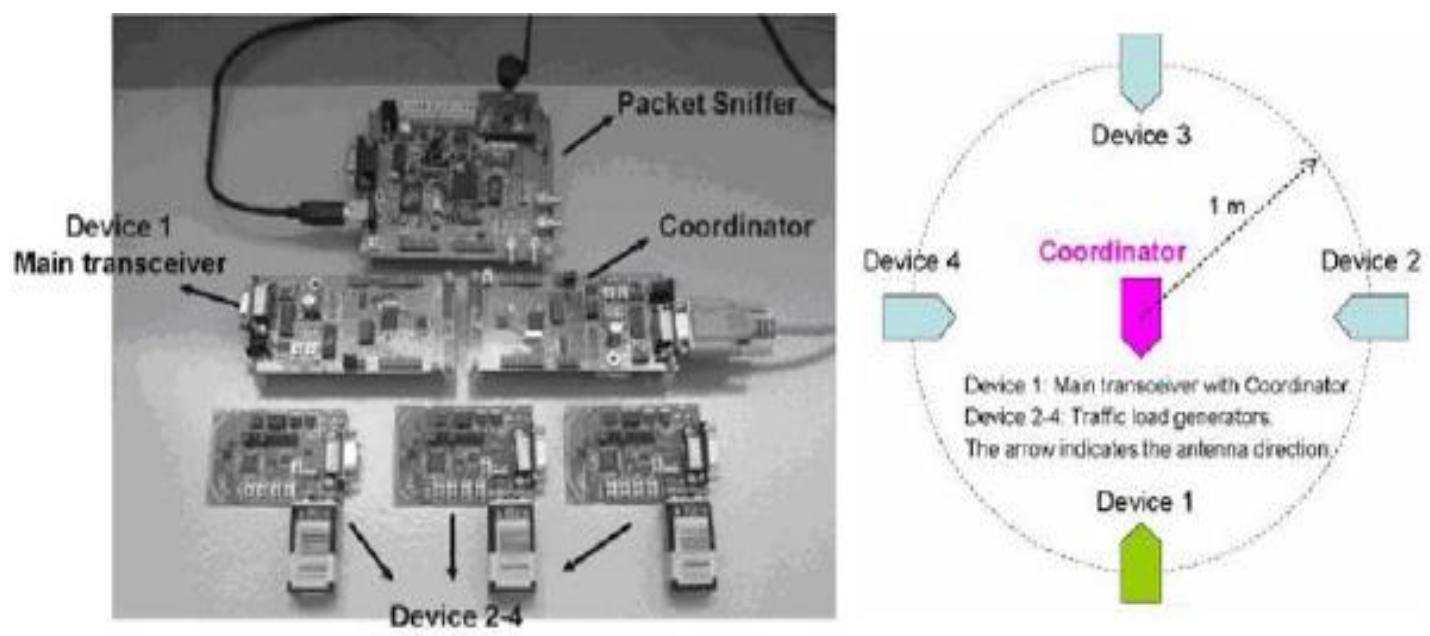

Figura 3.3: Bancada de testes e Distribuição dos geradores de Tráfico e o Coordenador da rede. Fonte (Lee, 2005)

O estudo conclui como eficiente as características do IEEE 802.15.4, porém indica que é necessário um estudo das características da pilha do padrão Zigbee, tais como o roteamento (camada de rede), segurança, tempos e velocidades de transmissão etc., parâmetros que são abordados em nosso estudo.

\subsection{Wireless Sensor Networks: Performance Analy- sis in Indoor Scenarios}

O trabalho realizado por Ferrari et. al (2007) tem por objetivo a avaliação de desempenho do padrão proprietário Z-Wave em ambientes Internos (Indoor). Na realização dos experimentos como o Packet error rate os autores criam paralelos entre o padrão Z-Wave ${ }^{1}$ e o Padrão ZigBee evidenciando uma perda menor na transmissão para o Z-Wave para distâncias que superam os $20 \mathrm{~m}$. Outro aspecto interessante deste trabalho são os dois tipos de cenários internos propostos nos experimentos. O primeiro deles é um cenário com o modelo de transferência direta entre os nós remotos e o nó coordenador da rede. O segundo

\footnotetext{
${ }^{1} \mathrm{O}$ Z-Wave é uma tecnologia proprietária (ZENSYS 2007) para nós sensores criada sobre as especificações da norma IEEE 802.15.4, e segundo o fabricante possui as mesmas características do padrão ZigBee. Nas especificações deste novo padrão destaca-se o uso de topologias malha.
} 
cenário é composto por uma rede com roteadores medindo o atraso nas comunicações entre os nós remotos e o coordenador.

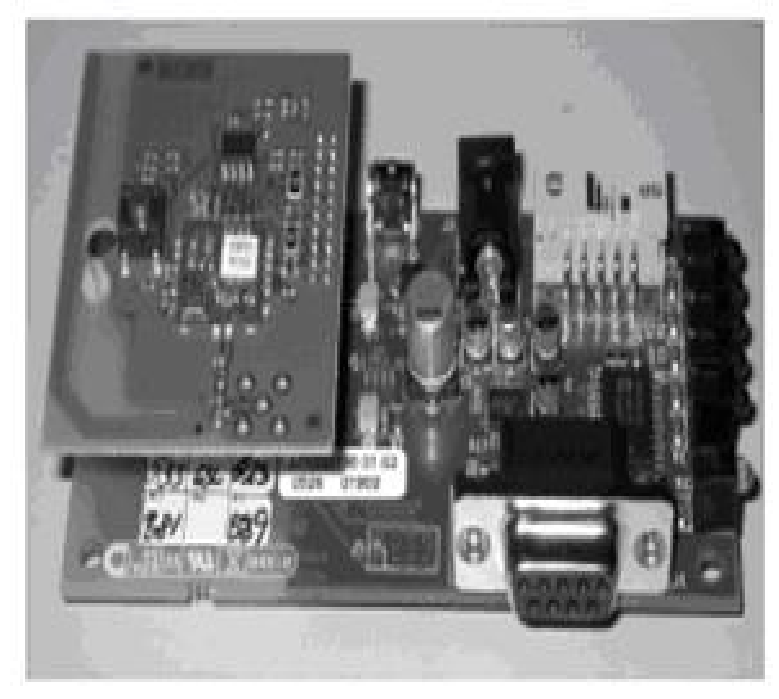

Figura 3.4: Nó sensor Z-Wave (módulo de teste). Fonte (Ferrari et al., 2007)

Entre outras métricas de desempenho consideradas para este estudo temos: o nível de RSSI segundo a variação de distâncias entre os nós com uma separação máxima de $80 \mathrm{~cm}$ e um RSSI de $-70 \mathrm{dBm}$ considerando uma potencia inicial de transmissão de $0 \mathrm{dBm}$. Na vazão de dados o tamanho máximo do payload é de 90 bytes. O trabalho analisa a vazão entre os diferentes dispositivos transmissores da rede (coordenador e roteadores).

Finalmente o trabalho realiza uma comparação dos resultados de Delay obtidos através de resultados experimentais com os resultados das simulações, obtendo-se como resultado uma vazão $40 \%$ menor ao obtido através de simulações.

O trabalho publicado por Ferrari et. al. (2007) é possivelmente um das análises mais completas de aplicação de duas tecnologias de comunicação Z-Wave e ZigBee para RSSF. Porém, alguns aspectos como o consumo de energia dos nós segundo os modelos de transmissão utilizados não fazem parte deste estudo.

Finalmente, com o objetivo de criar paralelos com os resultados dos trabalhos experimentais existentes na literatura, são apresentados na tabela 3.1 alguns dos resultados dos trabalhos mais relevantes.

Embora existam na atualidade diversos trabalhos com as características da norma 
Tabela 3.1: Trabalhos Experimentais

\begin{tabular}{|c|c|c|c|}
\hline & Petrova et. Al. (2006) & Hyncica et. Al. (2006) & Ferrari et. Al (2007) \\
\hline Alcance & $35 \mathrm{~m}$ & $44 \mathrm{~m}$ & $20 \mathrm{~m}$ \\
(Interno) & $70 \mathrm{~m}$ & & - \\
(Externo) & & $-68 \mathrm{dBm} /-70 \mathrm{dBm}$ & \\
RSSI & $-47 \mathrm{dBm}$ & & 20 e 40 Bytes \\
(Interno) & $-37.5 \mathrm{dBm}$ & 32 Bytes & Mesh \\
(Externo) & 20 e 40 Bytes & Estrela & \\
Payload & Peer-to-Peer & & \\
Topologia & & & \\
\hline
\end{tabular}

IEEE 802.15.4 e do padrão ZigBee, a maior parte deles com resultados obtidos através de simulações ou análises matemáticas, faz-se necessário a realização de trabalhos experimentais na aplicação do padrão ZigBee em RSSF. Existem alguns trabalhos importantes publicados recentemente, no entanto, estes não atingem todas as métricas que poderiam ser úteis na criação de novos hardwares para RSSF sobre este padrão. Os experimentos realizados (ambientes Internos e Externos) serão úteis para auxiliar no futuro desenvolvimento de hardware e aplicações para RSSF ZigBee/IEEE 802.15.4.

Baseados nos trabalhos existentes realizados com as características do IEEE 802.15.4 e o padrão ZigBee, determinou-se a escolha de algumas métricas para sua aplicação neste estudo que não são consideradas na literatura existente como: Distância máxima de separação entre os nós da rede. Alcance de uma RSSF sobre o padrão Zigbee em ambientes internos e externos através do uso de topologias. Análises do impacto no consumo de energia nos diferentes eventos na comunicação de um nó sensor. Os modelos de comunicação com beacon e sem beacon e seu impacto na RSSF. Caracterização do cenário de avaliação segundo os níveis de RSSI. 
Capítulo 4

METODOLOGIA

Este capítulo apresenta a metodologia utilizada no projeto de pesquisa. Ao mesmo tempo são descritas de forma detalhada as soluções propostas para a análise de consumo de energia, assim como os recursos de hardware e software que foram utilizados. Finalmente são apresentados os ambientes de obtenção de dados (Interno e Externo), são mecionadas algumas considerações sobre a distribuição da rede e prévias à realização dos experimentos de desempenho. 


\subsection{Soluções Propostas}

Duas tecnologias de hardware de nós sensores são utilizadas na realização deste trabalho: a primeira é a arquitetura do Mica Motes (Mica2dot) e a segunda a arquitetura do TmoteSky. Ao mesmo tempo, uma ferramenta para análise de consumo de energia é desenvolvida utilizando LabView (como linguagem de programação para dispositivos virtuais).

\subsubsection{Ferramenta para análise do Consumo de Energia - Descrição da Montagem}

O sistema empregado foi um resistor de shunt de 10ohm (RASKOVIC, 2004). O valor da tensão é lido por um cartão de aquisição de dados PXI 6071E da National Instruments. Um Vi (Instrumento Virtual) construído através da linguagem de programação gráfica LabView, controlando o PXI, realiza a coleta e o processamento dos valores lidos.

O diagrama em blocos do sistema montado é descrito na figura 4.1.

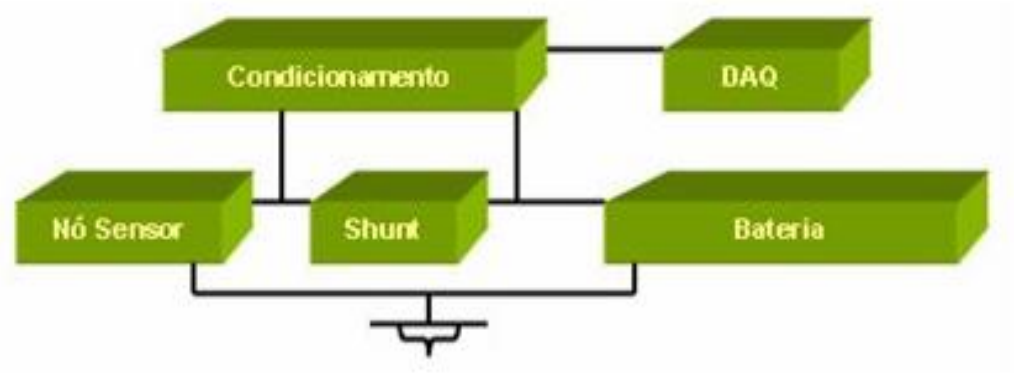

Figura 4.1: Diagrama de blocos da montagem para medida de Consumo de Energia

O sistema montado consiste nos seguintes blocos:

- O sistema em teste: o nó sensor e a fonte de energia (baterias);

- O bloco de aquisição de dados: um resistor shunt de $10 \mathrm{ohm}$ para a medição do consumo de corrente, o circuito de condicionamento dos sinais;

- Sistema de aquisição de dados PXI: composta por um PXI-8170 com uma placa DAQ 6071E e como interface para coleta dos dados um Vi (Instrumento Vitual), 
solução criada em LabView.

\subsubsection{Descrição da Interface Vi-Energy Para Coleta dos Dados}

O Vi-Energy (Virtual Instrument Energy) (Figura 4.2) é uma ferramenta construída em LabView para a coleta dos valores de consumo de energia obtidos através da Placa de Aquisição de Dados (DAQ) que consiste em um Osciloscópio virtual e um visualizador de Picos e Quedas de consumo da bateria (a configuração do estado de amostragens de Peaks and Valleys deverá ser feito segundo seja as exigências do usuário).

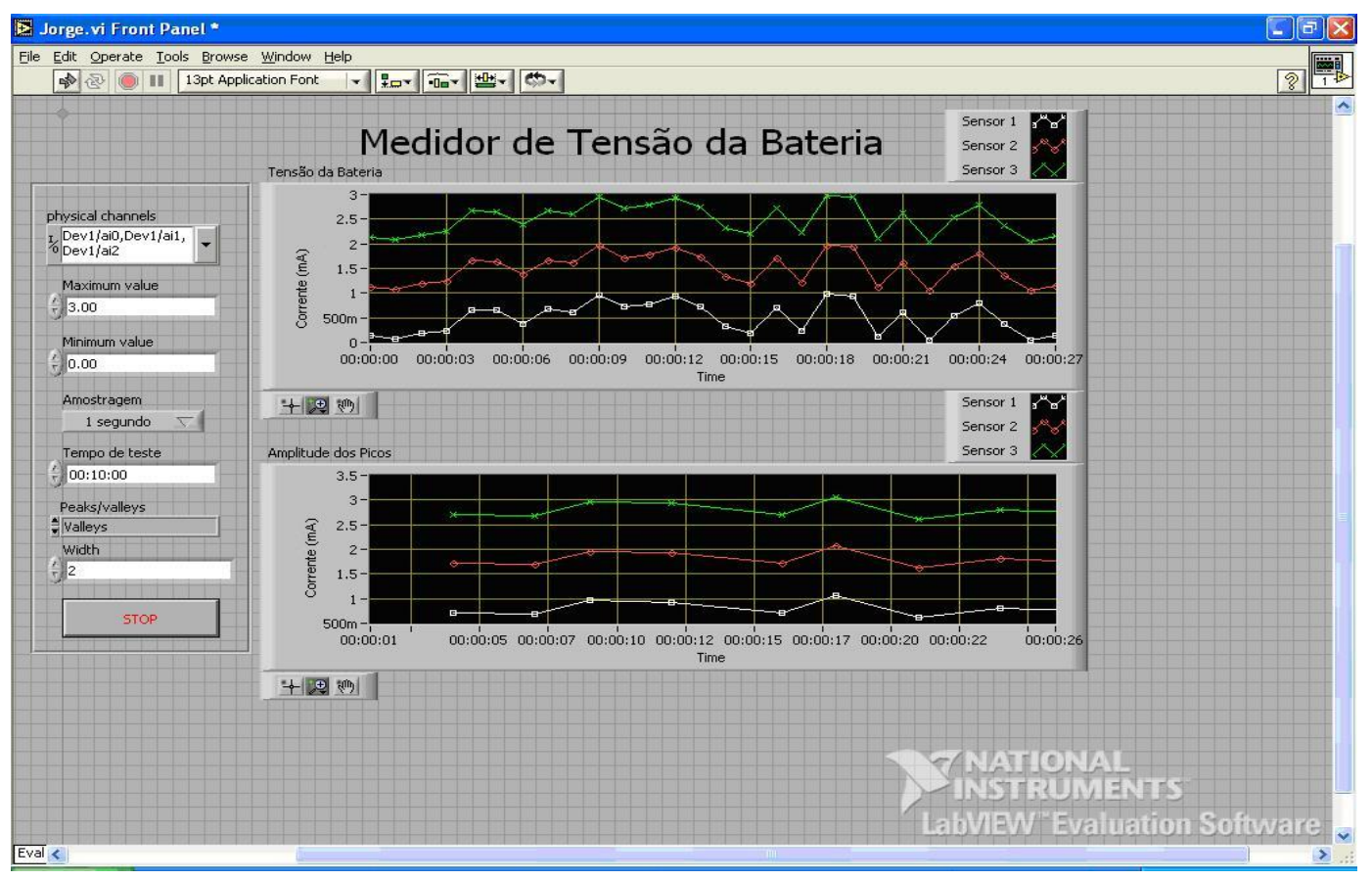

Figura 4.2: Interface do Programa Medidor de tensão da bateria

Os parâmetros de configuração do programa são descritos a seguir:

- Physical Channels: O número de entradas da DAQ que serão usadas. (o número de entradas indica o número de dispositivos ligados através da DAQ);

- Maximum Value: Indica a tensão máxima do hardware e que será suportado pela DAQ;

- Minimum Value: Indica a tensão mínima do hardware e que será suportado pela DAQ;

- Amostragem: Indica o intervalo de tempo entre uma amostra e outra; 
- Tempo de Teste: Tempo de duração da amostragem;

- Peacks/Valleys: Segundo as necessidades do usuário;

- Width: Quantidade mínima de pontos em uma amostra para ser coletada;

\subsection{Ferramenta para Filtragem dos Logs de dados}

Os dados coletados são armazenados em arquivos de Log, e a estrutura e comprimento dos pacotes são variáveis segundo a aplicação em uso; como conseqüência uma ferramenta diferente para cada aplicação deverá ser desenvolvida. O uso deste tipo de ferramenta é comum nas redes Ethernet pelo fato que suas características em relação à codificação do Log serem sempre as mesmas. No caso das RSSFs existem dados adicionais dentro do pacote de roteamento proporcionados pelo protocolo e o hardware utilizado, pelo qual faz-se necessário criar pequenos scripts que proporcionem uma leitura e processamento eficiente dos arquivos de Log.

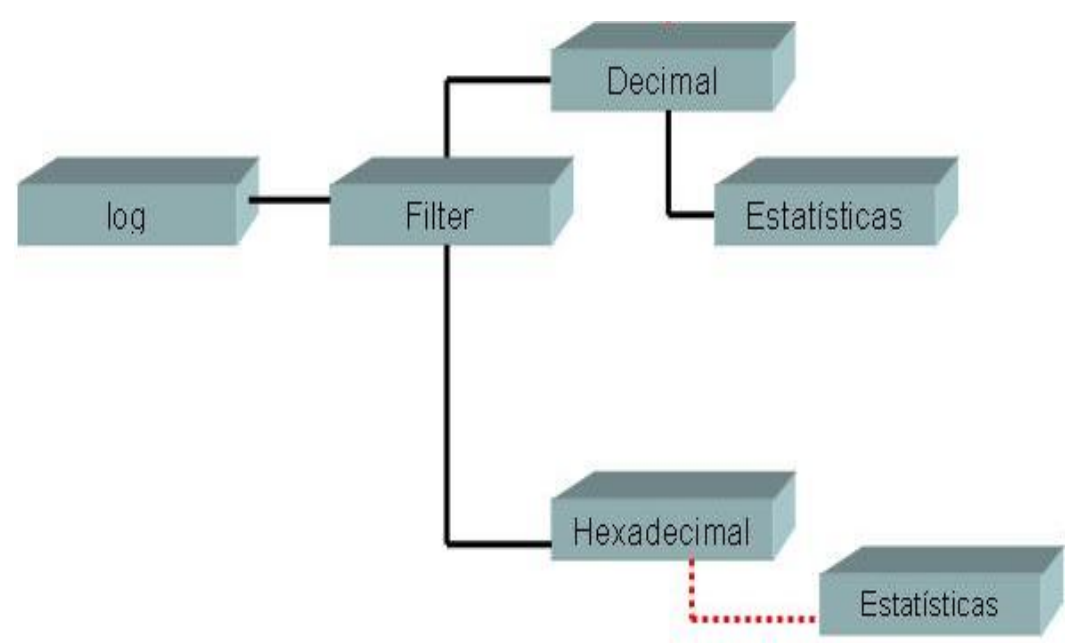

Figura 4.3: Diagrama de Blocos do Filter-Log.nc

O Filter-Log.nc é um script bastante simples, porém é muito útil durante a análise dos arquivos de log. A sintaxe é mostrada a seguir: 


\subsection{Hardware Empregado nos Experimentos}

Dentro do presente estudo são montadas duas RSSF no núcleo de Humanlab no LSI (Laboratório de Sistemas Integráveis), porém, não são iguais devido as suas diferenças na arquitetura de hardware e ao protocolo de comunicação em uso em cada uma delas. A primeira é uma rede baseada na arquitetura do Mica2dot $(915 \mathrm{MHz})$, a segunda é uma rede baseada na arquitetura do TmoteSky $(2.4 \mathrm{GHz})$ sobre a norma IEEE 802.15.4. Porém, em termos gerais, ambas redes são independentemente homogêneas de composição fixa ou estacionária (são definidas como tal devido ao fato que cada nó não é situado num lugar específico e fixo dentro do ambiente de rede).

O TmoteSky (Figura 4.4 e 4.5), desenvolvido pela Moteiv Corporation (MOTEIV, 2006), é a última geração de Motes de Berkeley. Compatível com o Telosb (CROSSBOW, 2005) são motes baseados no padrão ZigBee com baixo consumo de energia, taxa de transmissão de dados de 250Kbps e aplicações para RSSF de fácil desenvolvimento. O TmoteSky possui um sistema de rádio RF baseado no chip CC2420 (CHIPCON, 2006) trabalhando na banda ISM (Industrial, Scientific and Medical) de $2.4 \mathrm{GHz}$ o que permite interoperabilidade com outros dispositivos IEEE 802.15.4. O sistema de rádio trabalha com modulação O-QPSK (Offset Quadrature Phase-Shift Keying), um microcontrolador MSP430 de 8MHz da Texas Instruments com 10k RAM e 48 k Flash, uma interface de programação e coleta de dados via USB e um sistema de autenticação e encriptação na camada de hardware AES $128^{1}$.
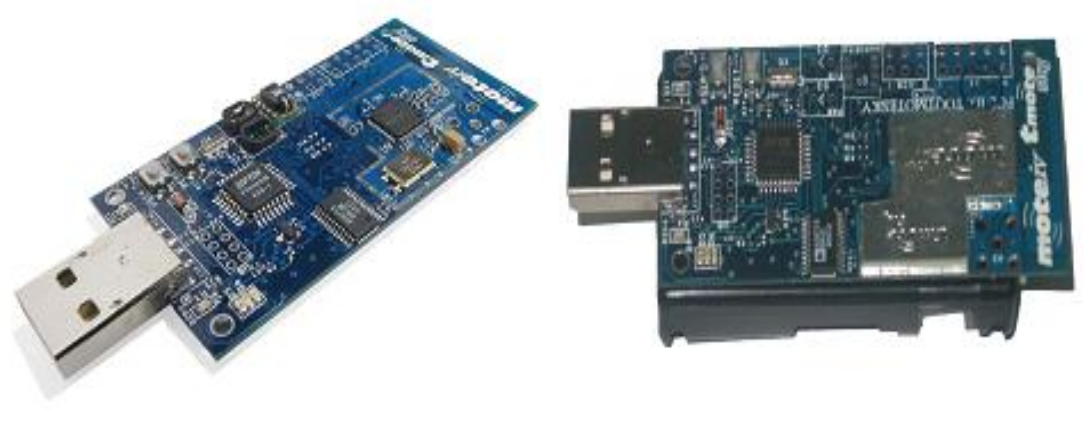

Figura 4.4: TmoteSky

\footnotetext{
${ }^{1}$ A norma IEEE 802.15.4 inclui na camada física um sistema de encriptação de dados baseado em chaves simétricas (AES128), no entanto, aspectos de segurança não são abordados neste trabalho
} 


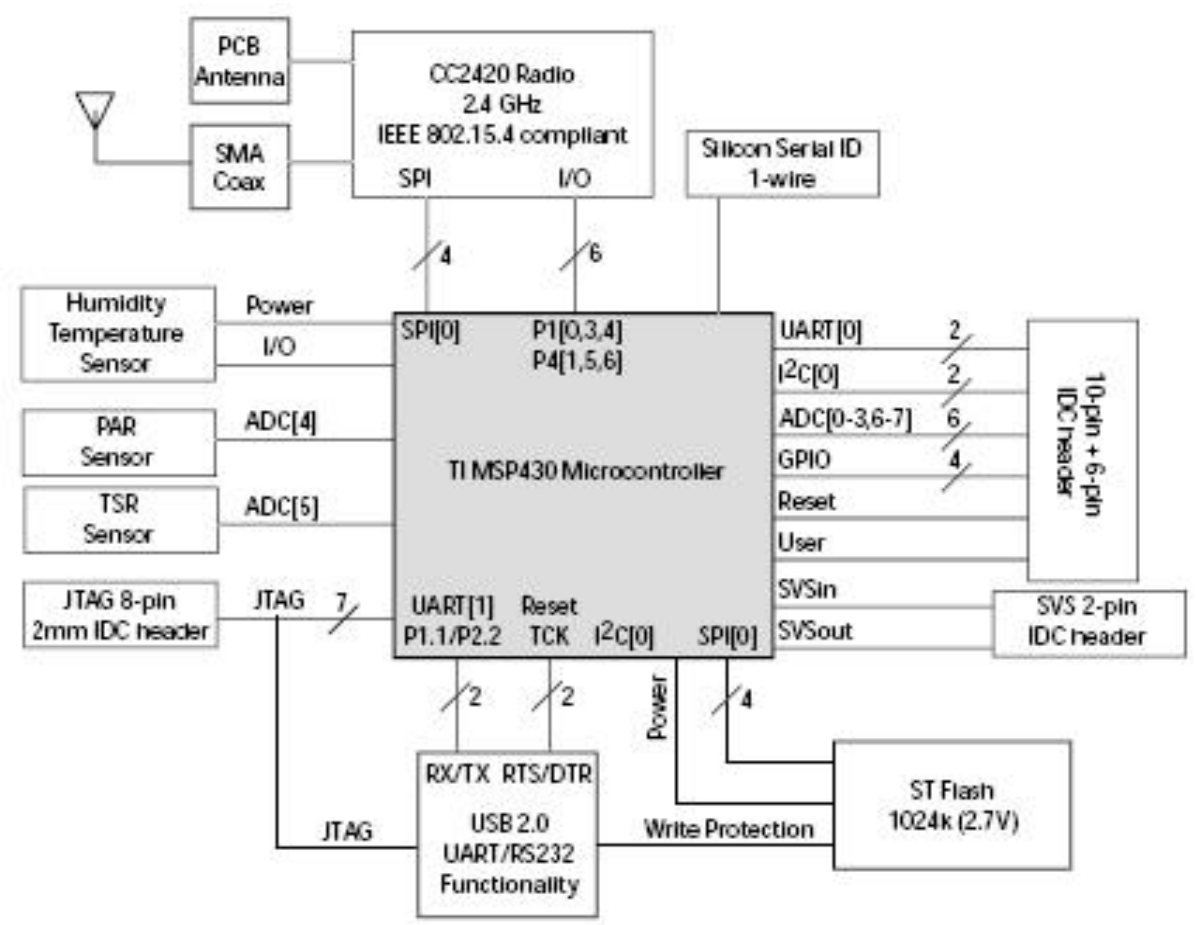

Figura 4.5: Diagrama de Blocos do Modulo TmoteSky. Fonte (Chipcon, 2006)

O segundo hardware, é o Mica2dot (Figura 4.6) desenvolvido pela Universidade de Berkeley (BERKELEY, 2003) e comercializado pela Crossbow, possui um microcontrolador ATMega 128L e o sistema de rádio é baseado no chip CC1000 da chipcon que trabalha com baixa potência e baixos níveis de tensão, opera em UHF na faixa ISM. A faixa de operação de freqüência varia entre os $433 \mathrm{MHz}$ ou $915 \mathrm{MHz}$. Este sistema de rádio utiliza a modulação FSK (Frequency Shift Key) que permite atingir taxas de transmissão da ordem de $76.8 \mathrm{Kbps}$.

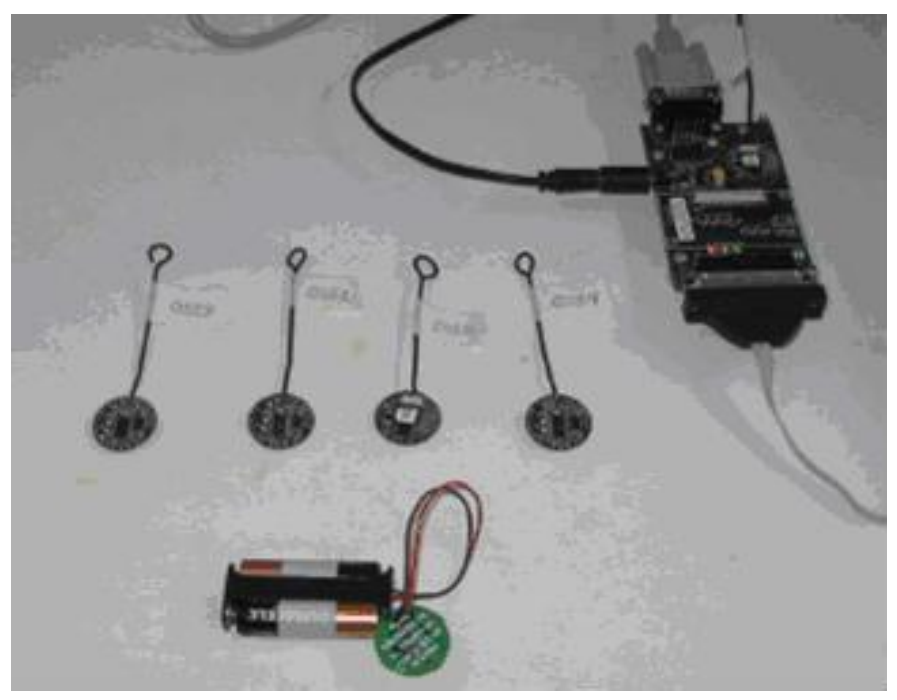

Figura 4.6: Mica2dot 


\subsection{Cenários de Avaliação}

É muito comum que as simulações em software não repliquem as condições de obtenção de dados de uma situação real, pois não conseguem capturar os erros que ocorrem na interação do hardware transmissor sem fio e o ambiente de propagação. Neste trabalho, foram escolhidos dois cenários reais (Interno e Externo) para a realização dos experimentos obtendo-se resultados de maior exatidão.

\subsubsection{Cenário de Avaliação Ambiente Interno}

O cenário escolhido para a avaliação em ambientes internos é um ambiente de $240 \mathrm{~m}^{2}$ localizado no bloco $\mathrm{C}$ do prédio de Engenharia Elétrica da Escola Politécnica da Universidade de São Paulo (Figura 4.7).

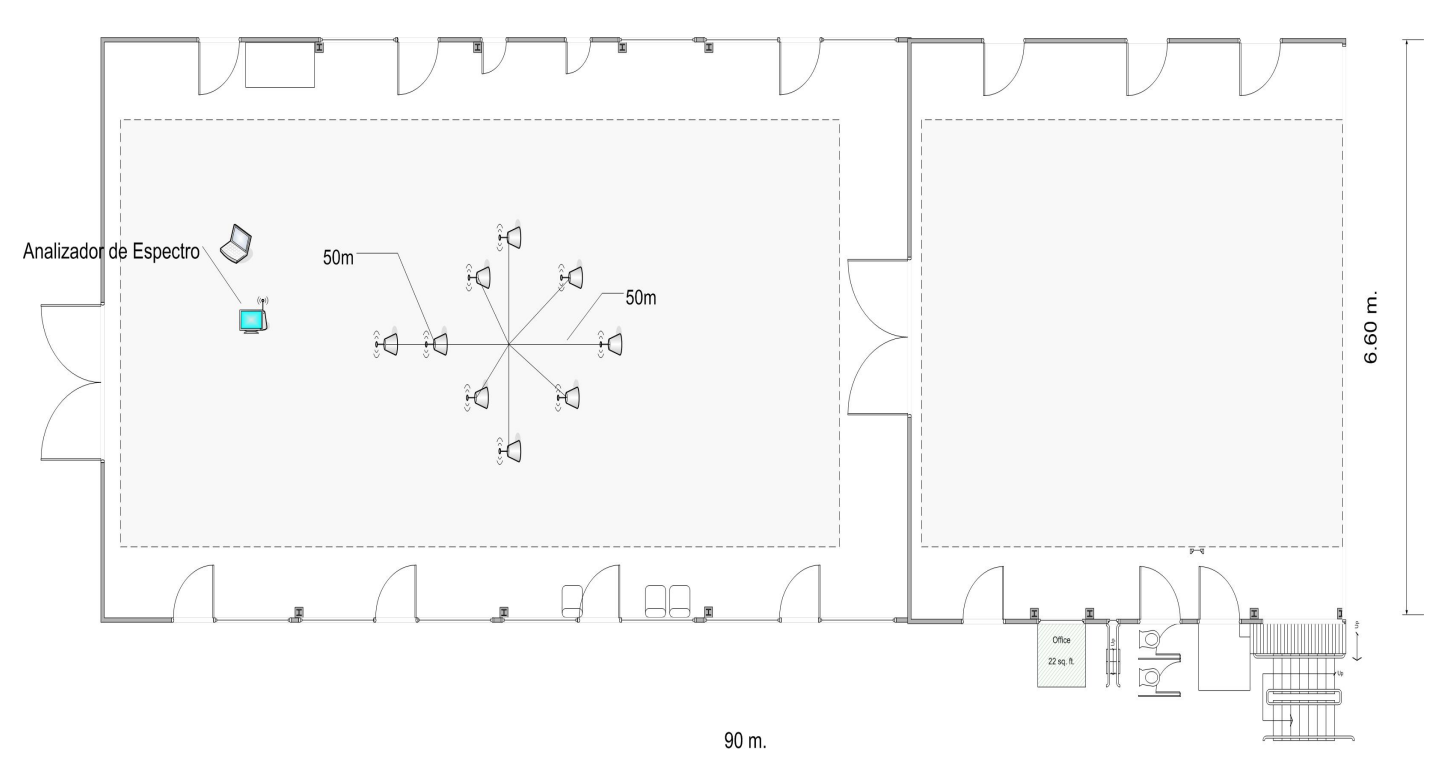

Figura 4.7: Cenário para a realização dos experimentos - Ambiente Interno

A escolha deste cenário de avaliação responde às seguintes justificativas:

- Primeiro: O ambiente possui um trânsito reduzido de pessoas, o qual facilita a realização dos testes de alcance e intensidade do sinal recebido sem nenhum tipo de interferências físicas em movimento (alto fluxo de pessoas); 
- Segundo: O ambiente escolhido é de fácil acesso e provê espaço necessário para a realização dos experimentos de desempenho; ao mesmo tempo o ambiente possui a maior parte dos elementos necessários para nossa avaliação em relação a sua estrutura física (Paredes de concreto, janelas de vidro, mesas e alguns móveis de oficina que, finalmente, são considerados como parte do experimento na caracterização do ambiente de propagação);

- Terceiro: A escolha do cenário facilita o traslado dos equipamentos como: Analisador de Espectro (HP8565), Analisador de Semicondutores (HP4156), PXI para a realização dos testes de energia, todos estes indispensáveis para a realização de alguns dos experimentos de desempenho.

\subsubsection{Cenário de Avaliação Ambiente Externo}

Inicialmente o ambiente escolhido para os experimentos de desempenho em ambientes externos foi o pátio do prédio de Engenharia Elétrica da Escola Politécnica, localizado em frente ao galpão didático. No entanto, depois da realização dos primeiros experimentos de desempenho (alcance do sinal) foi necessário mudar o ambiente devido às restrições de espaço. O ambiente escolhido finalmente para realizar os experimentos de desempenho em ambientes externos foi uma área de aproximadamente $300 \mathrm{~m}^{2}$, localizada ao lado do prédio de Tv Digital, parte posterior do prédio de administração da Escola Politécnica da Universidade de São Paulo (Figura 4.8). 


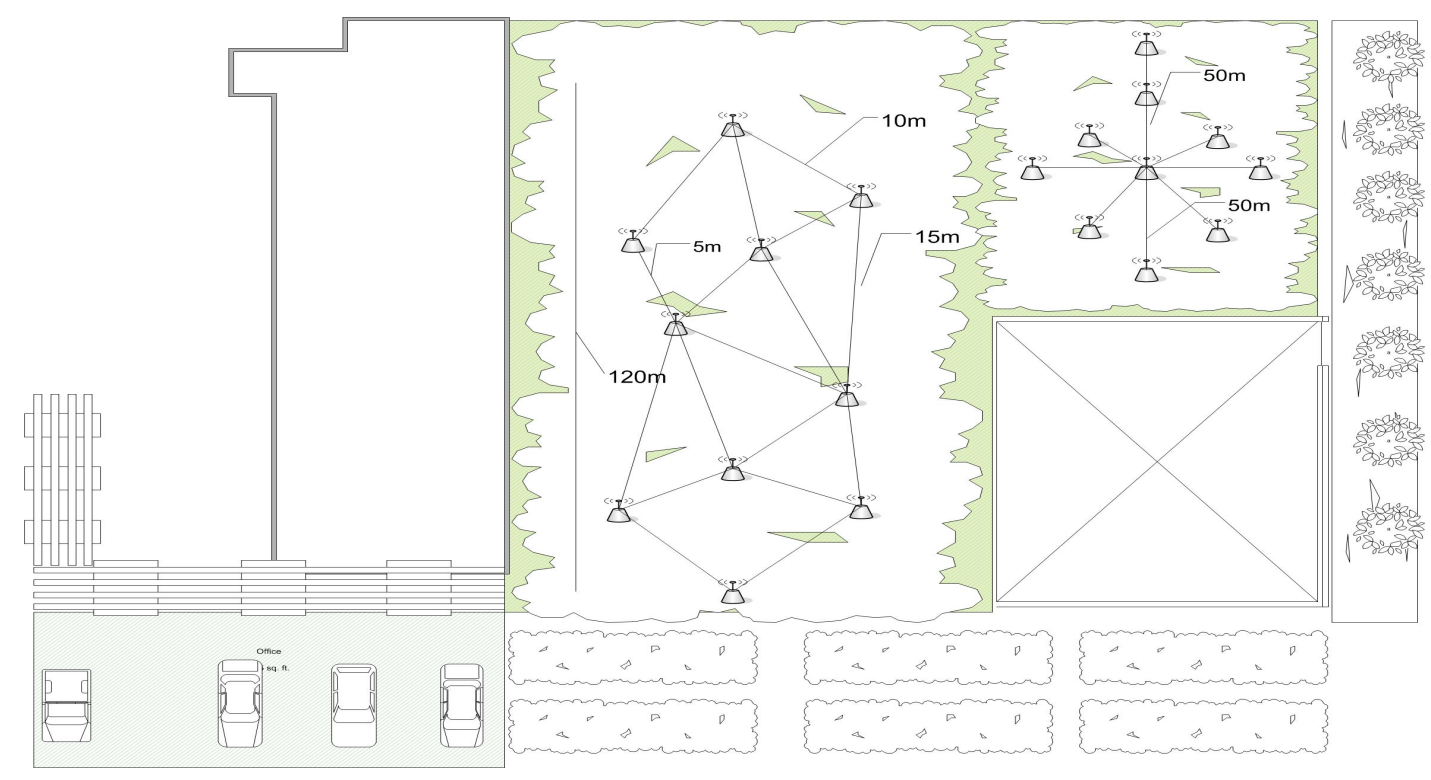

Figura 4.8: Cenário para a realização dos experimentos - Ambiente Externo

A escolha deste cenário de avaliação responde às seguintes justificativas:

- Primeiro: O ambiente é suficientemente extenso para a realização dos testes de alcance de sinal e de cobertura da rede;

- Segundo: O ambiente possui trânsito reduzido de pessoas o que facilita na pratica a realização dos experimentos de desempenho a campo aberto;

- Terceiro: O ambiente possui as características necessárias para a realização dos experimentos de RSSI (obstáculos).

\subsection{Configuração do Hardware para Avaliação}

A rede é composta por dez nós sensores, sendo um nó sensor configurado na base como nó coordenador e outros nove como dispositivos comuns. Inicialmente para os testes de modelos de transmissão, todos os nós da rede serão programados com a opção BeaconEnabled e para a segunda avaliação serão programados com a opção Beacon-Disabled. Para os testes de topologia e roteamento o protocolo Surge-Telos é compilado nos nós sensores. O tempo de envio entre pacotes (Time-Rate) é configurado para transmitir a cada $1000 \mathrm{~ms}^{2}$ (Figura 4.9). O Time-Rate é o mesmo em todos os experimentos realizados

\footnotetext{
${ }^{2}$ A edição do Time-Rate é feita através do S.O Tinyos o arquivo encontra-se disponível no modulo de roteamento.
} 
com a exceção dos experimentos realizados na camada de enlace para os modelos de transmissão (ver Capitulo V; Camada de Enlace).

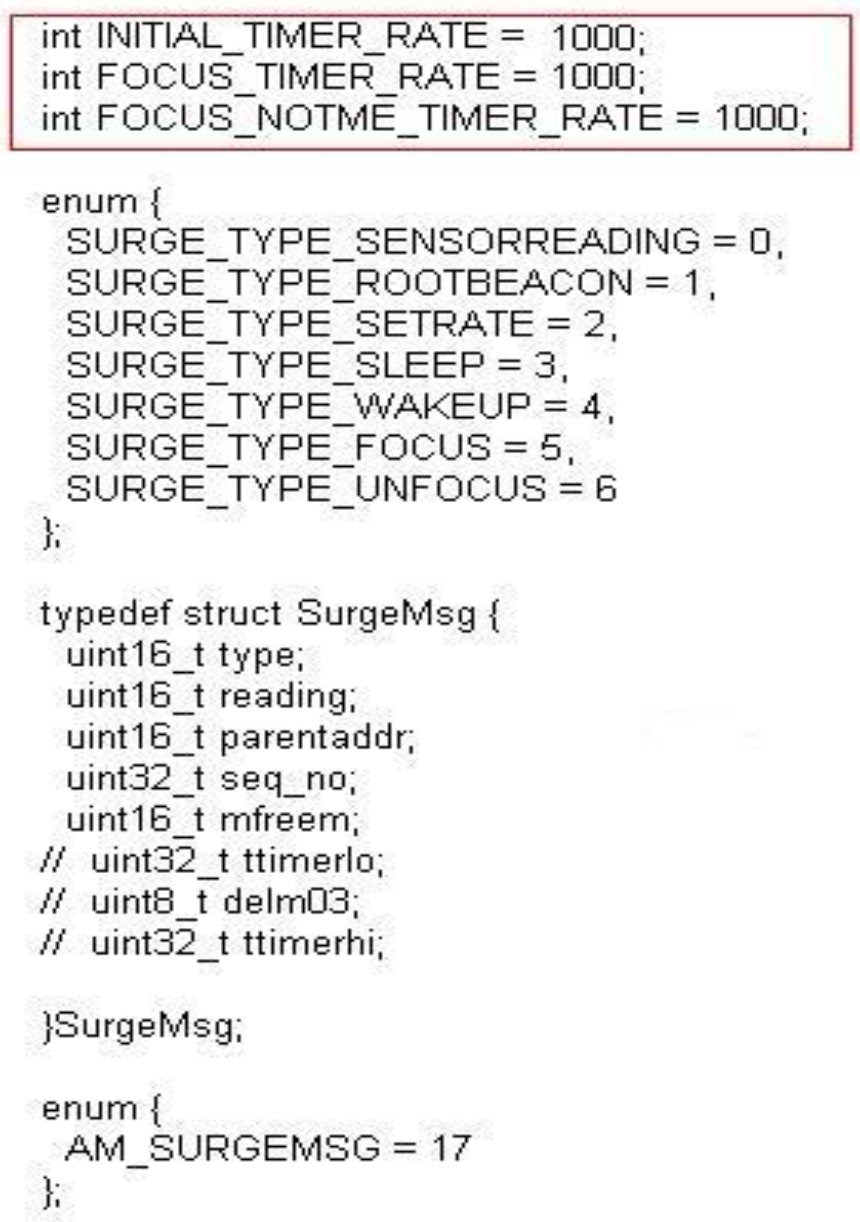

Figura 4.9: Código para configuração do Time-Rate

Para a análise de alcance do sinal no ambiente interno é montado um Analisador de Espectro HP8565E e ao mesmo tempo e de forma conjunta é montada a rede de sensores. Para este caso específico é configurado um nó da rede só como receptor (Data Sink), a finalidade desta configuração é evitar que o nó receptor (montado ao lado do analisador de espectro) distribuía algum tipo de mensagem para a rede que confunda a leitura do RSSI capturado pelo analisador de espectro (Figura 4.10). As configurações realizadas para a caracterização do ambiente de propagação segundo os níveis de RSSI é descrito ao detalhe na seção 4.5.2. 


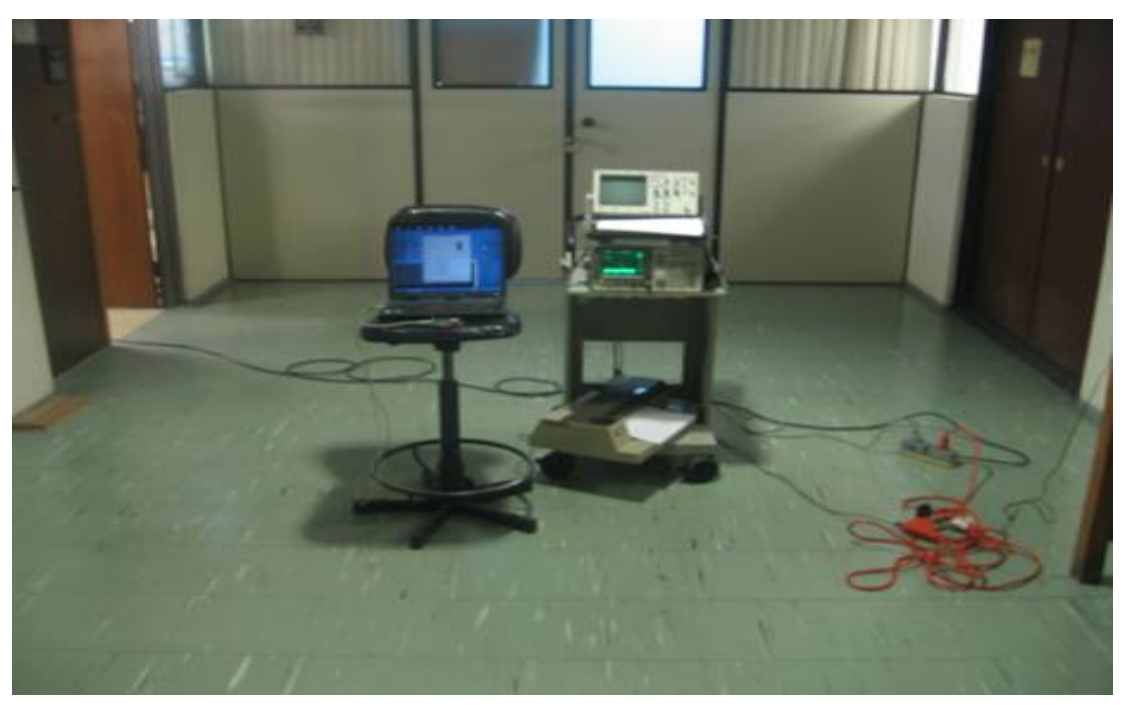

Figura 4.10: Bancada de testes para análise de RSSI (HP8565E)

Para a realização dos experimentos de sincronização se faz necessário conhecer os valores iniciais de consumo de energia. O primeiro deles é o consumo de energia do nó quando se tem o sistema de rádio desligado e o segundo valor é quando se encontra sincronizado na rede. O tempo de sincronização é o resultado do tempo que leva desde a ligação do nó até o envio da primeira solicitação de acesso ao canal (tais eventos são identificados relacionando o consumo de energia com os dados armazenados nos logs gerados pelos nós da rede). Para este experimento é utilizado um Analisador de Precisão de Semiconductores (Precision Semiconductor Analyzer) HP-4156A o qual permitirá alimentar através de seus SMUs aos nós com uma tensão em volts de 3.0v, de forma simultânea é delimitada uma potência de barreia em $\mathrm{m} A$ com o objetivo de proteger o circuito do nó das possíveis variações de potência do equipamento de testes.(Figura 4.11)

SMU-1

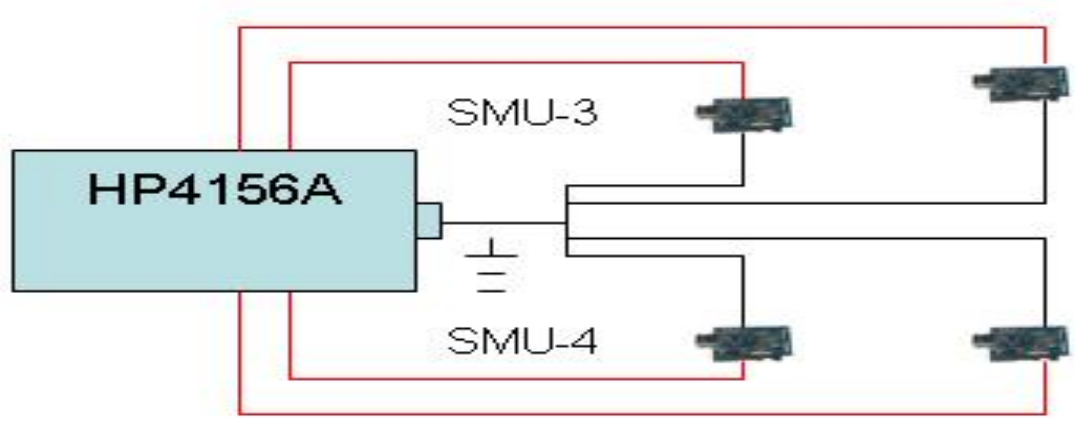

SMU-2

Figura 4.11: Diagrama de Conexão do HP4156A com os nós sensores 


\subsubsection{Considerações Finais na Distribuição da rede nos Cenários de Avaliação.}

No percurso da realização dos experimentos de desempenho foi observada a perda de sinal entre os nós sensores logo após de ter sido feito a distribuição dos mesmos ao nível do solo (Figura 4.12).

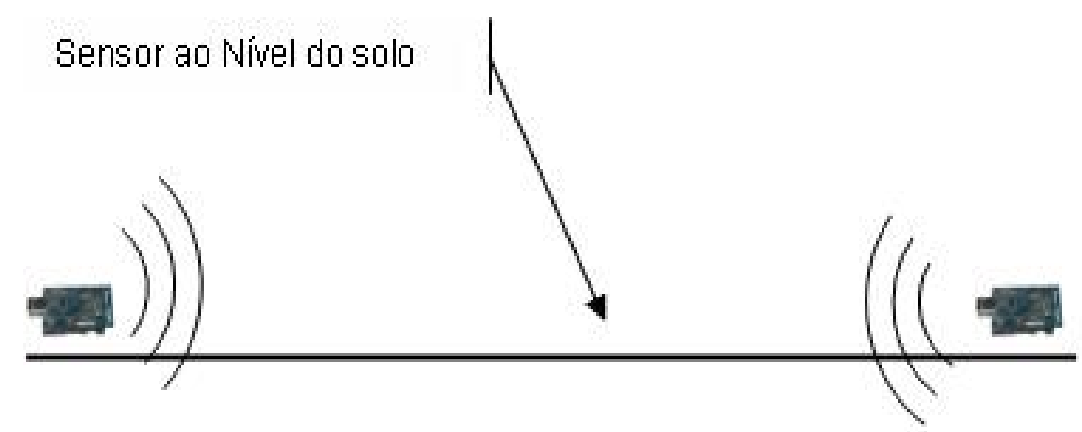

Figura 4.12: Disposição inicial dos nós

As possíveis justificativas respondem a possíveis fenômenos de reflexão e absorção ${ }^{3}$. Por exemplo, no processo de transmissão de um sensor a onda reflete com o solo (isso é devido ao comprimento da onda e à proximidade com o solo) eliminando de forma total a fase da onda ${ }^{4}$ transmitida. Quando o pico de uma onda coincide com outro pico temos um resultado máximo $(1+1=2$ ) (Figura 4.13(a)). Isto é denominado Interferência Construtiva. Quando um pico coincide com um vale (Figura 4.13(b)) temos uma completa anulação da onda $(1+(-) 1=0)$, isto é chamado de Interferência Destrutiva.

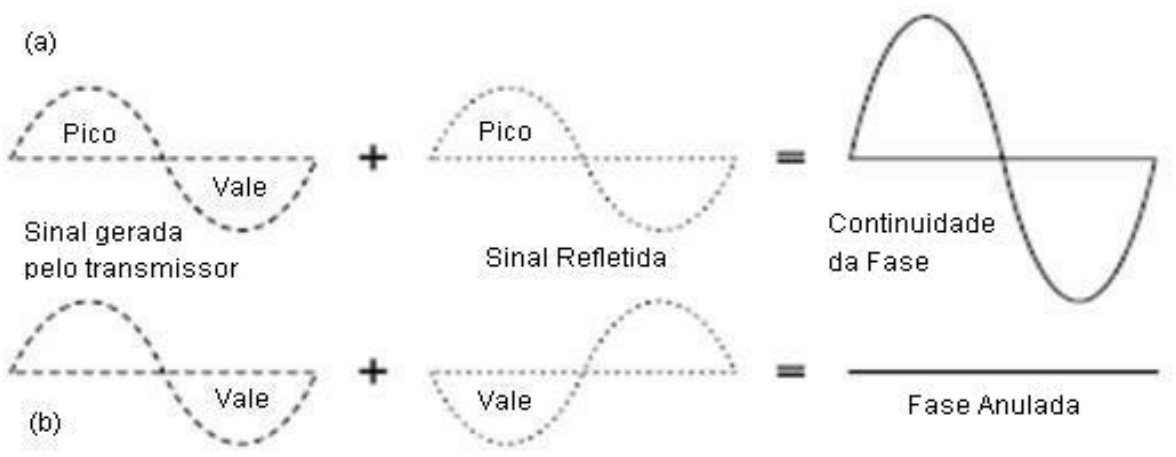

Figura 4.13: Onda Construtiva e Onda Destrutiva

\footnotetext{
${ }^{3}$ Quando as ondas eletromagnéticas atravessam algum material geralmente se debilitam ou atenuam. A quantidade de potência perdida vai depender de sua freqüência e das características do material.

${ }^{4}$ Para que o conjunto de ondas seja somado ou cancelado precisariam ter exatamente a mesma longitude de onda e uma relação de fase fixa.
} 
Finalmente, com o objetivo de eliminar a possibilidade de algum dos fenômenos antes mencionados, possíveis anulações de fases da onda pela proximidade dos nós transmissores com o solo, a distribuição dos nós foi feita sobre bases de madeira de $50 \mathrm{~cm}$ de altura.(Figura 4.14)

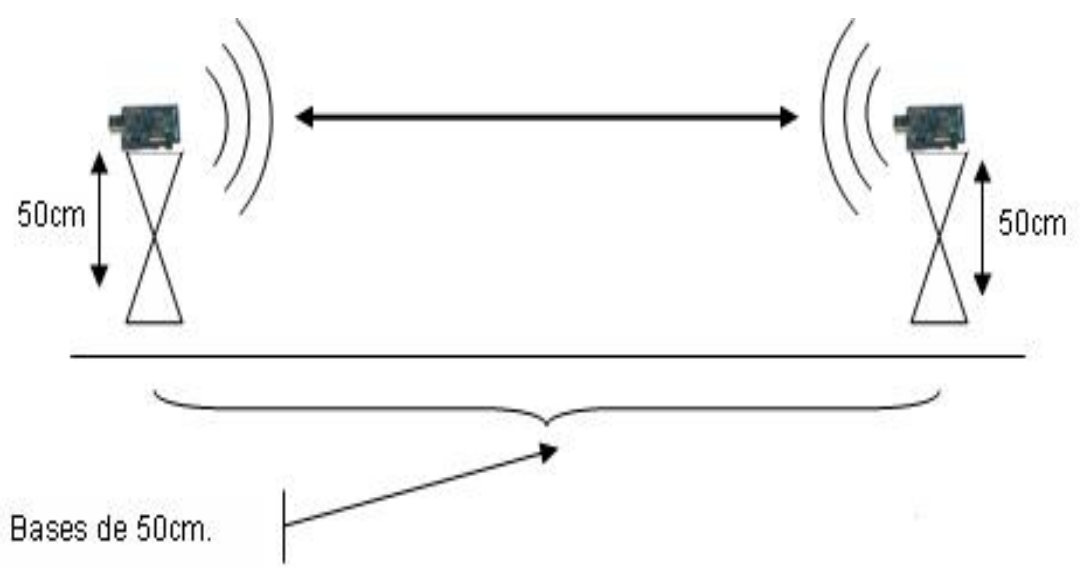

Figura 4.14: Disposição dos nós nas bases

Como resultado obteve-se uma boa comunicação entre os nós da rede para a realização dos experimentos de desempenho.

\subsubsection{Configuração do Hardware para a Análise do RSSI}

Os procedimentos empregados para a realização de medições de propagação de sinais eletromagnéticas não são triviais. Para a utilização prática dos resultados obtidos de uma medição interessam as atenuações rápidas e em conseqüência procura-se saber o nível destas atenuações em função dos ambientes de propagação, considerando basicamente a estrutura física do mesmo. Para eliminar os efeitos de atenuação rápida, o procedimento padrão usado pelos investigadores tem sido determinar o nível de RSSI através do calculo médio de múltiplas medições sobre um determinado setor. O tamanho do setor considerado para os experimentos pelos distintos pesquisadores pode ser variável, Rappaport and McGillem (1989), mantêm o transmissor em um ponto fixo e traslada o receptor sobre uma distância de $6 \lambda$ para realizar 128 medições, que logo são representadas como valor médio. Estas medidas são logo confirmadas utilizando técnicas de banda larga. Seidel and Rappaport (1992), mantêm um transmissor em um ponto fixo e trasladam o receptor sobre uma distância de $20 \lambda$ em forma longitudinal, para obter um número 
significativo de medições que são apresentadas como o valor médio para configurar um ponto de medição.

Para a correta planificação de qualquer uma destas técnicas ou sistemas de medição resulta essencial conhecer os fatores que possam alterar a propagação eletromagnética, sua magnitude e sua influência nas distintas bandas de freqüência.

Em condições de propagação no espaço livre a relação entre a potência de sinal recebida e transmitida (perda de transmissão) por duas antenas separadas numa distância $r$ é (eq. 4.1):

$$
P_{r}(d)=P_{t}\left(\frac{\lambda}{4 \pi d}\right)^{2} \frac{G_{t} G_{r}}{L}
$$

Onde $P_{r}(\mathrm{~d})$ é a potência recebida em função da distância, $P_{t}$ é a potência transmitida, $\lambda$ é o comprimento de onda do sinal, $d$ é a distância T-R (Transmissor-Receptor), $G_{t}$ é o ganho do transmissor, $G_{r}$ é o ganho do receptor, $L$ representa as perdas.

Para a realização dos experimentos no ambiente de propagação interno foram utilizadas três equipamentos de testes o primeiro deles é um Gerador de Ondas HP8350B (Sweep Oscilator HP5350B), o qual gera ondas RF, sendo para nosso caso em uma freqüência de $2.45 \mathrm{GHz}$ com uma potência de saída de $10 \mathrm{dBm}$ e máxima de até $17 \mathrm{dBm}$, devidamente verificada por um medidor de potência HP436A (Power Meter HP436A) o qual verifica a saída da potência através de uma ponta detector de potência (sensor), o procedimento em menção é chamado de Calibração da Potência de Saída do Gerador. Finalmente, no extremo do receptor se utilizou um Analisador de Espectro HP8565A (Espetrum Analyzer HP8565A). O esquema de conexão pode ser observado na figura 4.15 . 

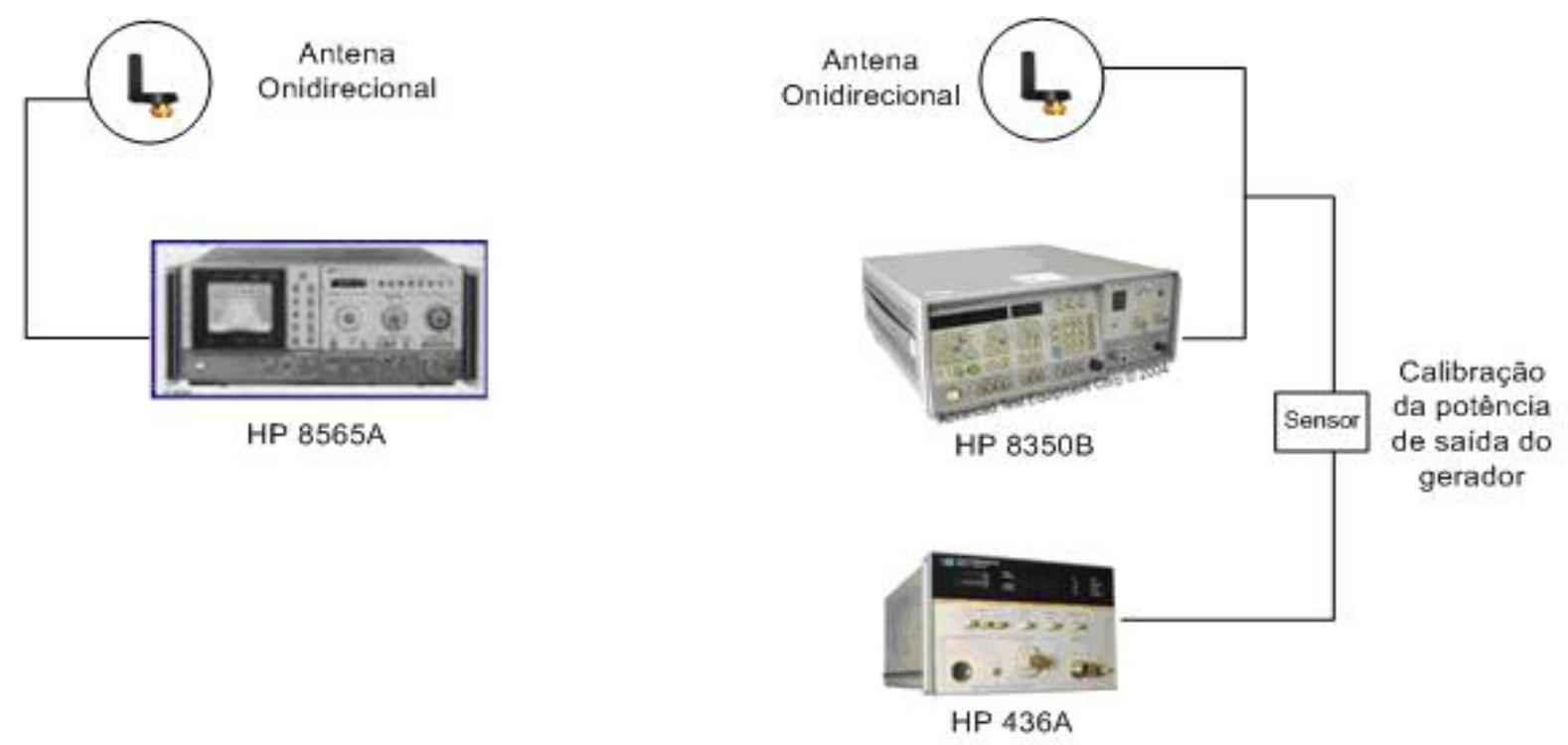

Figura 4.15: Montagem dos Equipamentos de testes para a análise do RSSI

Na realização dos experimentos o número total de medições realizadas foi na ordem de 500 em um ambiente interno.

\subsubsection{Montagem da Placa de Sensores (Sensorboard) do Mica2 para o TmoteSky}

Na realização dos experimentos de consumo de energia do nó se inclui a realização de medidas de consumo de energia do nó plataforma e o nó plataforma com a placa de sensores incorporada. Para o caso do TmoteSky, plataforma de hardware sobre a qual são realizados os experimentos de desempenho, não possui nenhum tipo de sensor incorporada na base da mesma (Ver Figura 4.4), pelo qual se fez necessário a montagem de alguns sensores com o objetivo de obter um valor real de consumo de energia de uma verdadeira plataforma de sensoriamento (nó sensor). 

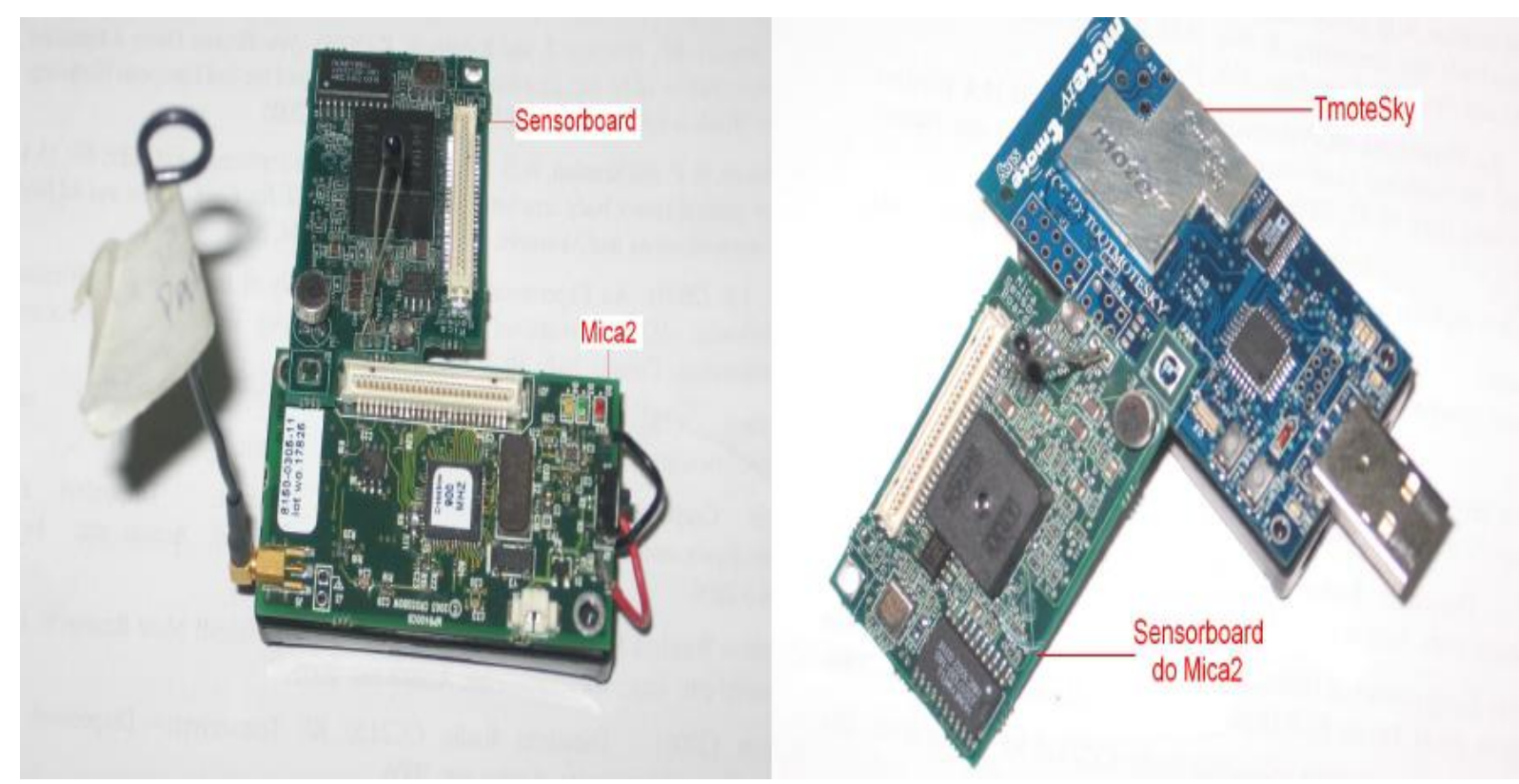

Figura 4.16: Mica2 e SensorBoard - TmoteSky

Baseados em um experimento realizado por Polastre (2004), quem incorporou a placa de sensoriamento do Mica2 (Figura 4.16 ) sobre a Plataforma do Telos, foram realizados as modificações para repetir a mesma experiência sobre a plataforma do TmoteSky (ver Figura 4.18).

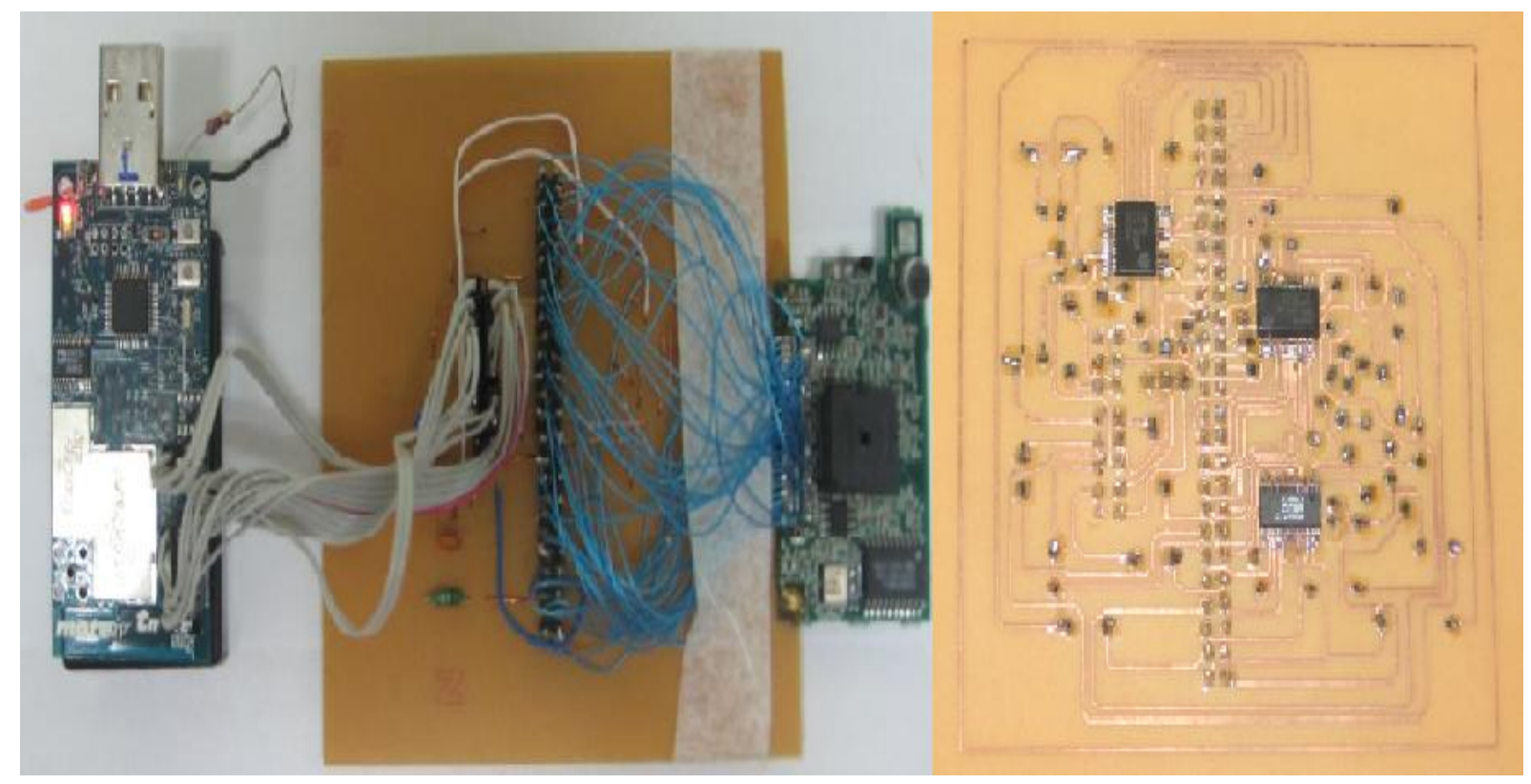

Figura 4.17: TmoteSky com o Sensorboard do Mica2 

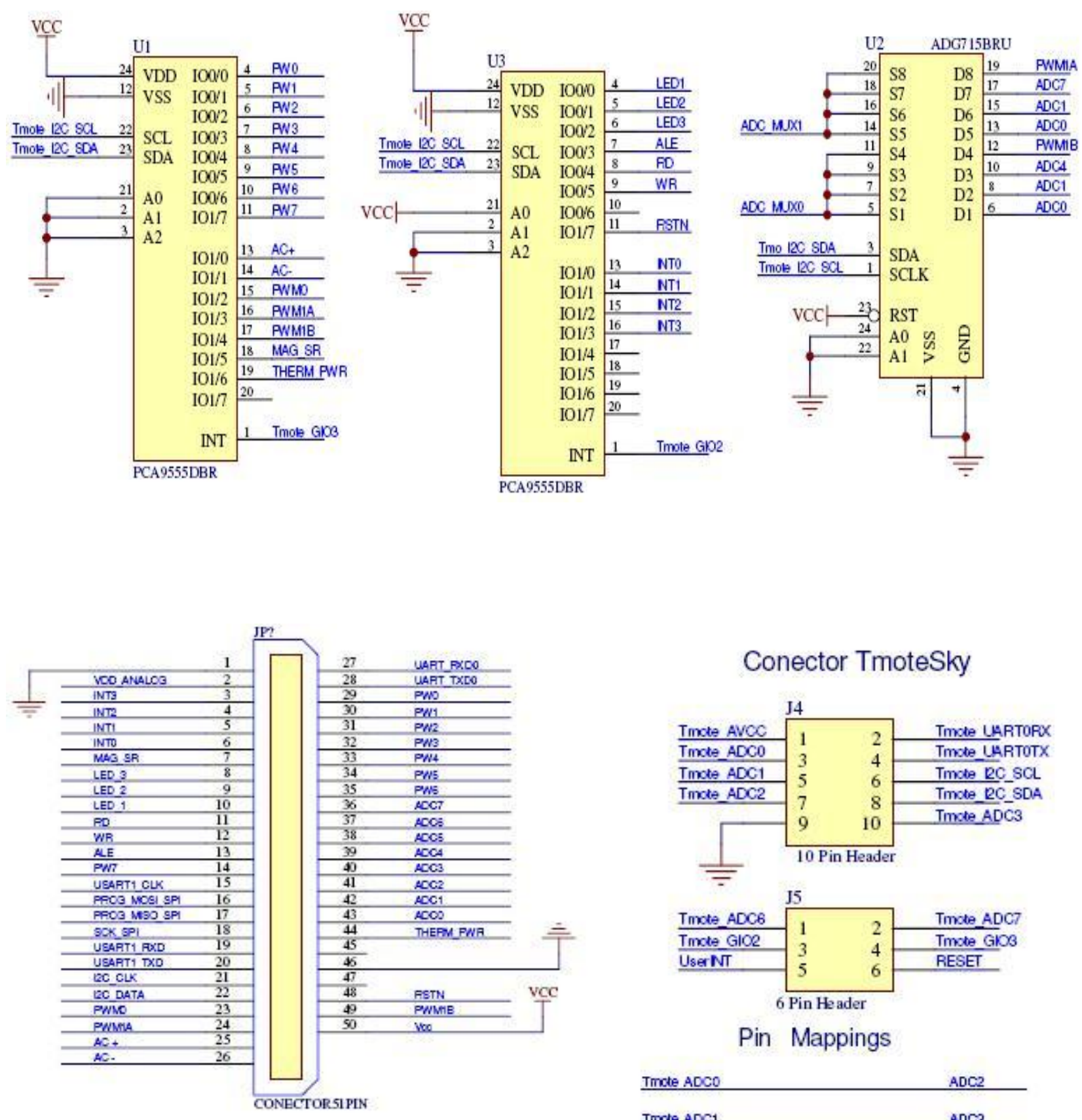

\section{Conector TmoteSky}
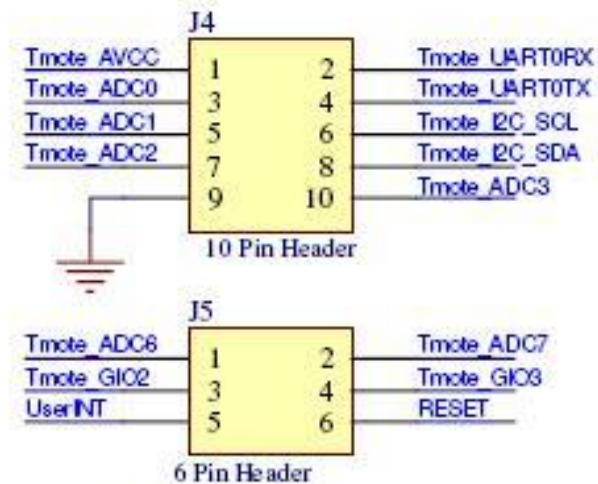

Pin Mappings

\begin{tabular}{|c|c|c|}
\hline Imote ADCO & & $\mathrm{ADC2}$ \\
\hline Timole ADC1 & & $\mathrm{ADC3}$ \\
\hline Tmole ADC2 & & $A D C 5$ \\
\hline Imole ADCB & & $A D O 5$ \\
\hline Thate ADCE & & $A D C M U D O D$ \\
\hline Tmole ADC7 & & ADC MUXX \\
\hline Imcle UARTOTX & & USAPT1 RXD \\
\hline Imcle UARTOPX & & USAPT1 TXD \\
\hline Imole $12 C, S C L$ & LC_CLK & USAPTI_CLK \\
\hline
\end{tabular}

Figura 4.18: Esquematico 


\section{Capítulo 5}

\section{RESULTADOS DOS}

EXPERIMENTOS

Neste capítulo apresentam-se os resultados dos experimentos realizados na camada física, camada de enlace e na camada de rede. Foram consideradas e observadas as métricas de:

- Vazão de Dados: É o número de bits por segundo que chegam ao coordenador;

- Perda de Pacotes: É o número de pacotes perdidos durante a transmissão dos nós da RSSF até o nó coordenador;

- Consumo de Energia: É o consumo de energia pelos nós da RSSF, segundo o tipo de comunicação empregada. 


\subsection{Camada de Rede}

As análises realizadas nesta camada baseiam-se no estudo das topologias existentes no padrão Zigbee. Seu comportamento segundo as áreas de cobertura considerando algumas variáveis de desempenho, tais como: a vazão de dados, densidade da rede, tempos de sincronização do nó na rede e, finalmente, para uma referência da qualidade do enlace entre os nós segundo a variação de distâncias e a topologia empregada é realizada uma análise da taxa de perda de pacotes.

\subsubsection{Análise em Ambiente Interno (Alcance Do Sinal)}

Com o objetivo de conhecer o alcance do sinal do nó comum (transmissor) na rede até o nó coordenador (receptor) é montada uma bancada composta por dois nós sensores (um transmissor e um receptor). A separação (distância) entre eles é feita de forma progressiva até atingir a distância máxima de alcance de sinal do nó sensor.

A análise realizada foi em função da variação das distâncias e sua relação com a vazão de dados expressada em bits por segundo (bps)

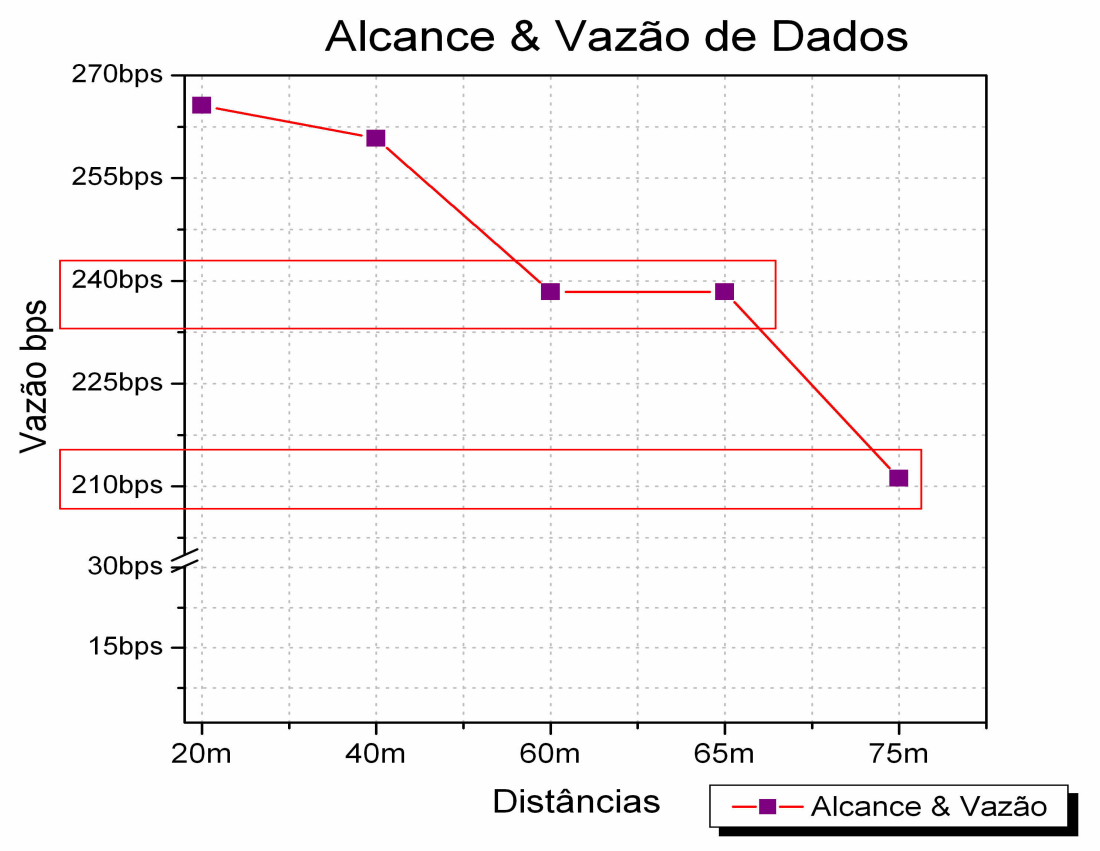

Figura 5.1: Alcance \& Vazão de Dados Ambiente Interno

Os valores na Figura 5.1 mostram que em distâncias até os $65 \mathrm{~m}$ a queda da vazão de 
dados está em 5 bps dos $20 \mathrm{~m}$ até os $40 \mathrm{~m}$ e de $12 \mathrm{bps}$ dos $40 \mathrm{~m}$ até os $65 \mathrm{~m}$, para o caso dos $75 \mathrm{~m}$ a diminuição de dados se faz muito mais significativa sendo de 54.4 bps em relação à vazão inicial para os 20m. Conforme os valores são apresentados na tabela 5.1.

Tabela 5.1: Alcance \& Vazão de Dados.

\begin{tabular}{|c|cc|}
\hline Distância $(\mathrm{m})$ & Vazão TmoteSky (bps) & Vazão Mica2dot (bps) \\
\hline 20 & 265,6 & 148.9 \\
40 & 260,8 & 143.6 \\
60 & 238,4 & 137 \\
65 & 238,4 & 137 \\
75 & 211,2 & 134.1 \\
\hline
\end{tabular}

Os valores apresentados na tabela 5.1 indicam uma vazão de dados que muda significativamente em função das distâncias, especificamente em distâncias que superam os 40m. Porém, foi necessário realizar uma análise de RSSI com o objetivo de avaliar a sensibilidade do receptor e criar uma relação com a vazão de dados em distâncias a partir dos $60 \mathrm{~m}$ até os $75 \mathrm{~m}$. Observa-se também a vazão de dados para os Mica2dot nas mesmas distâncias, apresentando uma vazão menor, porém, mais estavél.

O primeiro resultado aos 60m indica um nível de RSSI de -65.17 dBm (ver Figura 5.2) e uma vazão de dados de 238.4bps (Tabela 5.1)

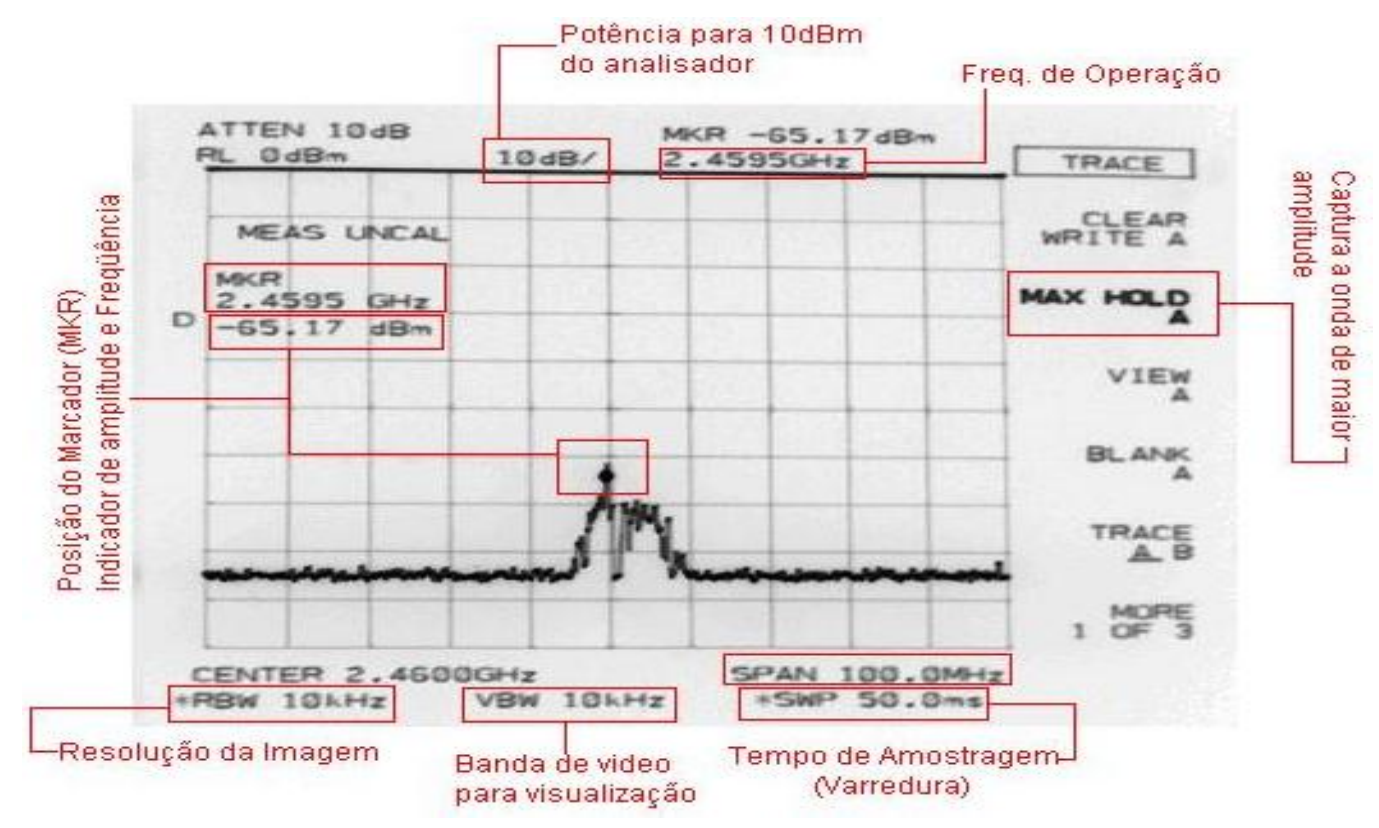

Figura 5.2: Intensidade do Sinal Recebido RSSI aos 60m. (imagem extraída do analisador de espectro) 
O segundo teste foi realizado aos $75 \mathrm{~m}$ de distância entre o transmissor e o receptor, o resultado obtido foi um nível de RSSI de $-72.83 \mathrm{dBm}$ (Figura 5.3) e uma vazão de dados a essa mesma distância de 211.2bps (Tabela 5.1).

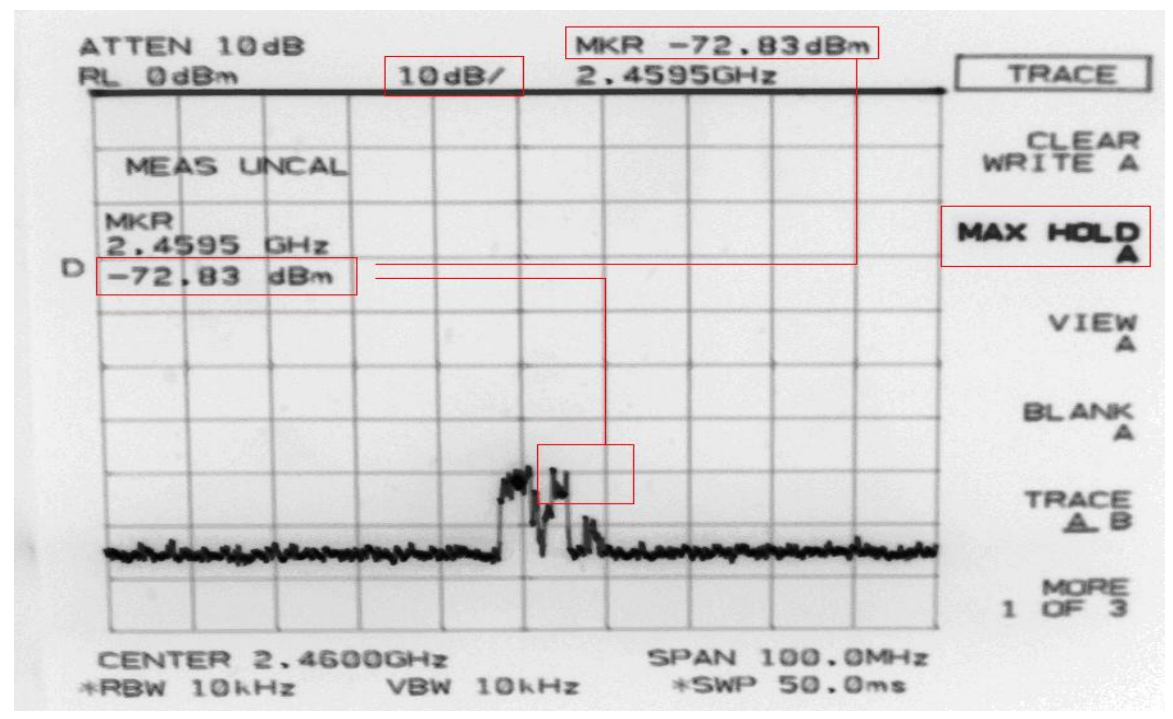

Figura 5.3: Intensidade do Sinal Recebido RSSI aos 75m (imagem extraída do analisador de espectro)

A sensibilidade do receptor empregado no TmoteSky é de -92 dBm, no entanto, não é recomendável atingir esse valor, pois mesmo que exista maior eficiência na recepção quanto maior seja a sensibilidade do receptor deverá ser sempre considerada a integridade dos dados para determinar se o processo de transmissão se deu de forma eficiente.

Os resultados mostram que a variação RSSI é significativa de acordo com o incremento da distância entre os nós sensores e o nó receptor (Tabela 5.2).

Tabela 5.2: Alcance \& Vazão de Dados e RSSI.

\begin{tabular}{|ccc|}
\hline Distância(m) & Vazão bps Tx & RSSI \\
\hline 20 & 265,6 & \\
40 & 260,8 & \\
60 & 238,4 & -65.17 \\
65 & 238,4 & \\
75 & 211,2 & -72.83 \\
\hline
\end{tabular}

No entanto, de forma inicial e como resultado dos experimentos de alcance do sinal realizados podemos dizer que, as redes de sensores que empregam o padrão Zigbee são bastante confiáveis para sua aplicação em ambientes internos $(60 \mathrm{~m})$, pois a taxa de 
transferência de pacotes em relação ao nível de RSSI indicam uma transmissão eficiênte considerando a integridade dos pacotes transmitidos e recebidos segundo a variação das distâncias, apresentados na tabela 5.2.

\subsubsection{Análise em Ambiente Externo (Alcance Do Sinal)}

A análise de alcance do sinal realizado em um ambiente externo segue os mesmos procedimentos e métricas dos testes realizados no ambiente interno considerando de igual forma a variação das distâncias e sua relação com a vazão de dados expressada em bits por segundo (bps).

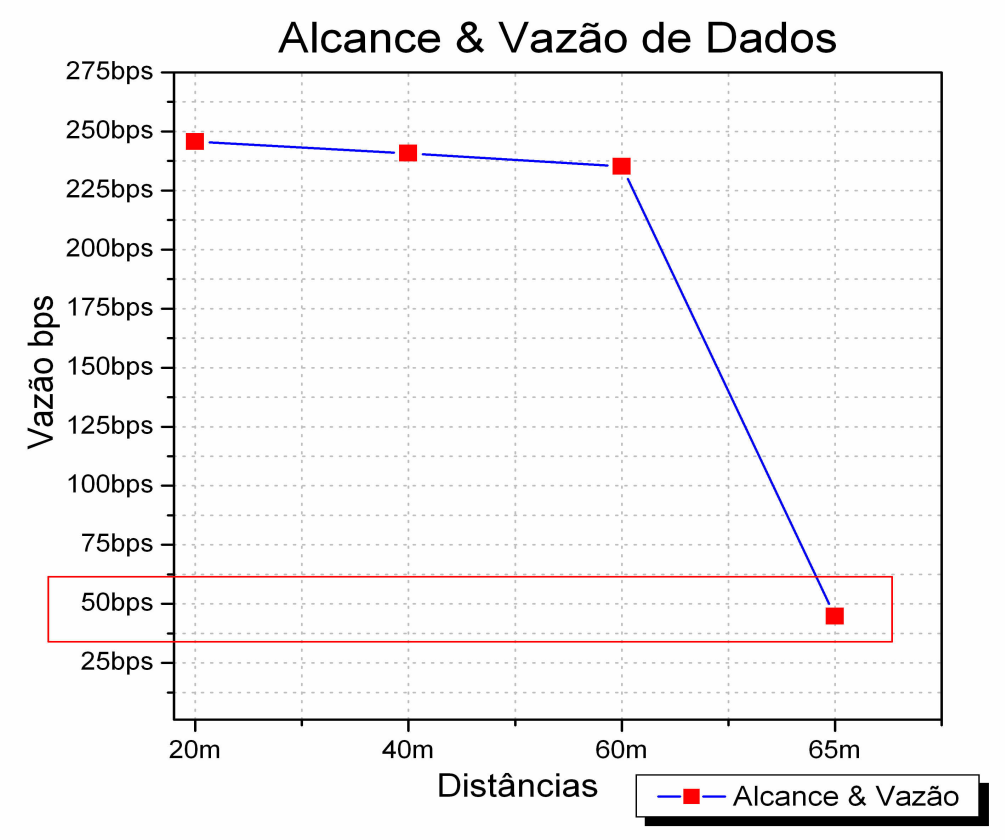

Figura 5.4: Alcance \& Vazão de Dados - Ambiente Externo

Observa-se na figura 5.4 que os valores de vazão de dados são quase lineares até os $60 \mathrm{~m}$, no entanto, apresenta uma queda significativa em distâncias superiores à mesma. Inicialmente a separação entre os nós foi de 10m, mas os resultados apresentados não foram significativos pelo qual a distância de separação entre os nós foi determinada em $20 \mathrm{~m}$.

Os testes de alcance realizados foram repetidos cinco vezes em média segundo a variação das distâncias com o objetivo de eliminar possíveis erros durante a transmissão. Os valores gráficados na figura 5.4 são apresentados na tabela 5.3. 
Tabela 5.3: Alcance \& Vazão de Dados (valores médios)

\begin{tabular}{|c|cc|}
\hline Distância(m) & Vazão TmoteSky (bps) & Vazão Mica2dot (bps) \\
\hline & & \\
20 & 245,6 & 153.17 \\
25 & - & 104.53 \\
40 & 240,8 & - \\
60 & 235,2 & - \\
65 & 44,8 & - \\
\hline
\end{tabular}

Observa-se (Tabela 5.3) uma vazão pouco variável até os $60 \mathrm{~m}$. No entanto, aos $65 \mathrm{~m}$ a queda da vazão como conseqüência da perda de pacotes é significativa. Já os valores apresentados pelos mica2dot determinam um alcance máximo de $25 \mathrm{~m}$ e com uma perda que começa a ser significativa nesta mesma distância. Acredita-se que uma rede com uma densidade maior poderia resolver os problemas de alcance nas redes sobre este tipo de arquiteturas como é o caso do mica2dot (900Mhz).

\subsubsection{Análise das Topologias e Densidade da Rede}

O padrão especifica o uso de três topologias de rede, as quais são: Estrela (Star), Malha (Mesh) e Árvore (Cluster Tree), das quais somente as topologias Estrela e Malha fazem parte desta avaliação.

Como foi mencionado na seção anterior existem limitações iniciais no alcance do sinal do nó sensor. Porém, podem ser superadas com o uso ou aplicação da topologia de rede mais adequada para uma determinada aplicação. Sendo possível realizar um conjunto de testes nos quais são consideradas algumas métricas de desempenho, tais como: Vazão de dados, densidade da rede, cobertura da rede segundo a topologia empregada e tempo de sincronização do nó sensor na rede.

1. Vazão de Dados:

Para os testes de vazão de dados é incrementado o número de nós em dez com o objetivo de aumentar a densidade da rede e analisar seu comportamento segundo a variação das distâncias.

A primeira topologia a ser avaliada é a topologia em Estrela. Os experimentos 
sobre o uso e aplicação desta topologia foram realizados em um ambiente interno e externo. A distribuição da rede pode ser observada na figura 5.5:

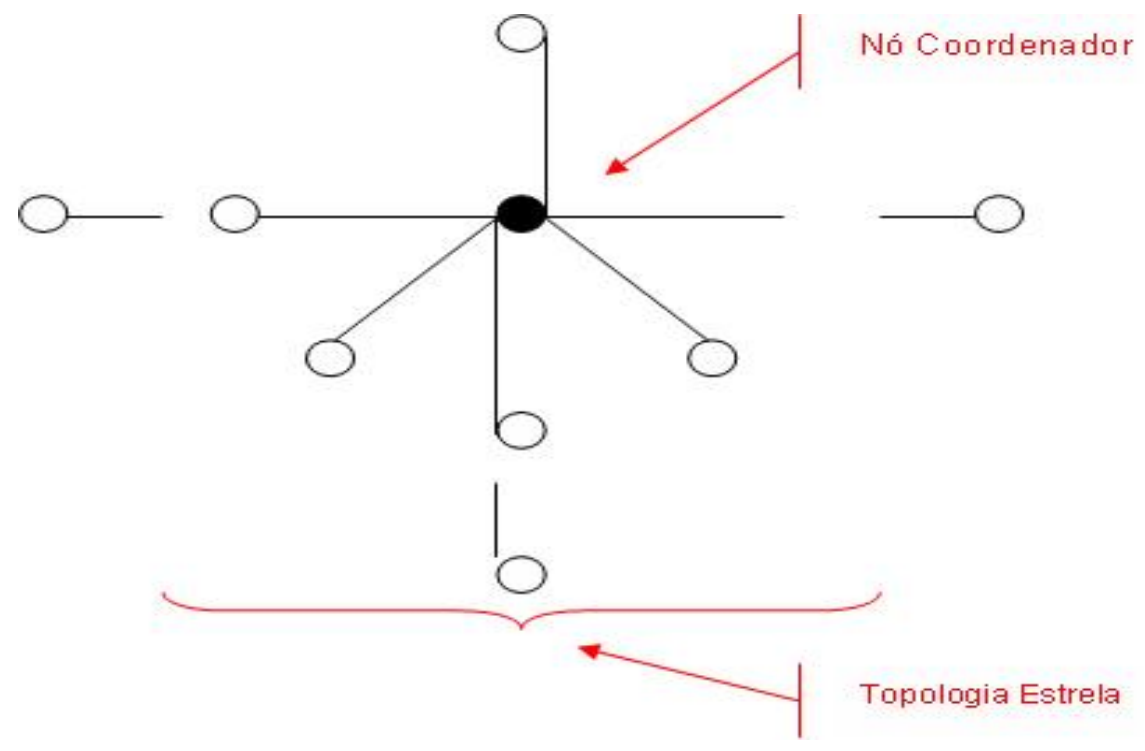

Figura 5.5: Distribuição da Rede - Topologia Estrela

Os resultados obtidos são apresentados na figura 5.6 e 5.7, que evidenciam uma maior eficiência da topologia Estrela em ambientes internos:

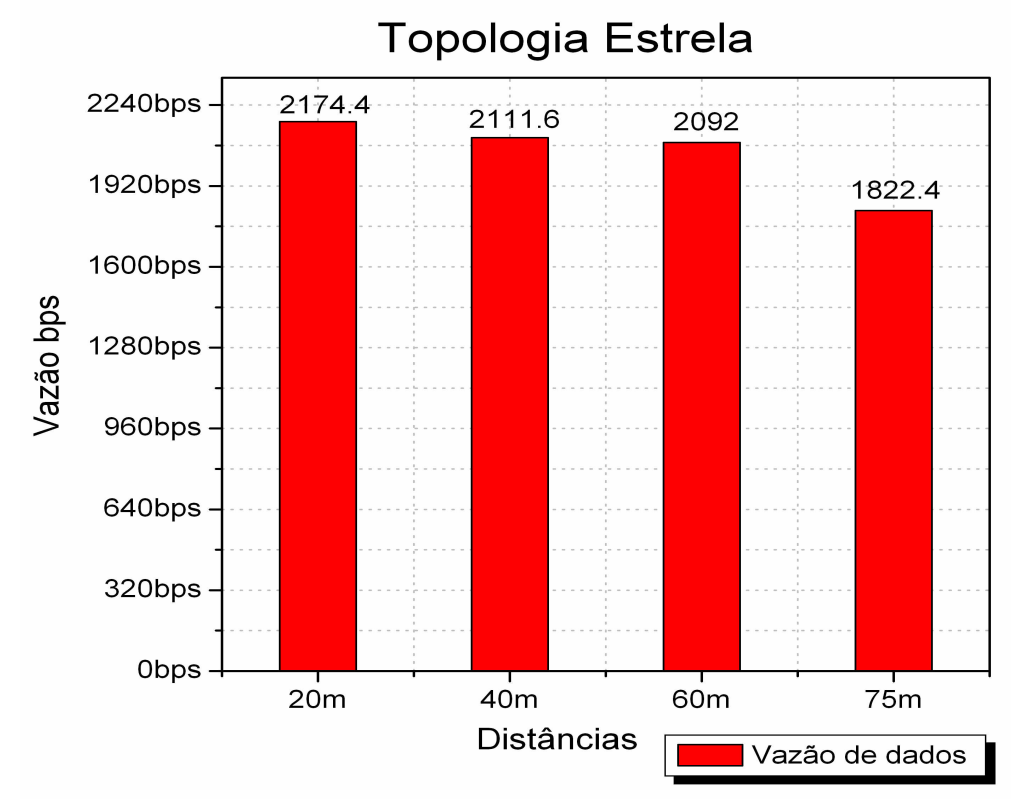

Figura 5.6: Vazão de dados - Topologia Estrela (Ambiente Interno) 


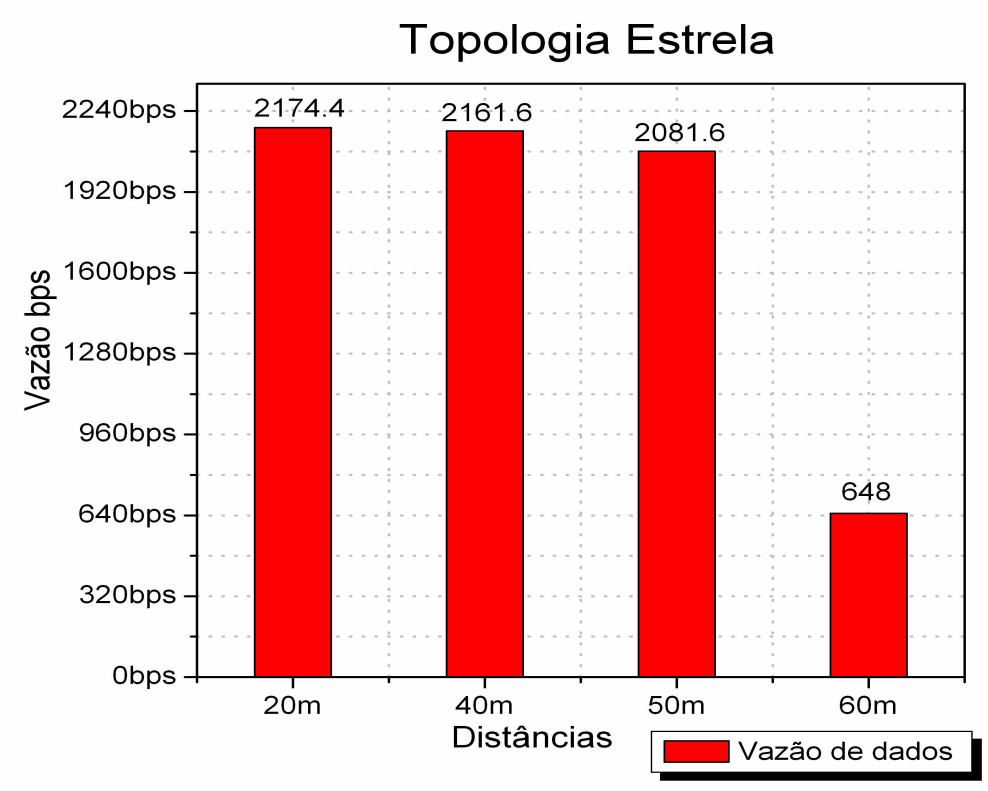

Figura 5.7: Vazão de dados - Topologia Estrela (Ambiente externo)

Pode-se observar nos gráficos das figuras 5.6 e 5.7 que o alcance de uma topologia em estrela está limitado aos $75 \mathrm{~m}$ em ambientes internos e aos $50 \mathrm{~m}$ em ambientes externos. No entanto, possui um tipo de comunicação mais continua, ou seja, apresenta pouco tempo de inatividade dos nós sensores da rede ${ }^{1}$. Os valores de vazão obtidos nos diferentes ambientes de teste (Interno e Externo) apresentam semelhanças significativas nos primeiros 40m. Finalmente, o aumento da densidade da rede permitiu um maior alcance efetivo até os $50 \mathrm{~m}$, com uma taxa de transferência pouco variável.

A segunda topologia a ser avaliada é a tipo Malha (mesh). Para a realização deste experimento os nós sensores são distribuídos de forma aleatória (ver figura 5.8), ou seja, sem nenhum tipo de critério a ser aplicado, apresentando os seguintes resultados (Figura 5.9):

\footnotetext{
${ }^{1}$ Quanto menor é o tempo de inatividade do nó na rede, maior é o consumo de energia e menor o tempo de vida da rede.
} 


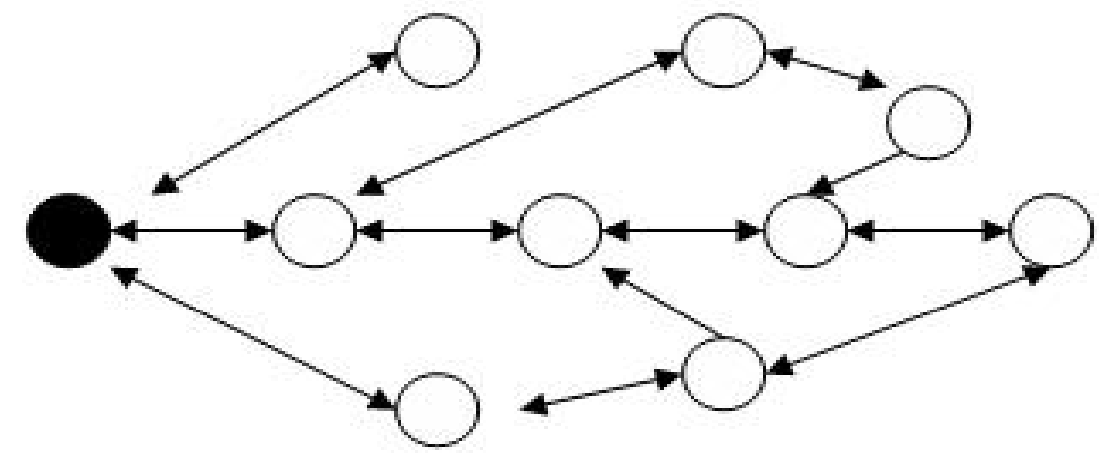

Nó Coordenador
Nó comum na rede

Figura 5.8: Distribuição Aleatória da Rede

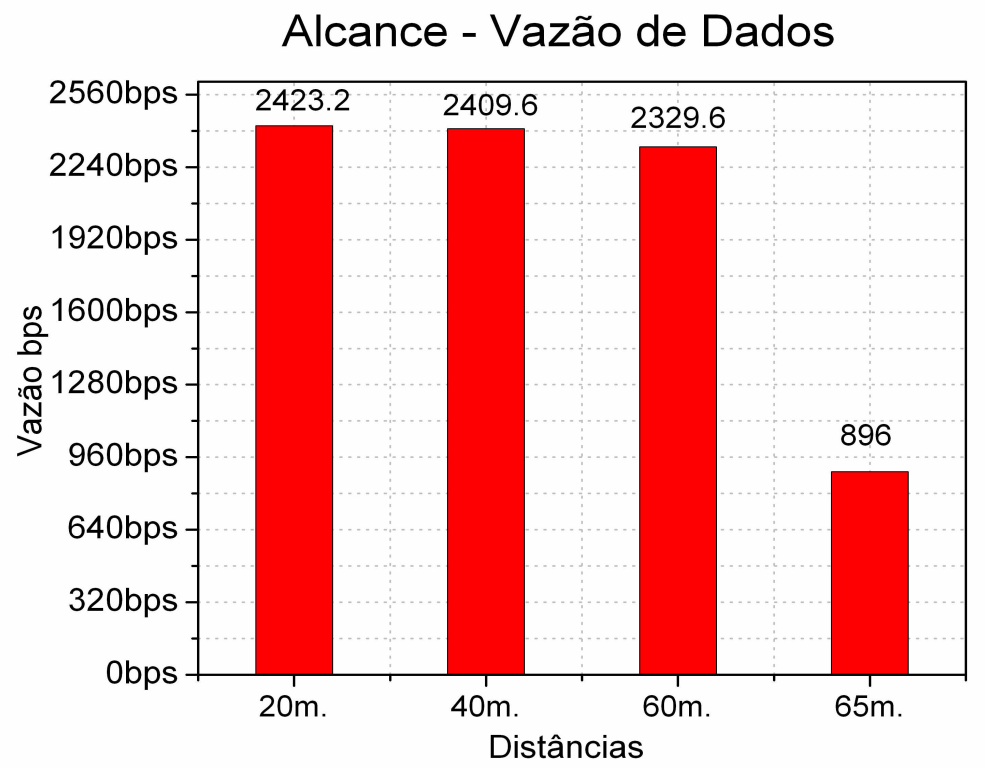

Figura 5.9: Vazão de Dados e Área de Cobertura (Distribuição Aleatória)

Pode-se observar (Figura 5.9) que os resultados obtidos evidenciam o mesmo comportamento com relação às distâncias comparadas com os testes inicias de alcance de sinal apresentados na figura 5.4 (ambientes externos). No entanto, existe um incremento na vazão de dados devido ao aumento da densidade da rede ${ }^{2}$. Ao mesmo tempo, pode-se atribuir um melhor comportamento da rede com relação ao uso do protocolo multihop (Surge-Telos) compilado nos nós sensores. Na segunda distribuição da rede (Figura 5.10) é empregada a topologia tipo malha, os resultados são apresentados na figura 5.11:

\footnotetext{
${ }^{2} \mathrm{O}$ incremento da densidade da rede resulta no aumento no número de vizinhos de um nó, e a criação de múltiplas rotas de comunicação entre eles o qual eleva a conectividade da rede.
} 


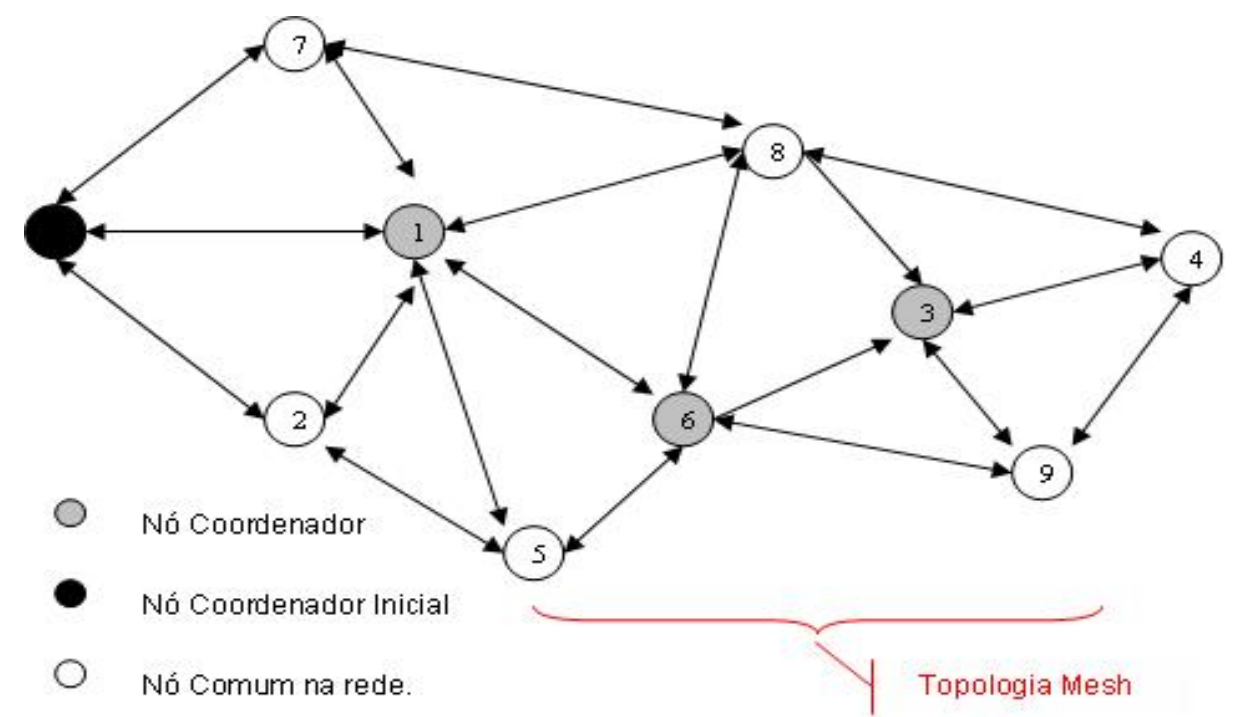

Figura 5.10: Distribuição da Rede - Topologia tipo Malha

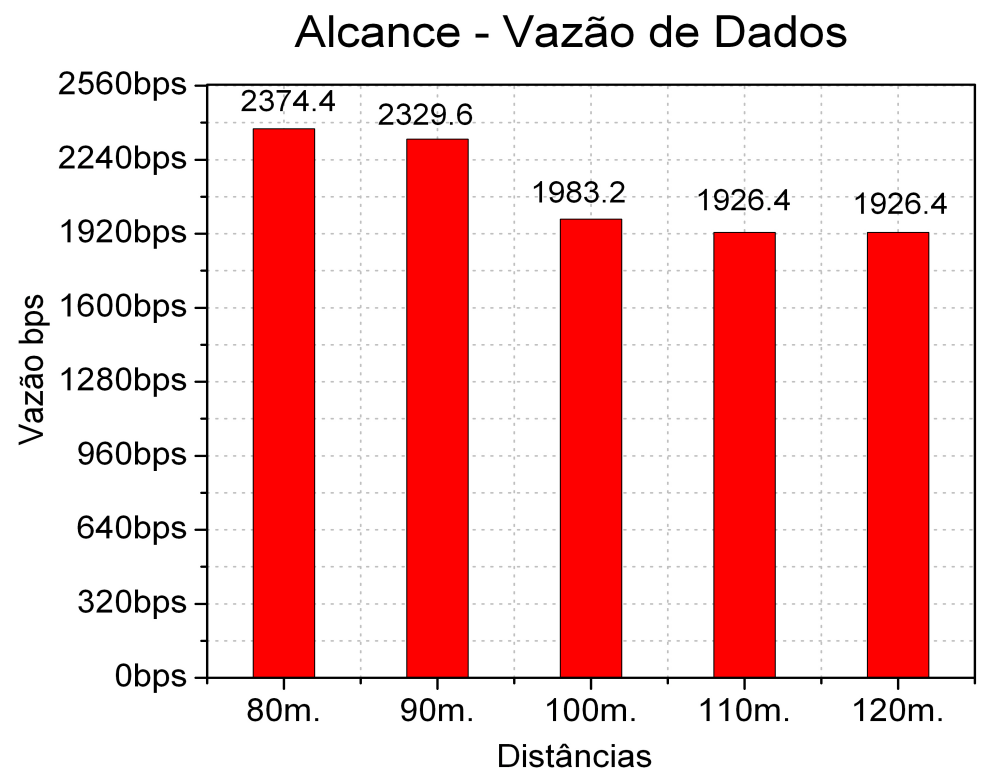

Figura 5.11: Vazão de Dados e Área de Cobertura (Topologia tipo Malha)

Nos experimentos iniciais de alcance do sinal é determinado de acordo com as distâncias de alcance que são de até $75 \mathrm{~m}$ para cenários Internos e de até $50 \mathrm{~m}$ para cenários externos, no entanto, foi confirmado que estas distâncias de cobertura podem ser incrementadas segundo a topologia empregada e a densidade da rede. A queda de vazão aos 100m tem relação direta com o incremento nas distâncias de separação dos nós da rede (sendo inicialmente de 10m e logo apos de 15m) com o objetivo de atingir uma maior área de cobertura (Figura 5.10), sendo assim, existe 
uma vazão quase linear até os $120 \mathrm{~m}$ de alcance da rede o qual indica que o uso da topologia malha e o incremento na densidade da rede permite ou facilita o aumento no alcance do sinal e como conseqüência se tem maiores áreas de cobertura.

Uma das características observadas na organização da rede sobre o uso da topologia malha é que o incremento da densidade da rede cria um maior número de nós vizinhos diversificando o número de rotas de um nó sensor para outro, o qual contribui com o baixo consumo de energia e uma melhor organização da rede (o qual não aconteceu nos experimentos realizados com a topologia em Estrela). Neste processo de organização da rede, os nós obtêm informações de seus vizinhos para organizar a tabela de roteamento (As mensagens de controle de roteamento transportam a informação do nó emissor, como: distância do nó coletor de dados expressada em níveis de RSSI, atributo do nó, se é coordenador ou não comum na rede etc.).

Na construção e organização da rede foram determinados eventos ${ }^{3}$ como:

(a) O primeiro deles corresponde à eleição de coordenadores onde cada nó executa um algoritmo para determinar se será coordenador (eleição, que possivelmente esteja condicionada ao posicionamento do nó na rede);

(b) O segundo de conexão entre dispositivos, que possue diversos estados com o objetivo que gerenciar os recursos de energia da rede;

(c) O terceiro é a criação espontânea de redes, promovidas pelo algoritmo de eleição de coordenadores e os diversos estados de conexão dos dispositivos para gerenciamento de recursos. A criação ou formação de novas redes não é especificamente função do processo de mobilidade da mesma, como é comum nas redes $A d$-Hoc (KWANG et. al, 2006);

(d) O quarto evento chamado de finalização, acontece quando o nó coordenador escolhido determina os nós que formarão parte do núcleo da rede e organizarão o acesso de novos na mesma caso a estrutura da rede ainda não tenha sido alcançada.

\footnotetext{
${ }^{3}$ Cada um destes eventos é próprio do protocolo de roteamento em uso (Surge-Telos proporcionado pelo TinyOs), sendo que suas características são maximizadas através da topologia malha.
} 


\section{Taxa de Perda de Pacotes:}

A realização dos experimentos de Taxa de Perda de Pacotes é feita de forma conjunta e nos mesmos cenários que os experimentos realizados sobre a distância de cobertura das topologias em Estrela e Malha, e considerando também o mesmo número de nós em cada cenário. Os resultados dos experimentos são mostrados nas tabelas 5.4, 5.5 e 5.6:

Tabela 5.4: Taxa de Perda de Pacotes - Topologia Estrela (Ambiente Interno).

\begin{tabular}{|cccccc|}
\hline Distância $(\mathrm{m})$ & Pacotes Tx & Pacotes Rx & $\%$ & Pacotes Perdidos & $\%$ \\
\hline 20 & 2720 & 2718 & 99,93 & 2 & 0,07 \\
40 & 2650 & 2640 & 99,62 & 10 & 0,38 \\
60 & 2650 & 2615 & 98,68 & 35 & 1,32 \\
75 & 2500 & 2278 & 91,12 & 222 & 8,88 \\
\hline
\end{tabular}

Tabela 5.5: Taxa de Perda de Pacotes - Topologia Estrela (Ambiente Externo).

\begin{tabular}{|cccccc|}
\hline Distância $(\mathrm{m})$ & Pacotes Tx & Pacotes Rx & $\%$ & Pacotes Perdidos & $\%$ \\
\hline 20 & 2720 & 2718 & 99,93 & 2 & 0,07 \\
40 & 2720 & 2702 & 99,34 & 18 & 0,66 \\
50 & 2650 & 2602 & 98,19 & 48 & 1,81 \\
60 & 2500 & 810 & 32,4 & 1690 & 67,6 \\
\hline
\end{tabular}

Tabela 5.6: Taxa de Perda de Pacotes - Topologia Malha (Ambiente Externo).

\begin{tabular}{|cccccc|}
\hline Distância $(\mathrm{m})$ & Pacotes Tx & Pacotes Rx & $\%$ & Pacotes Perdidos & $\%$ \\
\hline 20 & 3030 & 3029 & 99,97 & 1 & 0,03 \\
40 & 3030 & 3012 & 99,41 & 18 & 0,59 \\
60 & 2950 & 2912 & 98,71 & 38 & 1,29 \\
80 & 2950 & 2912 & 98,71 & 38 & 1,29 \\
100 & 2500 & 2479 & 96,32 & 21 & 0,84 \\
120 & 2500 & 2408 & 99,0 & 92 & 3,68 \\
\hline
\end{tabular}

Na realização dos experimentos de perda de pacotes observou-se que a seqüência de transmissão do protocolo Surge-Telos é de 256 ciclos. Logo após o término de um ciclo e iniciado o algoritmo para eleição dos nós coordenadores da rede, pelo qual pode continuar com a mesma organização ou iniciar uma nova. O processo é simples de identificar, pois o protocolo determina um número de seqüência para cada pacote 
transmitido o qual é contabilizado para obter a taxa de perda de pacotes no processo de transmissão (ver Figura 5.12 ).

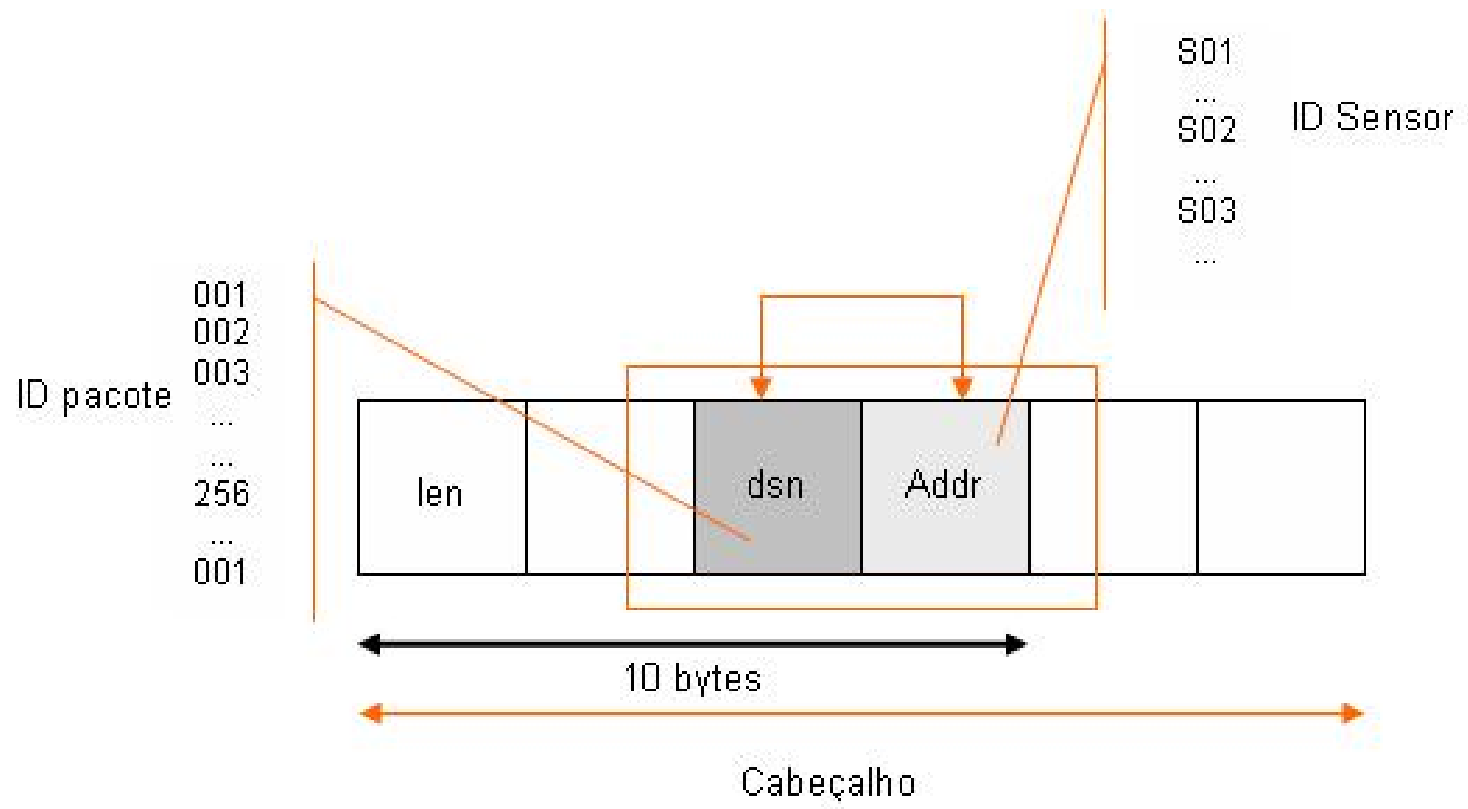

Figura 5.12: ID do Pacote e ID do sensor para o cálculo de Taxa de Perda de Pacotes

O alcance determinado como resultado dos experimentos realizados segundo o cenário de transmissão e a topologia empregada são apresentados na tabela 5.7:

Tabela 5.7: Taxa de Perda de Pacotes - Topologias Estrela e Malha.

\begin{tabular}{|ccccccc|}
\hline Topologia & Cenário & Alcance & $\mathrm{N}^{\mathrm{o}}$ Nós & bps & PLoss & Eficiência \% \\
\hline \multirow{2}{*}{ Estrela } & & & & & & \\
& Interno & 75 & 10 & 1822,4 & 8,88 & 91,12 \\
& Externo & 50 & 10 & 2081,6 & 1,81 & 98,19 \\
Malha & Externo & 120 & 10 & 1926,4 & 3,68 & 96,32 \\
\hline
\end{tabular}

O experimento de desempenho da topologia malha em ambientes internos não é exposto neste trabalho devido a que segundo experimentos inicias as características desta topologia são observadas potencialmente só em ambientes externos ${ }^{4}$.

\section{Sincronização:}

Sincronização é o tempo que leva para um nó sensor se sincronizar na rede seja este nó coordenador ou nó comum na rede. O processo envolve simultaneamente um

\footnotetext{
${ }^{4}$ Resultados Publicados no CiComp 2007 - Mexico
} 
consumo de energia gasto pelo nó até sua sincronização e que finalmente, pode ser considerado com um valor não aproveitado. Os experimentos de sincronização são realizados sobre duas configurações:

- A primeira configuração é realizar o experimento de sincronização sem o uso de antenas externas. Neste processo é avaliado o tempo de sincronização do nó de borda próximo à estação base e o tempo de sincronização de um nó comum na rede (Ver Figura 5.13):

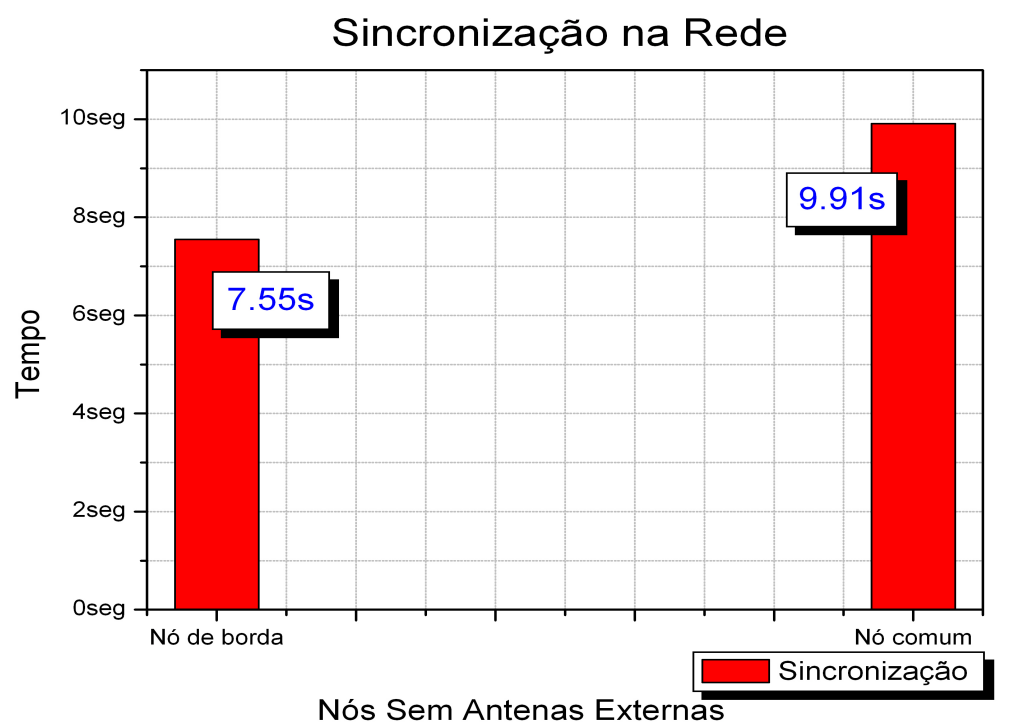

Figura 5.13: Sincronização nó de borda e nó comum na rede - Sem Antenas Externas

O tempo de sincronização é estimado em função do consumo de energia do nó a partir do momento em que for ligado até o envio do primeiro request para seu acesso ao canal de transmissão. No percurso deste processo é iniciado por primeira vez o algoritmo para eleição de coordenadores sendo na maioria dos casos o primeiro nó a se sincronizar na rede.

- A segunda configuração contempla o uso de uma antena externa acoplada na base do nó sensor (Ver Figura 5.14). O processo é válido para o nó de borda e para o nó comum na rede. Os resultados dos experimentos são apresentados na figura 5.15 . 


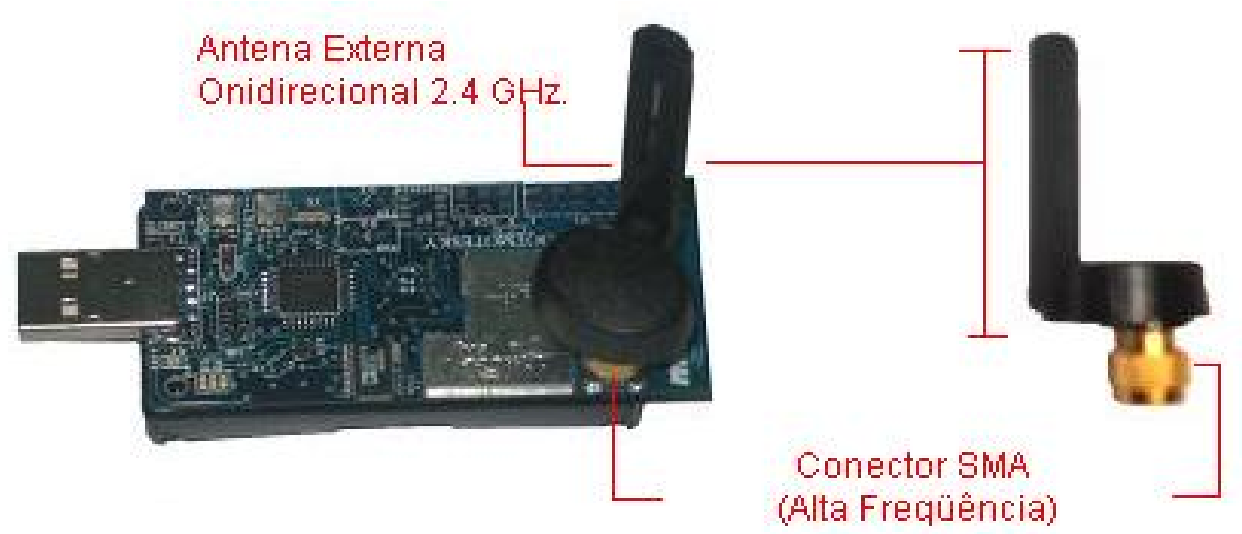

Figura 5.14: Montagem da Antena Externa para o nó sensor

A montagem de uma antena externa é feita em função do cálculo da longitude de onda para uma freqüência de $2.4 \mathrm{GHz}$, a qual é:

$$
\begin{gathered}
\mathrm{f}=2.4 \mathrm{GHz} \\
=2.400 .000 .000 \text { ciclos } / \text { segundo } \\
\text { Longitude de Onda Lambda }(\lambda)=\mathrm{c} / \mathrm{f} \\
=3^{*} 10^{8} / 2.4^{*} 10^{9} \\
=1.25^{*} 10^{-} 1 \mathrm{~m} \\
=12.5 \mathrm{~cm} .
\end{gathered}
$$

A freqüência e a longitude de onda ${ }^{5}$ determinam a maior parte do comportamento de uma onda eletromagnética, desde o tamanho das antenas até os objetos que se encontram no caminho das redes que tentamos colocar em operação. Ao mesmo tempo, são responsáveis das diferenças entre os padrões de comunicação a escolher.

\footnotetext{
${ }^{5}$ Uma onda possui certa velocidade, frequiência e longitude de onda. As quais estão conectadas através de uma simples relação: Velocidade=Freqüência $*$ Longitude de Onda
} 


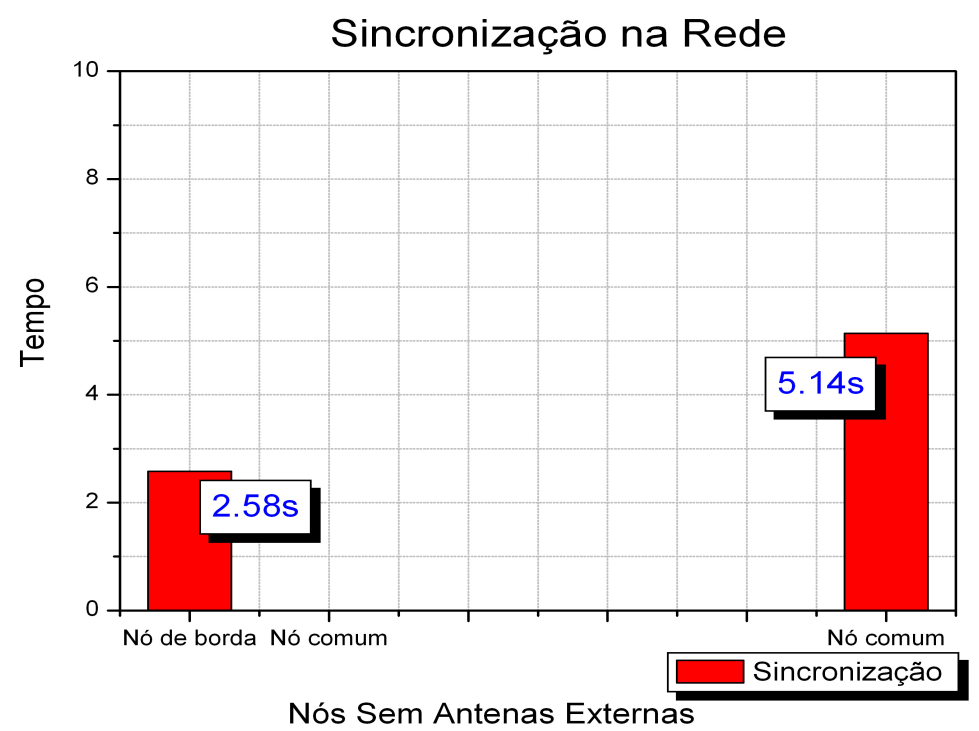

Figura 5.15: Sincronização nó de borda e nó comum na rede - Com Antenas Externas

Observa-se (Figura 5.15) uma clara eficiência na sincronização dos nós com antenas externas. A eficiência está em função do tempo de sincronização e a energia inicial não aproveitada (pode-se dizer da taxa de energia que não é utilizada em benefício de processo de transmissão algum). Quanto menor seja o tempo de sincronização do primeiro nó na rede (na prática nó de borda) menor será o tempo de sincronização dos nós comum na rede e como conseqüência o ciclo de transmissão será iniciado rapidamente e com um consumo menor de energia não aproveitável (Tabela 5.8).

Tabela 5.8: Sincronização e Consumo de Energia

\begin{tabular}{|cccc|}
\hline Configuração & Dispositivo & Tempo & Energia $(\mathrm{m} A)$ \\
\hline \multirow{3}{*}{ Sem Antena } & Nó de Borda & 7.55 & 5.9 \\
& Nó Comum & 9.91 & 5.9 \\
& & & \\
Com Antena & Nó de Borda & 2.58 & 5.15 \\
& Nó Comum & 5.14 & 5.15 \\
\hline
\end{tabular}

O uso de antenas externas diminui o tempo de sincronização dos nós na rede, como conseqüência o consumo de energia não aproveitável é menor. O tempo de inicio do algoritmo para eleição de coordenadores também é menor e a sincronização da rede acontece de uma forma mais eficiente. No entanto, o consumo de energia pode ser maior, mas a implantação destes componentes em sensores para aplicações 
em ambientes externos se faz necessário quando se deseja obter uma melhora na cobertura da área monitorada.

\section{Consumo de Energia da Rede:}

Na realização dos experimentos de consumo de energia do nó sensor é avaliado os diferentes estados na transmissão da rádio do nó, tais como: Modo Recepção $\left(\mathrm{R}_{x}\right)$ e Transmissão $\left(\mathrm{T}_{x}\right)$, modo em espera transmissor (Idle $\mathrm{T}_{x}$ ) e receptor (Idle $\mathrm{R}_{x}$ ). Os resultados dos experimentos são apresentados e comentados a seguir.

Nos experimentos de consumo de energia, observou-se a variação do consumo de corrente $(\mathrm{m} A)$ dos diferentes estados do sistema de comunicação. O primeiro valor corresponde ao consumo de energia do nó em estado de transmissão continua, com um valor inicial de $19.75 \mathrm{~m} A$ e máximo de $20.6 \mathrm{~m} A$ apresentados na figura 5.16 .

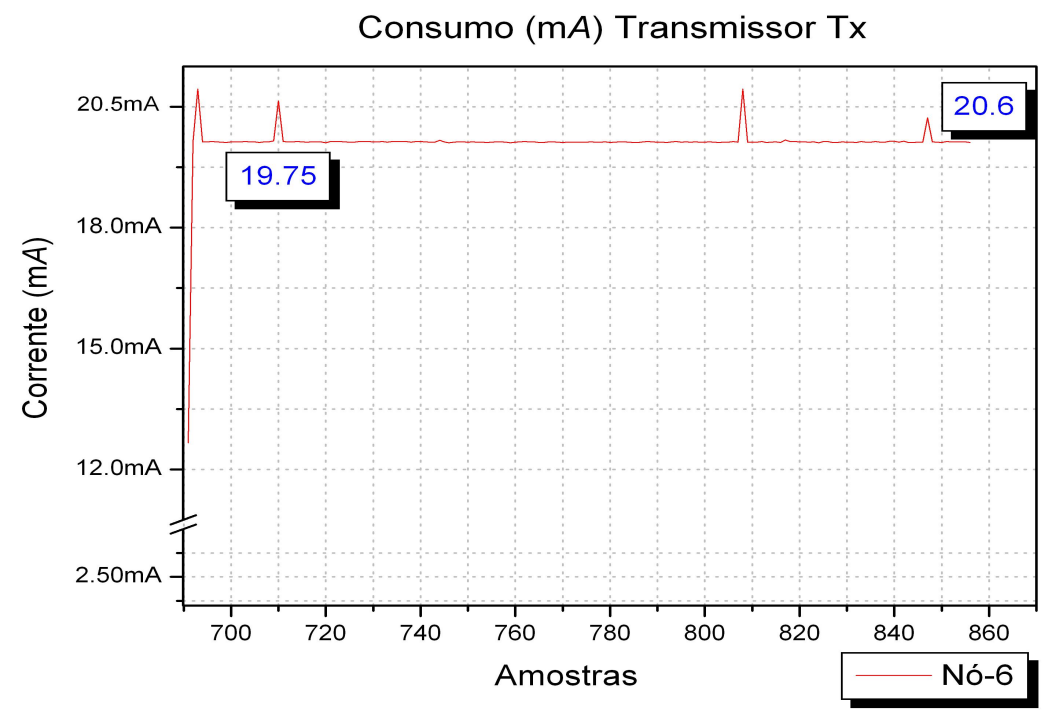

Figura 5.16: Consumo (mA) Transmissor $\mathrm{T}_{x}$ (TmoteSky)

O consumo linear observado na Figura 5.16 corresponde ao estado de sincronismo do sistema de rádio do nó $(19.75 \mathrm{~m} A)$ e os picos observados pertencem a uma transmissão realizada $(20.6 \mathrm{~m} A)$. É necessário comentar que o padrão Zigbee permite a transmissão de grandes seqüências de dados em intervalos curtos de tempo, o qual permite observar um consumo pulsado de energia, pois, o transmissor muda de estado constantemente diminuindo o consumo de energia do nó.

Para a análise de energia do nó em modo recepção considerou-se os mesmos 
procedimentos de valor médio de todas as medições realizadas para este parâmetro, obtendo-se como resultado um consumo mínimo de $17.83 \mathrm{~m} A$ e máximo de $19.92 \mathrm{~m} A$ apresentados na figura 5.17. Observa-se que existem alguns picos como resultados da variação do estado de recepção para a transmissão do nó (A mudança do estado de receptor para transmissor do nó é muitas vezes em razão ao envio do ACK de confirmação do pacote recebido). Este tipo de eventos se faz comum como resultado das medições em um ambiente real.

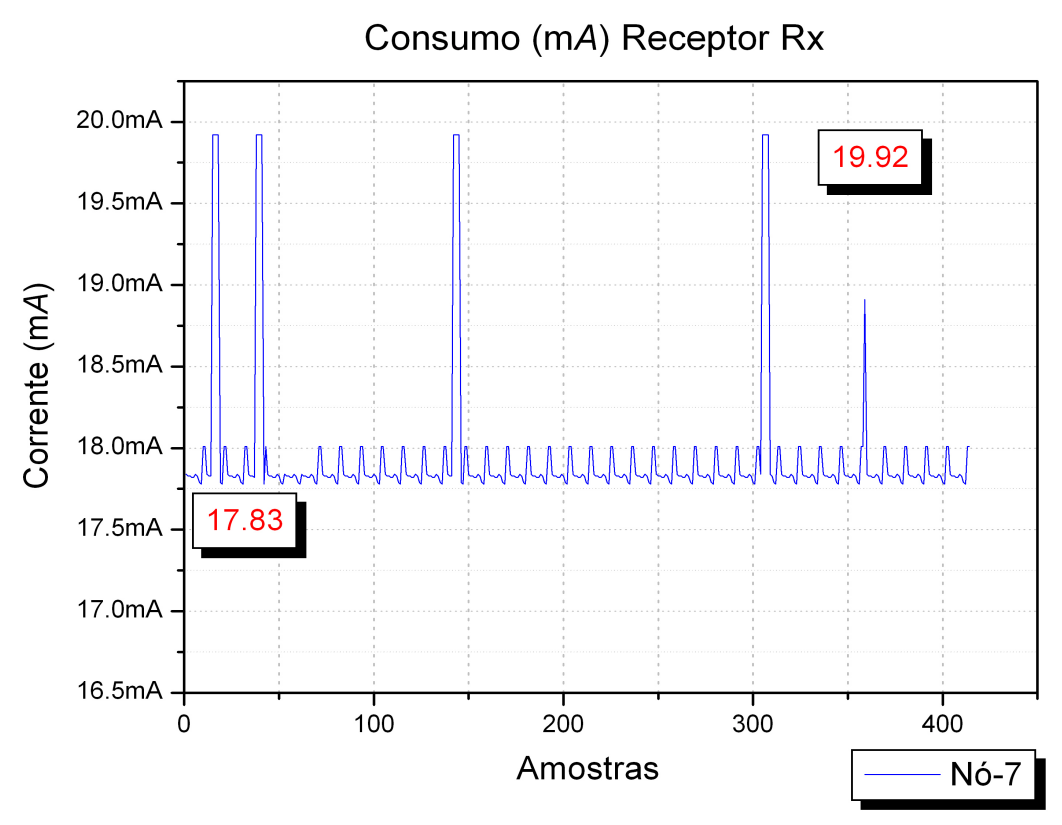

Figura 5.17: Consumo (mA) Receptor $\mathrm{R}_{x}$ (TmoteSky)

No processo de comunicação, o nó muda de transmissor ativo para transmissor em espera Idle $\mathrm{T}_{x}$, estado que pode se ver prolongado segundo as características da rede (densidade, topologia, aplicação de monitoramento etc.), as quais são comuns no padrão ZigBee. Como mencionado nos parágrafos anteriores, devido à transmissão de dados ser realizada de forma rápida e em grandes quantidades de bits, o processo de transmissão em uma aplicação de monitoramento não terá que ser precisamente contínuo. A maior parte da rede estará em modo de espera (Idle) com o sistema de rádio ligado (Idle radio On) (Figura 5.18), com o sistema de rádio desligado (Idle radio Off) ou dormindo Sleep, gerando uma vantagem no consumo de energia e tempo de vida do nó e da rede em seu conjunto (Figura 5.19). 


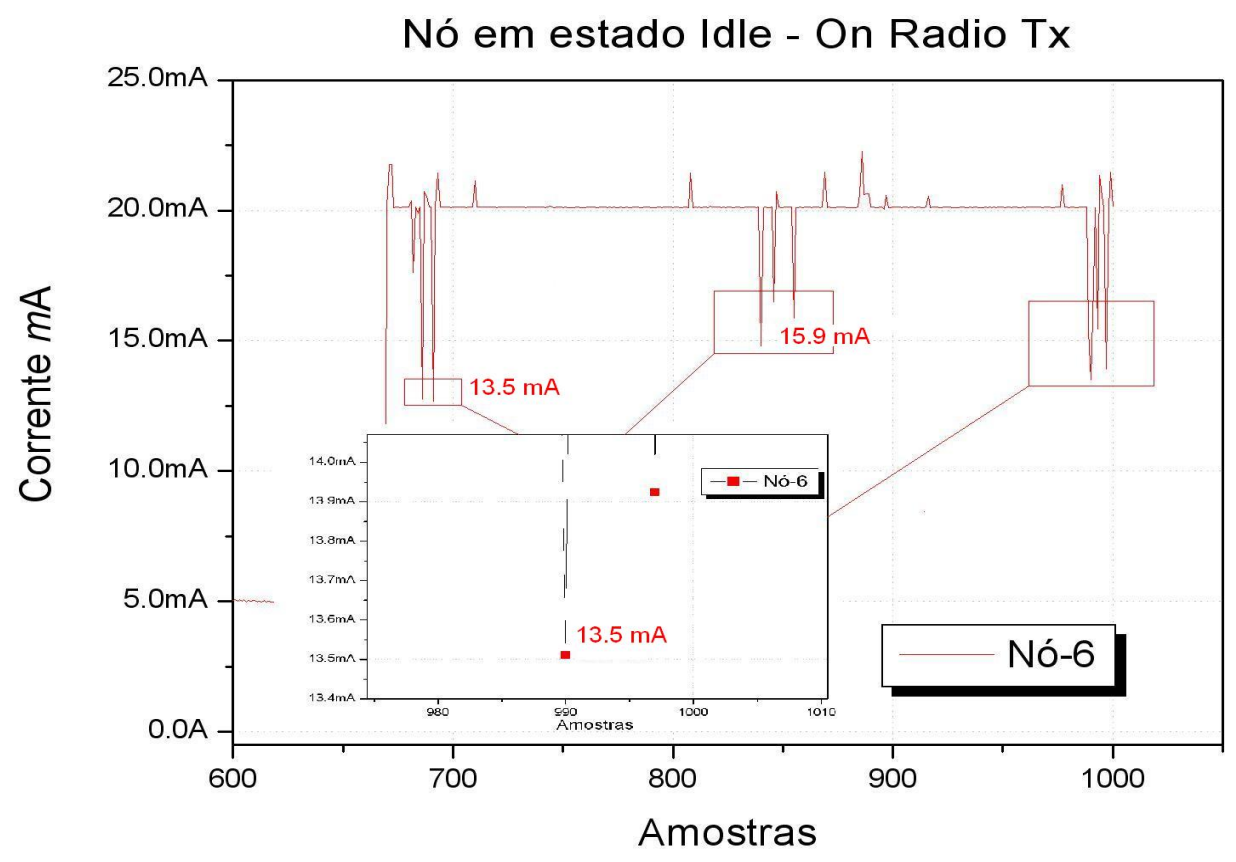

Figura 5.18: Consumo (mA) Nó em estado Idle $\mathrm{T}_{x}$ (TmoteSky)

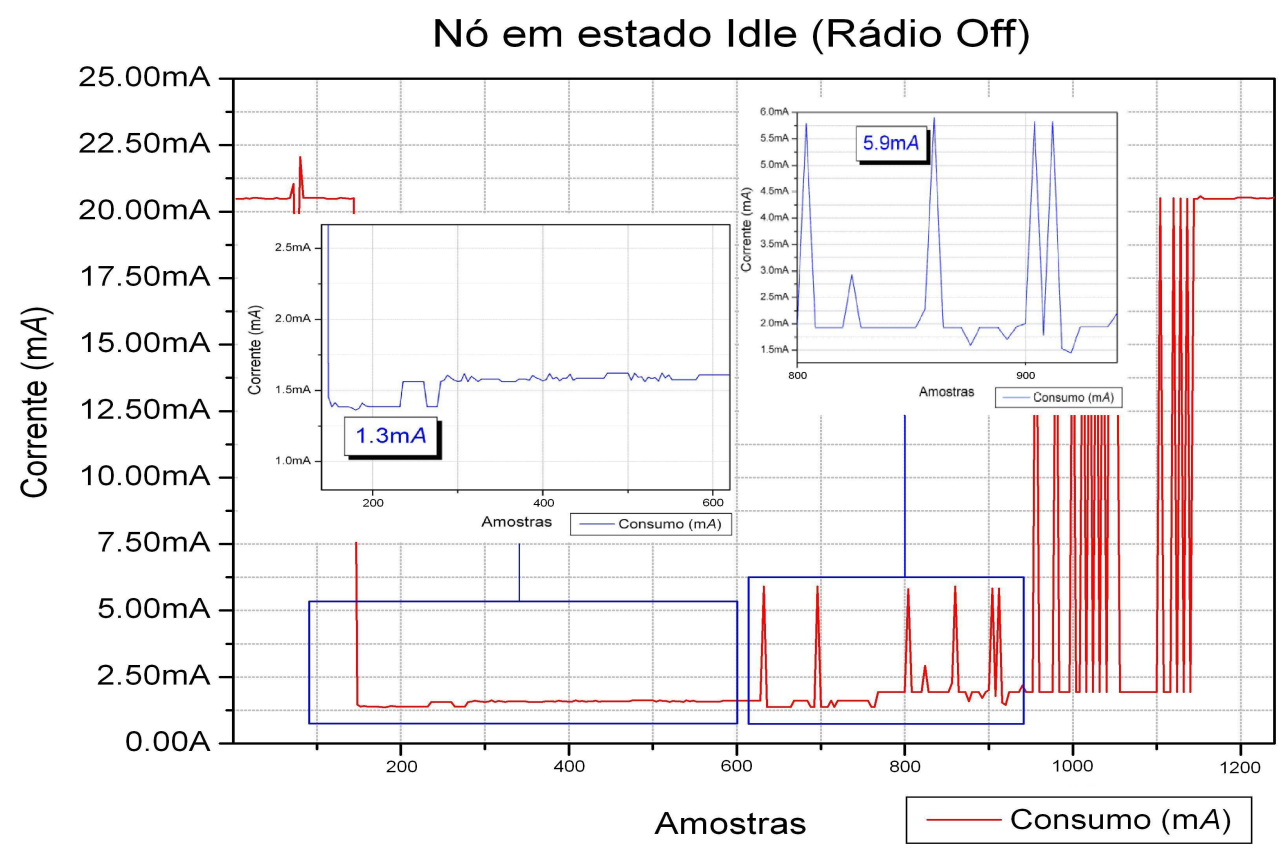

Figura 5.19: Consumo (mA) Nó em estado Idle (Rádio Off)

Os resultados das análises são apresentados em seu conjunto na tabela 5.9 
Tabela 5.9: Consumo de corrente (mA) TmoteSky (802.11.4)

\begin{tabular}{|c|c|c|c|}
\hline Plataforma (Nó Sensor) & Configuração & Min $(\mathrm{m} A)$ & Max $(\mathrm{m} A)$ \\
\hline \multirow{3}{*}{ TmoteSky } & & & \\
& Recepção & 17.83 & 19.92 \\
& Transmissão & 19.75 & 20.6 \\
& Idle Tx & 13.5 & 15.9 \\
& Idle Rádio Off & 1.3 & 5.9 \\
& Sleep & $1.6(\mu A)$ & $4.5(\mu A)$ \\
& Sensor & 26.0 & \\
\hline
\end{tabular}

\subsection{Camada de Enlace}

Nesta camada são avaliados os modelos de transmissão propostos na norma IEEE 802.15.4 e adotadas pelo padrão Zigbee como modelos de transmissão Beacon-Enabled e BeaconDisabled.

Na análise são empregadas métricas de desempenho como: vazão de dados e taxa de perda de pacotes (como um indicador de qualidade).

No percurso da realização dos testes foi criada uma relação entre a variação de distâncias e o tipo de comunicação empregada Beacon-Enabled e Beacon-Disabled medindo, o consumo de corrente pelos nós sensores em relação ao modelo de comunicação empregado. A configuração do temporizador para o ciclo de envio de pacotes é a cada $2000 \mathrm{~ms}$. O período de tempo determinado para captura dos log da rede foi de 300s (5 minutos).

1. Vazão de Dados:

Para a avaliação de vazão de dados, além das variáveis de tipos de transmissão escolhidas, são determinadas distâncias de $20 \mathrm{~m}$ até $75 \mathrm{~m}$ (as distâncias foram determinadas em função do alcance de sinal dos nós sensores com o coordenador). Na avaliação destas métricas leva-se em consideração que os nós enviam mensagens de forma contínua cada 2000ms e no tamanho máximo de 20 bytes. Os gráficos da Figura 5.20(a)e 5.20(b) mostram a vazão da rede para os dois tipos de transmissão. Observa-se que existe uma maior eficiência na transmissão com Beacon-Enabled atingindo taxas de 614 bps (nos 20m) e de 542 bps (nos $75 \mathrm{~m}$ ). Para o caso de transmissão Beacon-Disabled, atinge-se taxas de 512 bps (20m) e de 242 bps (75m). 
Em relação ao segundo caso, existe uma queda inicial de 16,67\% (20m) com relação ao primeiro caso. Os valores mais significativos são os obtidos nos $75 \mathrm{~m}$ existindo uma queda de 55,31\% na transmissão com Beacon-Disabled em comparação com a transmissão com Beacon-Enabled nas mesmas distâncias:

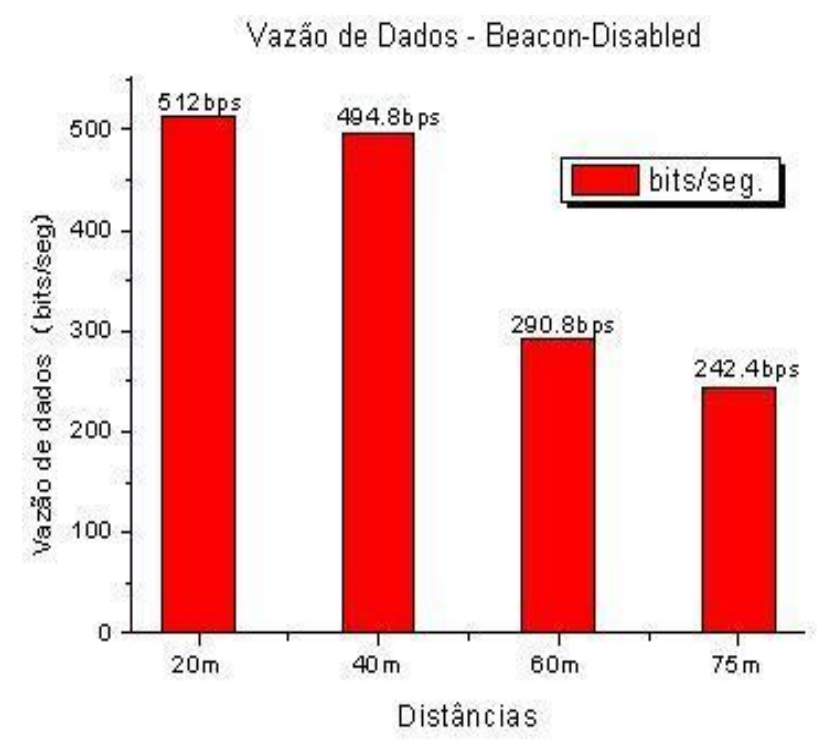

(a) Vazäo de Dados Beacon-Disabled

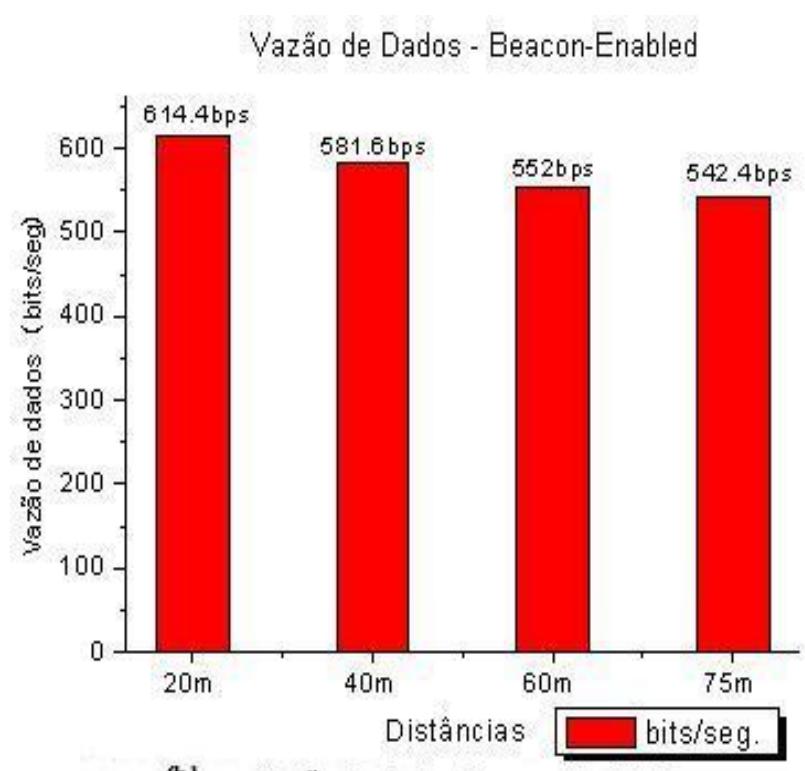

(b) Vazäo de dados Beacon-Enabled

Figura 5.20: Vazão de Dados Beacon-Disabled Beacon-Enabled

Pode-se concluir que a diferença de vazão está claramente determinada pelo modelo de transmissão empregado existindo uma eficiência de vazão de dados na transmissão com Beacon-Enabled em distâncias superiores a 40m. Isto é como resultado da comunicação permanente através do Beacon liberado pelo coordenador.

2. Taxa de Perda de Pacotes:

Para a avaliação da taxa de perda de pacotes (como um indicador de qualidade), da mesma forma que na avaliação de vazão de dados, são consideradas distâncias de transmissão de $20 \mathrm{~m}$ até os $75 \mathrm{~m}$ com relação ao nó coordenador da rede. 
Tabela 5.10: Perda de Pacotes Beacon-Disabled

\begin{tabular}{|cccccc|}
\hline Distância $(\mathrm{m})$ & Pacotes Tx & Pacotes Rx & $\%$ & Pacotes Perdidos & $\%$ \\
\hline 20 & 640 & 630 & 98,4 & 10 & 1,6 \\
40 & 618,5 & 602,5 & 97,4 & 16 & 2,6 \\
60 & 363,5 & 340,5 & 93,7 & 23 & 6,3 \\
75 & 303 & 277 & 91,4 & 26 & 8,6 \\
\hline
\end{tabular}

Observa-se na Tabela 5.10 (Beacon-Disabled) que a taxa de perda de pacotes aumenta conforme a variação das distâncias, sendo significativa em distâncias superiores aos $40 \mathrm{~m}$. Já no caso dos valores mostrados na Tabela 5.11 (BeaconEnabled) as taxas de perda de pacotes começam a ser significativas a partir dos $75 \mathrm{~m}$ com relação ao modelo Beacon-Disabled, pois permite ao coordenador o envio do beacon que dinamiza o canal de comunicação com os nós da rede informando constantemente sua posição e alcançando uma maior área de cobertura da rede.

Tabela 5.11: Perda de Pacotes Beacon-Enabled

\begin{tabular}{|cccccc|}
\hline Distância $(\mathrm{m})$ & Pacotes Tx & Pacotes Rx & $\%$ & Pacotes Perdidos & $\%$ \\
\hline 20 & 768 & 768 & 100 & 0 & 0,0 \\
40 & 727 & 726 & 99,9 & 1 & 0,1 \\
60 & 690 & 689 & 99,9 & 1 & 0,1 \\
75 & 678 & 671 & 99,0 & 7 & 1,0 \\
\hline
\end{tabular}

Pode-se concluir que a perda de pacotes é significativa no modelo de transmissão Beacon-Disabled e percebe-se que é incrementada segundo a variação das distâncias mostrando uma taxa alta de perda de pacotes a partir dos 60m. Em conseqüência, é clara a ineficiência do modelo de transmissão Beacon-Disabled em distâncias que ultrapassam os $40 \mathrm{~m}^{6}$.

\section{Consumo de Energia:}

Os testes de medida do consumo de energia foram realizados segundo os modelos de transmissãoBeacon-Disabled e Beacon-Enabled.

O consumo médio dos nós sensores com Beacon-Enabled é de 20.6mA (valor máximo) e as quedas de energia em determinados momentos é devido ao nó sensor entrar em

\footnotetext{
${ }^{6}$ Resultados Publicados no ERRC 2007. Rio Grande do Sul - Brasil
} 
estado de espera (idle $17.83 \mathrm{~m} A$ ). Na tabela 5.12 é medido o consumo de energia do nó sensor com Beacon-Disabled apresentando o consumo de corrente média de $23 \mathrm{~mA}$ devido ao envio do $A C K$ request. A variação de consumo de energia, devido ao envio do ACK request, está entre $21,56 \mathrm{~mA}$ e 22,98mA. Na transmissão Beacon-Disabled cada nó envia em média para o receptor 7,25 pedidos de confirmação no período de 300 segundos (5 minutos). Já em distâncias maiores (de até $75 \mathrm{~m}$ ) o envio de $A C K$ request chega a ser de 10,25 por nó sensor.

Tabela 5.12: Consumo de Energia do nó na rede.

\begin{tabular}{|c|c|c|}
\hline & Beacon-Disabled & Beacon-Enabled \\
\hline Minimo $\mathrm{m} A$ & 20.6 & 17.83 \\
Máximo $\mathrm{m} A$ & 23.0 & 20.6 \\
\hline
\end{tabular}

\subsection{Camada Física}

A motivação para a realização de medidas de propagação em ambientes confinados e externos pode ser por de diversas causas. No ambiente de uma empresa se tem por objetivo poder garantir uma boa cobertura do serviço de comunicação sem fio empregado em algum tipo de aplicação de monitoramento (como uma RSSF). No ambiente acadêmico e de pesquisa é necessario desenvolver ferramentas que ajudem no objetivo de criar novas soluções que permitam alcançar uma maior área de serviço do sistema de comunicação empregado.

No contexto da realização dos experimentos para caracterização do ambiente de propagação baseado nas características do RSSI se faz necessário conhecer a estrutura física do ambiente de propagação para estabelecer quanta atenuação experimentará o sinal, ao se propagar no ambiente de testes, atravessando paredes $^{7}$, objetos e difratasse em obstáculos.

O objetivo em questão é ter a habilidade de obter resultados que permitam determinar a melhor localização de uma estação base com a finalidade de garantir um maior nível de

\footnotetext{
${ }^{7} \mathrm{~A}$ penetração ou transmissão se produz quando o sinal se encontra em seu caminho com um obstáculo que é transparente para as ondas de rádio. Quando o sinal penetra um obstáculo experimenta uma perda, a qual será em função da espessura do objeto e do material do qual está composto.
} 
qualidade no processo de comunicação de uma rede de sensores sobre o padrão Zigbee.

Um aspecto importante prévio à execução dos experimentos de desempenho foi determinar o tipo de antena a ser utilizada para a qual a escolha no depende só do método de medição utilizado, mas também da capacidade de transmitir com um diagrama de radiação especifico. Por exemplo: para o caso de ter que medir a atenuação por propagação em espaços abertos convém utilizar antenas onidirecionais. O uso deste tipo de antenas possui a vantagem de que é muito provável que a antena definitiva a serem usadas no ambiente considerado apresente características semelhantes (O calculo para escolha e montagem da antena externa foi apresentada na secção de sincronização.).

De forma adicional a distância existente entre as antenas não deve ser excessiva para que o raio refletido no solo não influenciasse no valor total do sinal recebido. Para demonstrar o efeito da distância basta com recorrer à equação de Friis (RAPPAPORT, 1996). A equação de Friis para o haz direto tem a forma de (1):

$$
P_{r}=P_{t} \frac{G_{t} G_{r} \lambda^{2}}{(4 \pi d)^{2}}
$$

Onde $P_{r}$ é a potência recebida, $P_{t}$ é a potência transmitida, $G_{r}$ é o ganho da antena receptora e $G_{t}$ é o ganho da antena transmissora, é o cumprimento da onda e $d$ é a distância entre o transmissor e receptor para o haz refletido. Se a transmissão for ao nivél do solo pode-se deduzir facilmente que (2):

$$
P_{r}=P_{t} \frac{\alpha_{r} G_{t} \alpha_{r} G_{r} \lambda^{2}}{(4 \pi d)^{2}\left[1+\left(2^{h} / d\right)^{2}\right]}|\Gamma|^{2}
$$

Onde se assume que $\alpha=\alpha_{t}=\alpha_{r}$ é a perda de ganho que se experimenta por transmitir há o solo e receber desde ele em vez de transmitir diretamente há uma antena receptora, $h$ é a altura na que se encontram as antenas com relação ao solo que se supor igual e tipicamente de $2 \mathrm{~m}$ - e $|\Gamma|$ é a magnitude do coeficiente de reflexão de uma terra plana.

A montagem dos equipamentos de teste para a realização dos experimentos é ilustrada na figura 5.21 e 5.22, a disposição do analisador de espectro (Receptor) é determinada num lugar fixo, e a localização do gerador de ondas (transmissor) é modificada de forma 
progressiva, segundo seja o tipo de obstáculo a ser caracterizado.

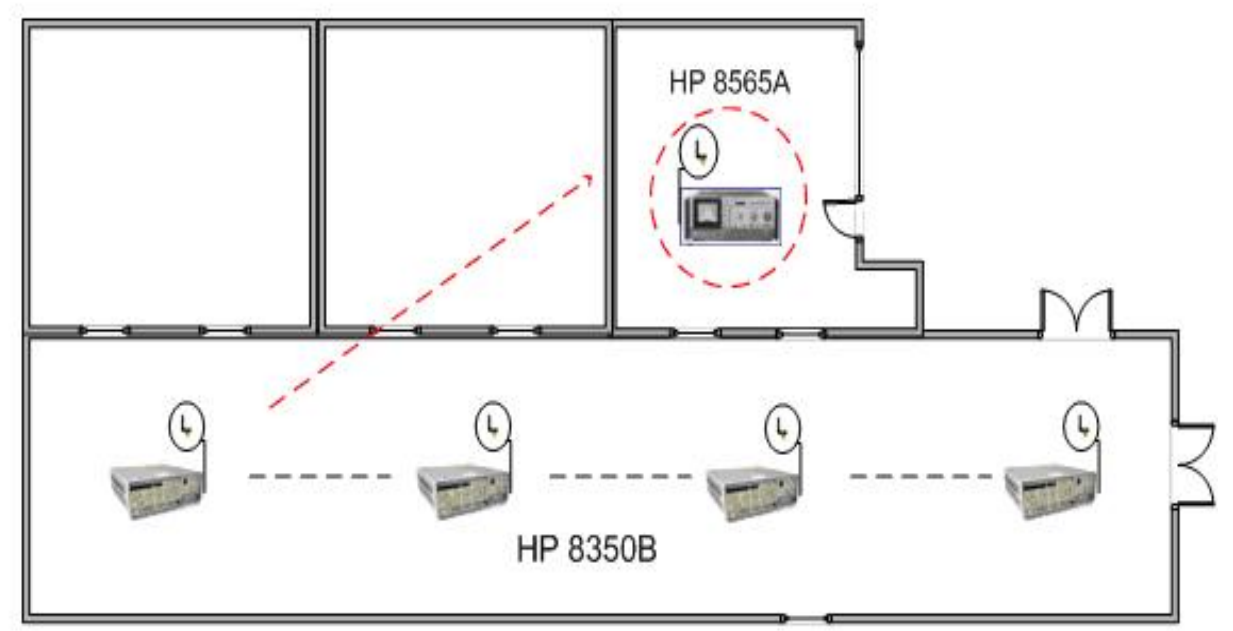

Figura 5.21: Cenário de LME - Distribuição 1

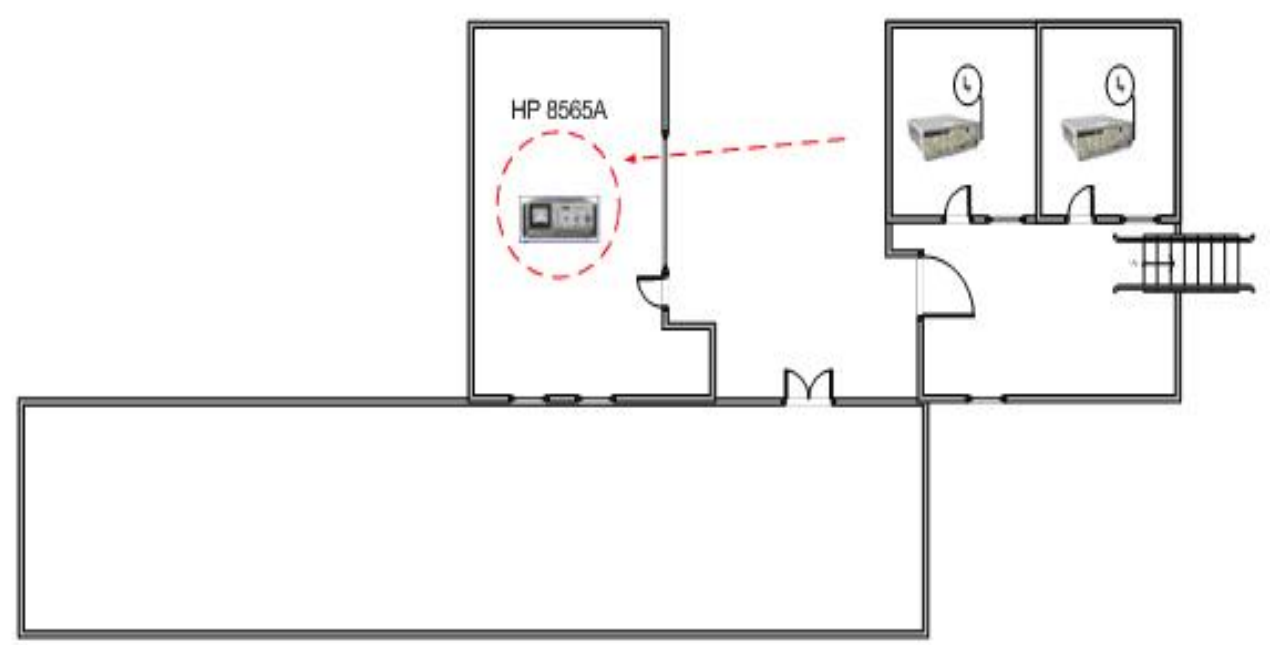

Figura 5.22: Cenário LME - Distribuição 2 
A avaliação do ambiente de propagação segundo o nível de RSSI está em função das características físicas do ambiente (BABAK et. al., 2006) em questão e os obstáculos que estas apresentam, tais como: paredes (concreto, tijolo), divisórias de madeira, vidros simples, divisórias e objetos metálicos.

A disposição do transmissor (gerador) e o receptor (analisador) foram determinados em função dos obstáculos, tal e como pode ser observados nas figuras 5.23 até 5.27:

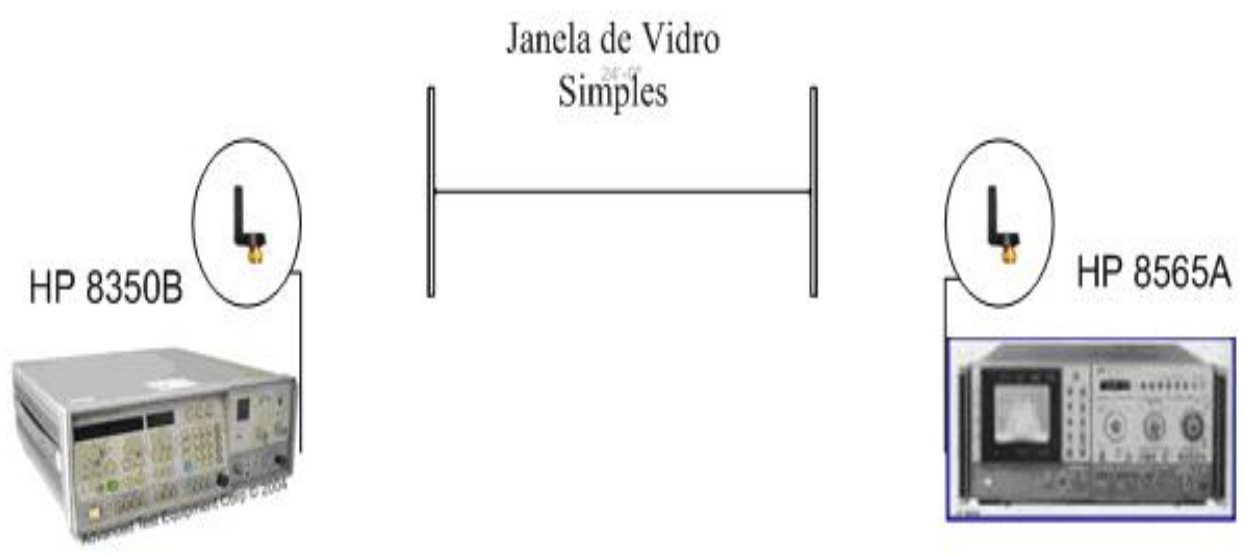

Figura 5.23: Atenuação Obstáculo - Vidro

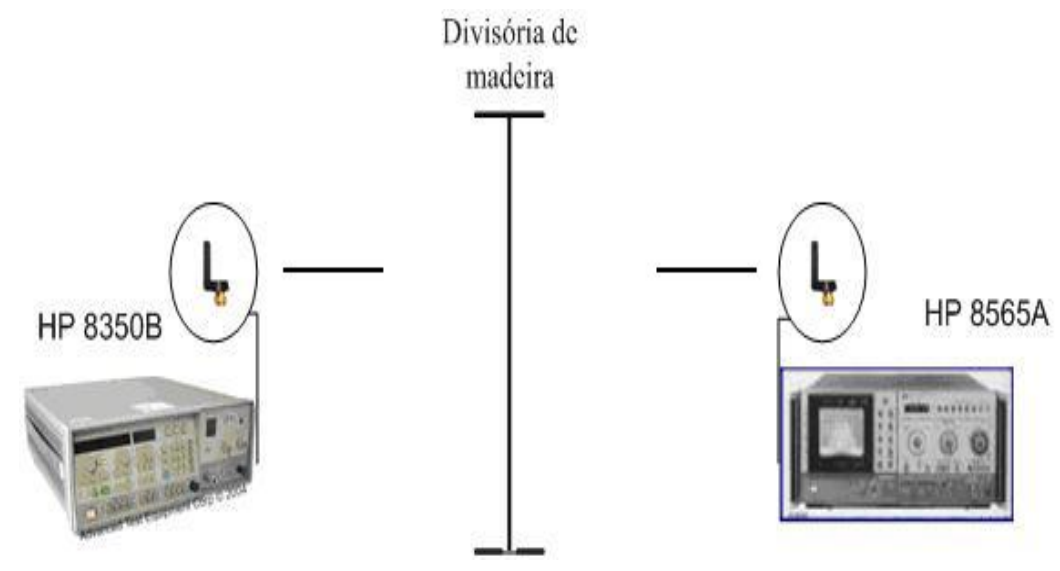

Figura 5.24: Atenuação Obstáculo - Divisória de Madeira 


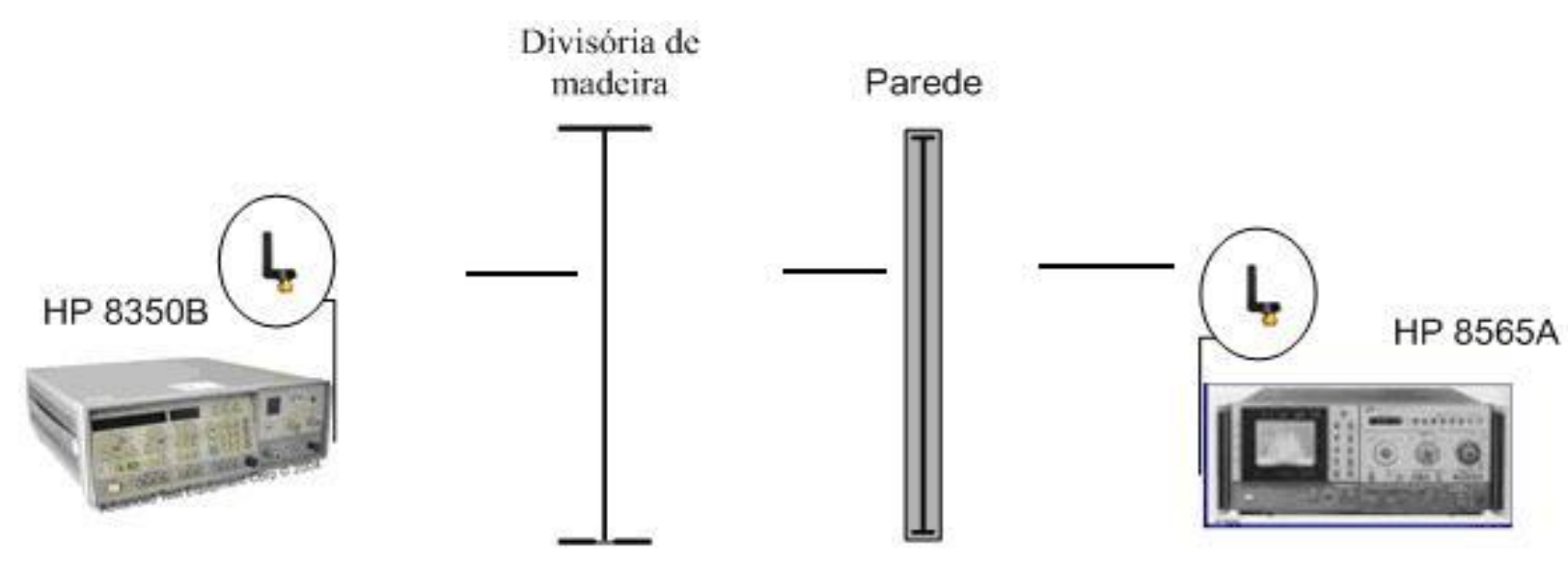

Figura 5.25: Atenuação Divisória - Parede

Lafortune and M. Lecours (1990), propõem agregar um fator adicional por cada parede que é atravessada como uma forma de simplificar a equação de Friis:

$$
P_{r}[d B m]=P_{r}\left(d_{0}[d B m]+n\left(\log d-\log d_{0}\right)+K A[d B]\right.
$$

Na equação 3 o valor $d 0$ é uma distância de referência da equação de Friis no ambiente de medição, a distância $d$ é um parâmetro e o expoente $n$ é o valor que se deseja determinar. Assume-se que $k$ é o número de paredes atravessadas e $A$ é a atenuação atribuível a cada parede. Neste caso, se supor que todas as paredes consideradas introduzem igual atenuação por ser do mesmo tipo (estrutura física). Para o caso de ser de diferente material ou de diferente espessura, será necessário considerar a contribuição de cada uma delas por separado (Ver Figura 5.26 e 5.27). Desta maneira se modelam independentemente da pendente da atenuação (fator $n$ ) e o efeito das obstruções $(A)$ em lugar de associarmos ambas a um só parâmetro. 


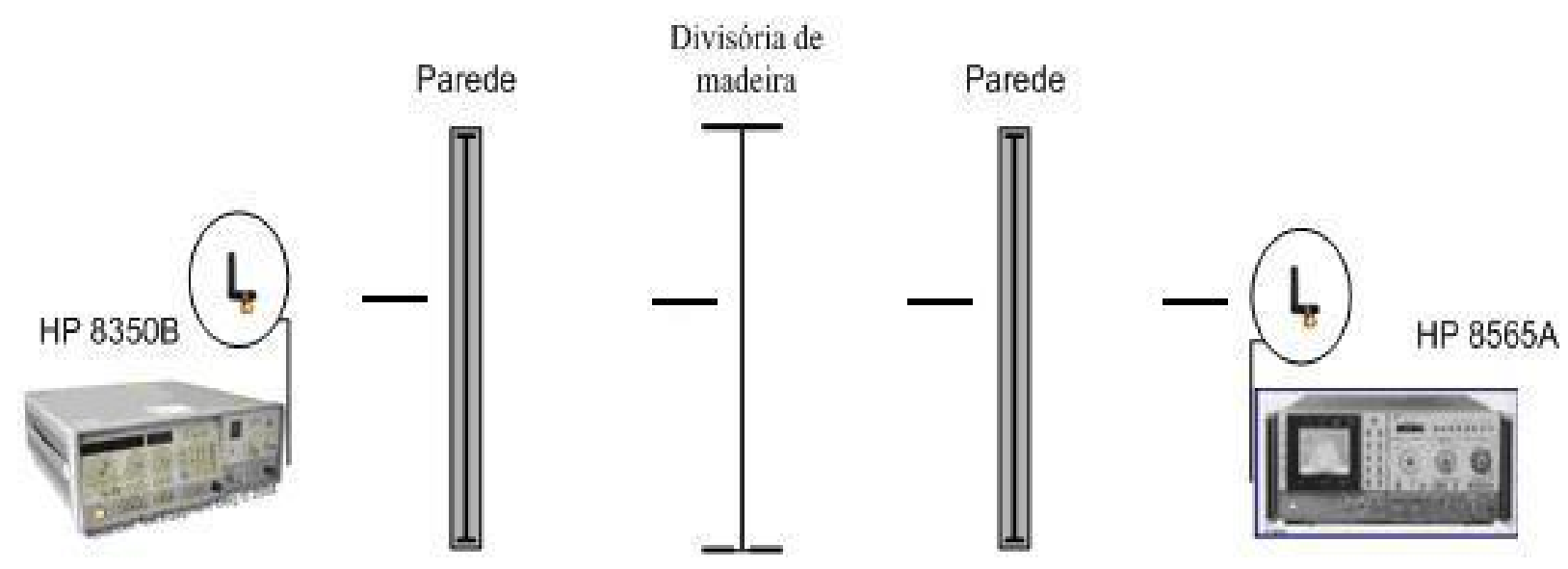

Figura 5.26: Atenuação Parede - Divisória - Parede

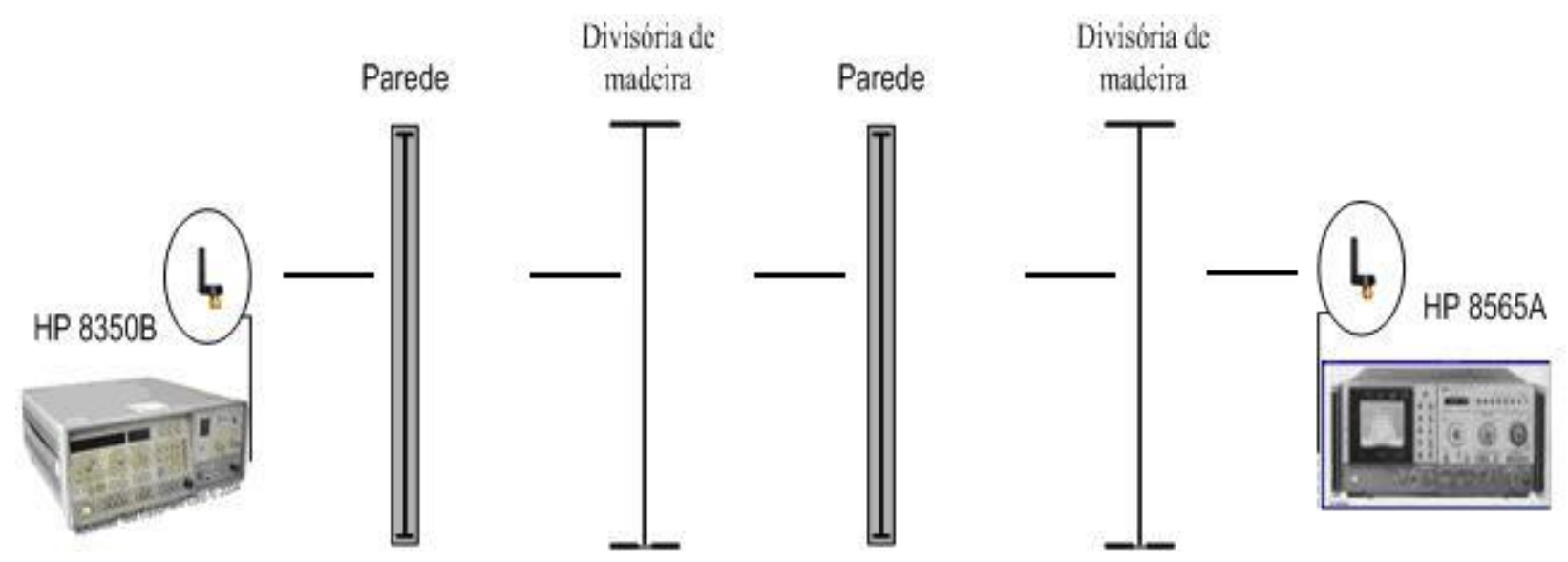

Figura 5.27: Atenuação Parede - Divisória - Parede - Divisória

Os resultados das medições de RSSI segundo o tipo de obstáculo são apresentados na tabela 5.13. Inicialmente, a potência de saída administrada pelo transmissor é de 10 dBm, segundo especificações do TmoteSky utilizado nos experimentos de comunicação e às especificações da norma IEEE 802.15.4.

Tabela 5.13: RSSI - Atenuação segundo obstáculos Potência de saida 10dBm

\begin{tabular}{|c|c|c|}
\hline Potência de saida $(\mathrm{dBm})$ & obstáculos & RSSI $(\mathrm{dBm})$ \\
\hline \multirow{3}{*}{$10 \mathrm{dBm}$} & Vidro comum & -31.5 \\
& Divisória de Madeira & -34.0 \\
Parede (Tijolo) & -49.5 \\
& Divisória + Parede & -59.0 \\
& Parede + Parede & -75.0 \\
& Porta de Madeira & -45.0 \\
\hline
\end{tabular}


Finalmente, com o objetivo de determinar uma maior eficiência na penetração de obstáculos pelo padrão Zigbee, é incrementada a potência de saída para $17 \mathrm{dBm}$, sendo que o objetivo inicial seria de $20 \mathrm{dBm}$, limitado finalmente para o nosso caso pelas características do hardware do equipamento de testes empregado que suporta apenas uma saída máxima de até $17.5 \mathrm{dBm}$. Os resultados são apresentados na tabela 5.14.

Tabela 5.14: RSSI - Atenuação segundo obstáculos Potência de saida 17dBm

\begin{tabular}{|c|c|c|}
\hline Potência de saida $(\mathrm{dBm})$ & obstáculos & RSSI $(\mathrm{dBm})$ \\
\hline \multirow{2}{*}{$17 \mathrm{dBm}$} & Vidro comum & -26.5 \\
& Divisória de Madeira & -30.0 \\
& Parede (Tijolo) & -44.0 \\
& Divisória + Parede & -42.5 \\
& Divisória + Parede + Divisória & -46.0 \\
& Parede + Parede & -54.17 \\
& Porta de Madeira & -39.8 \\
\hline
\end{tabular}

O ultimo análise corresponde ao nível de RSSI no segundo cenário de avaliação (Ambiente Externo). Para os testes de RSSI no ambiente externo é utilizado o transceptor RF CC2420, os dados são extraídos do pacote utilizando um sniffer decodificador proporcionado pela chipcon. Os valores obtidos através do sniffer são interpretados seguindo as recomendações contidas no datasheet do transceptor RF, o qual indica que o valor de RSSI é negativo em dBb, e é composto de um byte em complemento de dois que deve ser adicionado a um valor de off-set sendo valor deste de -45 dBm (MOTEIV 2006). O qual quer disser que se o valor recebido for de -3 o valor considerado devera ser de -48 $\mathrm{dBm}$.

Os resultados dos experimentos são apresentados na Tabela 5.15. 
Tabela 5.15: RSSI - Atenuação segundo obstáculos Potência de saida 10dBm

\begin{tabular}{|c|c|c|}
\hline Potência de saida $(\mathrm{dBm})$ & Área Sem Obstaculos $(\mathrm{dB})$ & Área com Vegetação $(\mathrm{dBm})$ \\
\hline \multirow{3}{*}{$10 \mathrm{dBm}$} & & -52 \\
& -25 & -57.1 \\
& -32 & -64.9 \\
& -36 & -71.8 \\
& -38.7 & -74.5 \\
& -46.3 & -78.0 \\
\hline
\end{tabular}

Os resultados correspondem aos valores médios do conjunto de medições realizadas para esta análise. No primeiro experimento realizado e montado um nó transmissor e uma base ao nível do solo (sendo que o solo esta composto por vegetação). No segundo experimento o receptor e o transmissor são colocados sobre bases de $75 \mathrm{~cm}$. com as antenas perfeitamente alinhadas. O objetivo mudar a altura dos dispositivos foi para eliminar os obstáculos da vegetação existente ao nível do solo. O resultado observado na tabela 5.15 foi apresenta uma melhor transmissão resultado da elevação dos dispositivos. 


\section{Capítulo 6}

\section{Conclusões e Trabalhos Futuros}

Diversos trabalhos foram desenvolvidos com o objetivo principal de avaliar o desempenho das características do IEEE 802.15.4, dentre os quais se destacam (LEE, 2005) e (PETROVA et. al., 2006), que realizam estudos das características da norma. Porém, observa-se que os experimentos realizados não consideram sua aplicação em uma RSSF, realizando unicamente análises do desempenho das camadas físicas e de enlace descritas na norma.

O presente trabalho considera as limitações computacionais de processamento e energia existentes nas RSSF e procura determinar a eficiência das mesmas em diferentes ambientes (Interno e Externo) de aplicação.

Para os testes do alcance do sinal realizados em ambientes internos (Indoor), pode-se determinar uma clara eficiência do padrão ZigBee em relação a alguns valores achados em (HYNCICA et. al., 2006) e (FERRARI et al., 2007), apresentados na tabela 6.1. 
Tabela 6.1: Trabalhos Experimentais - Alcance do Sinal

\begin{tabular}{|c|c|c|c|c|}
\hline & Petrova (2006) & Hyncica (2006) & Ferrari (2007) & Resultados \\
\hline $\begin{array}{c}\text { Alcance } \\
\text { (Interno) }\end{array}$ & $35 \mathrm{~m}$ & $44 \mathrm{~m}$ & $20 \mathrm{~m}$ & $65 \mathrm{~m}-75 \mathrm{~m}$ \\
(Externo) & $70 \mathrm{~m}$ & & & $60 \mathrm{~m}$ \\
RSSI \\
(Interno)
\end{tabular}

Diferentemente dos trabalhos realizados por (PETROVA et. al., 2006) e (HYNCICA et. al., 2006), nos quais as distâncias de separação (1m) entre os dispositivos não obedecem a uma análise da área de alcance destes dispositivos IEEE 802.15.4. Em nosso trabalho são determinadas distâncias progressivas, com o objetivo de determinar o alcance máximo de um nó sensor ZigBee para este tipo de ambiente, determinando-se um alcance efetivo de até $65 \mathrm{~m}$ do nó sensor, e máximo de $75 \mathrm{~m}$ com uma queda na vazão de $27.2 \mathrm{bps}$ em relação ao primeiro caso.

Com o objetivo de criar uma relação entre a queda na vazão de dados e a taxa de perda de pacotes nestas distâncias, foi realizada uma análise de RSSI. Os resultados $(-72.83 \mathrm{dBm})$ sugerem não ultrapassar estas distâncias $(75 \mathrm{~m})$, com o objetivo de evitar uma queda maior na vazão de dados e uma taxa elevada de perda de pacotes (Figura 6.1).

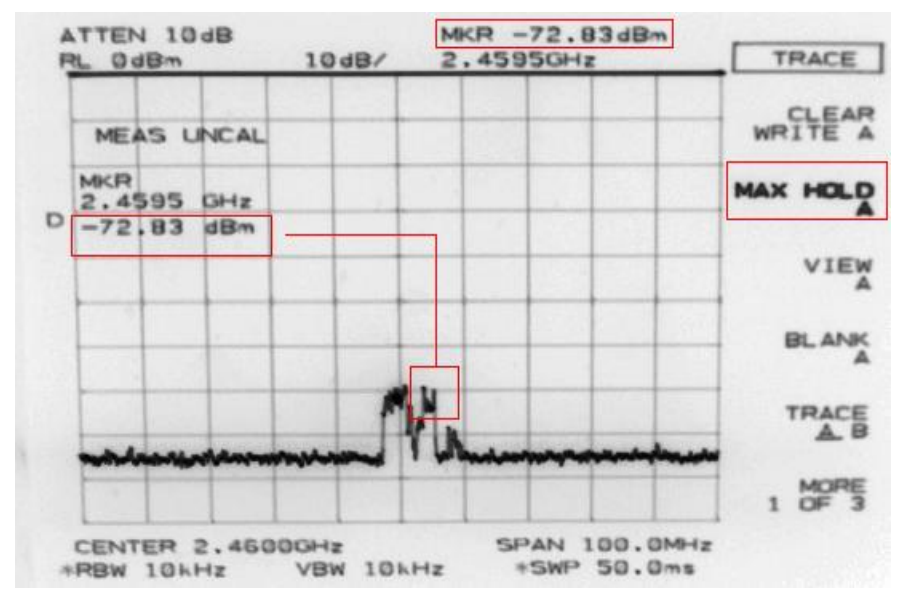

Figura 6.1: RSSI - Distância 75m ambiente interno.

Experimentos semelhantes foram realizados em Petrova et. al. (2006), no qual foram 
avaliados os níveis de RSSI segundo as variações do payload em distâncias de até 35m, atingindo um valor de $-47.5 \mathrm{dBm}$ para estas distâncias (Figura 6.2). Já em Ferarri et. al. (2007), a distância de separação determinada entre os nós foi de $80 \mathrm{~cm}$, porém o trabalho não determina qual foi o critério ou objetivo adotado para determinar esta separação entre os nós, sendo difícil criar uma relação com os resultados obtidos. Além disso, a potência de saída determinada para os nós sensores varia entre os $-25 \mathrm{dBm}$ até $0 \mathrm{dBm}$, obtendo resultados positivos (Figura 6.3) devido à proximidade existente entre os nós.

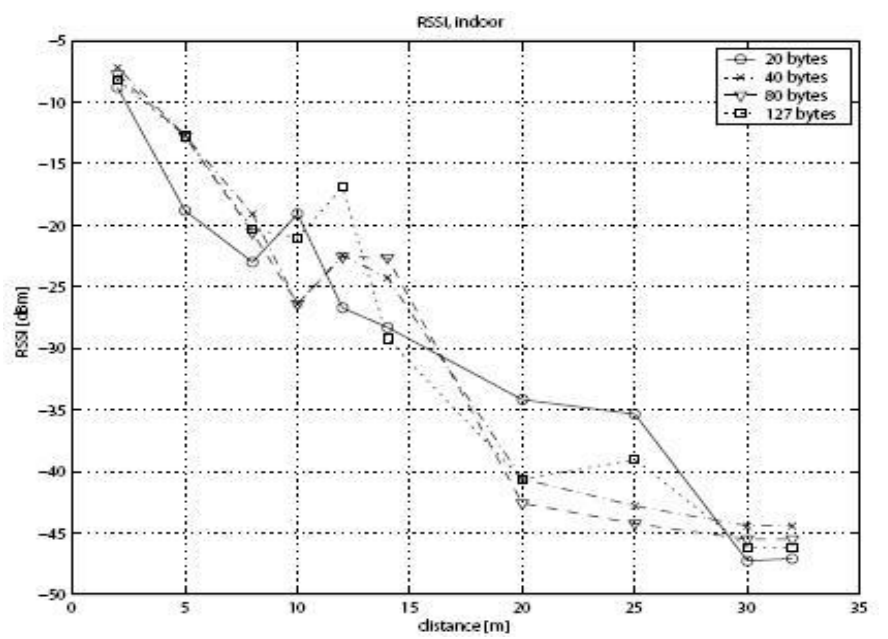

Figura 6.2: RSSI - Distância 35m ambiente interno. Fonte (PETROVA et. al. 2006)

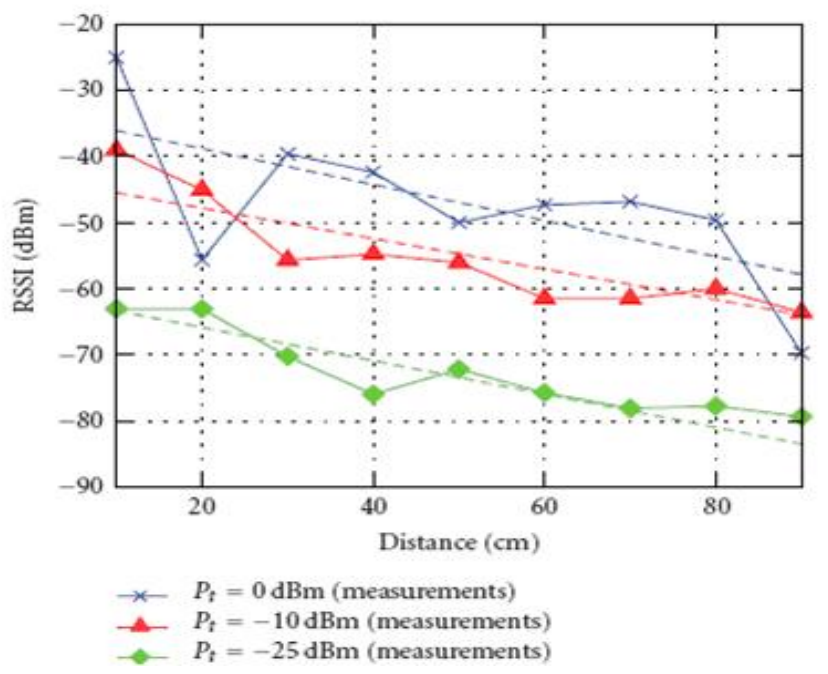

Figura 6.3: RSSI - Distância de separação 80cm ambiente interno. Fonte (FERRARI et. al. 2007)

Nas análises realizadas na camada MAC, entre os modelos de transmissão com beacon e sem beacon, conclui-se que o primeiro apresenta uma eficiência maior, com uma cobertura de rede de $75 \mathrm{~m}$, contra $40 \mathrm{~m}$ dos modelos sem beacon, os quais apresentam uma perda de 
pacotes significativa em distâncias superiores a essa. No entanto, em Lee (2005) se tem uma vazão maior (Figura 6.4) devido ao fato de que, nos experimentos realizados, esta foi calculada em função de 10000 pacotes enviados e recebidos satisfatoriamente. Porém, o autor não especifica a separação determinada entre os nós, o time rate estabelecido na transmissão dos pacotes, e nem o impacto no consumo de energia do nó segundo os modelos de transmissão aplicados, o qual torna quase impossível repetir os experimentos e criar comparações com os resultados obtidos.

No nosso caso, o time rate foi de $2000 \mathrm{~ms}$, com uma distância de separação de $3 \mathrm{~m}$ entre os nós. A vazão foi calculada em relação ao número de pacotes recebidos em um período de teste de 300s. Porém, os resultados obtidos, tanto em Lee (2005) como no nosso trabalho, indicam um melhor comportamento da rede através do modelo de transmissão com beacon.

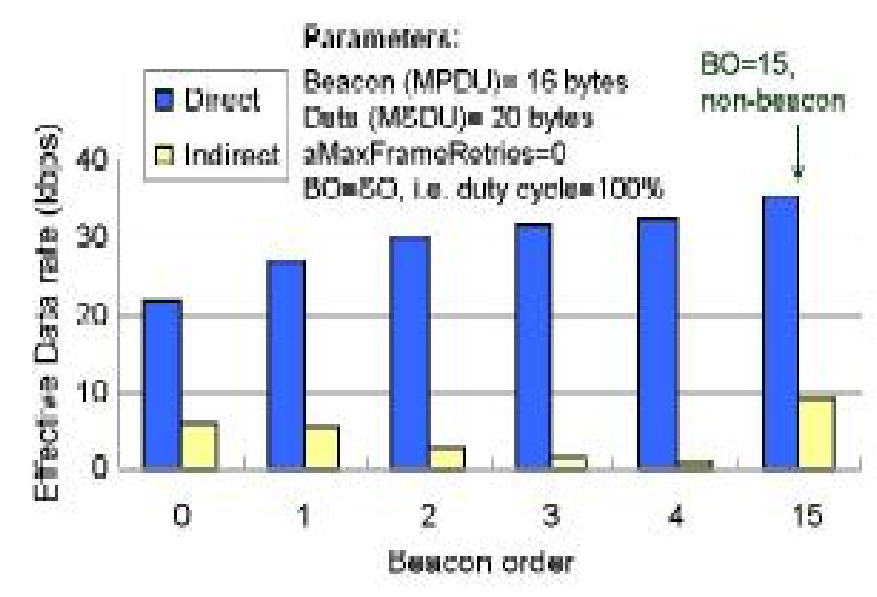

Figura 6.4: Vazão - Transmissão Direta e Indireta com beacon. Fonte (J. Lee 2005)

Os resultados dos experimentos dos modelos de transmissão apresentam um melhor comportamento do modelo Beacon-Enabled com relação à vazão e consumo de energia da rede, fazendo deste o modelo ideal para diferentes ambientes e aplicações. A diminuição do pacote MAC em $20^{1}$ bytes causa uma queda na vazão de dados em comparação com os resultados encontrados na literatura existente, como em Lee (2005). Porém, obteve-se um tempo menor de processamento e de uso de rádio na transmissão, criando um menor impacto no consumo de energia do nó, principalmente no modelo Beacon-Enabled.

Os resultados dos experimentos realizados sobre a aplicação de topologias demonstram uma clara eficiência da topologia malha em ambientes externos, uma ótima organização

\footnotetext{
${ }^{1}$ Tamanho mínimo permitido pelo IEEE 802.15.4, sendo que o máximo é de 127 bytes
} 
da rede e maiores áreas de cobertura com relação à topologia em estrela, a qual evidencia um maior consumo de energia do nó em conseqüência da rede em seu conjunto. Porém, esta apresenta-se eficiente em ambientes de cobertura reduzida, nos quais foram realizados a maior parte dos experimentos sobre o IEEE 802.15.4 existentes na literatura (POLLIN et. al. 2005) (TIMMONS; SCANLON 2004) (LEE, 2005) (PETROVA et. al, 2006) (preferencialmente experimentos realizados em ambientes internos) (Tabela 6.2).

Tabela 6.2: Trabalhos Experimentais - Alcance do Sinal

\begin{tabular}{|c|c|c|c|c|}
\hline & Petrova (2006) & Hyncica (2006) & Ferrari (2007) & Resultados \\
\hline Payload & 20 e 40 Bytes & 32 Bytes & 20 e 40 Bytes & 30 Bytes \\
Topologia & Peer-to-Peer & Estrela & Malha & Estrela e Malha \\
\hline
\end{tabular}

Na distribuição dos dispositivos através das topologias estrela e peer-to-peer, as distâncias máximas determinadas em (PETROVA et. Al, 2006), (FERRARI et. al. 2007) e (HYNCICA et. al. 2006) são de 1m. Mas os autores não especificam os testes realizados, e nem tampouco justificam o uso das mesmas na distribuição dos nós na rede.

Podemos concluir então que a topologia malha permite que a rede se ajuste automaticamente em sua inicialização, na entrada de novos dispositivos ou perda de dispositivos ${ }^{2}$. Para aplicações que requerem maior tempo de latência, a topologia tipo malha pode oferecer uma alternativa atrativa com boas coberturas externas, considerando que cada dispositivo só precisa de energia suficiente para se comunicar com seu vizinho mais próximo. Porém, com uma boa sensibilidade e um incremento moderado na potência de transmissão, uma rede com topologia tipo estrela (star) pode proporcionar uma cobertura total para toda a casa, considerando que a baixa densidade deste tipo de redes viabiliza a alimentação através de fontes de energia fixa para os nós da rede.

No processo de realização dos experimentos de alcance do sinal e topologias, considerouse como uma métrica determinante a taxa de perda de pacotes, como um indicador de qualidade para determinar a área de cobertura eficiente, segundo as características avaliadas no padrão ZigBee. Os valores determinados para cada topologia são

\footnotetext{
${ }^{2}$ Sendo que na maior parte dos experimentos realizados a topologia em estrela apresenta ser mais eficiênte neste processo
} 
apresentados em resumo na tabela 6.3.

Tabela 6.3: Topologias Estrela e Malha - Áreas de Cobertura. Fonte (Capitulo V)

\begin{tabular}{|ccccccc|}
\hline Topologia & Cenário & Alcance & N $^{0}$ Nós & bps & PLoss & Eficiência \% \\
\hline \multirow{2}{*}{ Estrela } & Interno & 75 & 10 & 1822,4 & 8,88 & 91,12 \\
& Externo & 50 & 10 & 2081,6 & 1,81 & 98,19 \\
Malha & Externo & 120 & 10 & 1926,4 & 3,68 & 96,32 \\
\hline
\end{tabular}

Nos experimentos de sincronismo, apresenta-se um tempo maior em relação aos apresentados por (COX; MILENKOVIC; JOVANOV, 2005) que é de 250us. Porém, os procedimentos adotados neste trabalho permitiram realizar a análise de sincronismo em uma rede em funcionamento real, determinando os benefícios em eventos adicionais, posteriores ao estado de sincronismo do nó de borda e nós comum na rede. Aliás, o procedimento e tempo de sincronismo são considerados desde o momento da ligação do nó até o envio do primeiro request e sua respectiva confirmação. Já para (COX; MILENKOVIC; JOVANOV, 2005), o tempo de sincronismo tem relação única com o tempo que leva para enviar um pacote de um nó para outro e sua respectiva confirmação de recepção.

Nos experimentos de caracterização do ambiente (Interno e Externo) através dos valores de RSSI, pode-se observar uma considerável penetração através dos obstáculos achados nos diferentes ambientes de propagação. Porém, em estruturas muito densas (duas ou mais paredes de concreto), a penetração para comunicações a $2.4 \mathrm{GHz}$ não é muito eficiente. O experimento de alcance do sinal em ambientes internos estabeleceu uma cobertura de $75 \mathrm{~m}$ com um RSSI de $-72.83 \mathrm{dBm}$. No entanto, é necessário considerar que as atuais especificações de sensibilidade da norma IEEE 802.15.4 especificam -85 dBm para a camada física a $2.4 \mathrm{GHz}$ e de -92 dBm para a camada física a 868-915 Mhz (802.15.4, 2003; CHIPCON, 2006; ZIGBEE, 2005). Para cada caso, os melhores equipamentos devem ser da ordem de $10 \mathrm{~dB}$, superiores às especificações, tal como é o caso do hardware utilizado nos experimentos (Chip CC2420), sendo que a sensibilidade do receptor é de -92dBm.

Pôde-se concluir que o alcance desejado varia em função da sensibilidade do receptor, assim como da potência do transmissor. A norma IEEE 802.15.4 especifica que cada 
dispositivo deve ser capaz de transmitir ao menos a $1 \mathrm{~mW}$. No entanto, dependendo das necessidades da aplicação, a potência de transmissão pode ser maior ou menor para aproveitar a energia.

\subsection{Contribuições Reais do Trabalho e Trabalhos Futuros}

Os estudos realizados sobre o padrão ZigBee, permitiu estabelecer novos valores com relação ao desempenho de uma RSSF em ambientes reais.

A principal motivação deste trabalho foi a de estabelecer valores obtidos em ambientes e aplicações reais sobre o uso do padrão ZigBee como referencia para os futuros desenvolvedores de hardware e software para este padrão de comunicações. Sendo assim conseguiu-se atingir os objetivos inicias incluindo em nossa análise os valores de alcance do sinal e vazão de dados da arquitetura Mica Motes (mica2dot).

Os diferentes alcances na transmissão mostrados na tabela 5.1 (Capitulo V) podem ser explorados para conseguir diferentes objetivos. Por exemplo, a baixa densidade de dados dos Mica2dot a $915 \mathrm{MHz}$ pode ser usada para lograr maior sensibilidade e maiores áreas de cobertura, reduzindo o número de nós requeridos para dar cobertura numa área maior (WANG, 2006), já a transmissão na camada física a $2.4 \mathrm{GHz}$ pode ser utilizada para conseguir saídas superiores e de pouca latência.

Os experimentos dos modelos, Beacon-Enabled e Beacon-Disabled realizados através da variação de distâncias, permitiu determinar a cobertura máxima de uma rede implementada sobre estes modelos. Ao mesmo tempo, o sistema utilizado para a análise de consumo de energia permitiu evidenciar o impacto destes modelos sobre a fonte de energia dos nós.

Determinou-se a eficiência da topologia Malha, observando-se uma rede auto-suficiente para aperfeiçoar o trafego de dados, obtendo-se como resultado uma maior área de 
cobertura através deste tipo de configurações.

No sistema utilizado para a análise do consumo de energia adota-se parte do sistema utilizado por Raskovic (2004). No entanto, a interface de leitura dos dados (Multímetro e Osciloscópio) e substituída por uma DAQ-PXI com uma maior capacidade de amostragem sendo que o tratamento dos dados é realizado através de um programa em LabView. A velocidade de amostragem e flexibilidade para a coleta e o tratamento dos dados permitiu uma eficiente análise dos diferentes estados do sistema de comunicação dos nós com bastante precisão, sendo que a pesar de ser um sistema bastante eficiente não existe uma referência na literatura existente, pois a maior parte das soluções achadas inclui o uso de equipamentos como Osciloscópio e Multímetro, e alguns outros análises de consumo de energia através de modelos matemáticos (KOHVAKKA, 2006).

A flexibilidade do sistema utilizado para a análise de consumo de energia, permitiu conhecer os valores de consumo do nó segundo o tipo de evento realizado, sendo estes valores no registrados na literatura existente.

No percurso da realização dos experimentos de topologias conseguiu-se determinar a distância máxima de separação dos nós na rede com o objetivo de incrementar a distância de cobertura da mesma. Os valores são apresentados na tabela 6.4.

Tabela 6.4: Distância de separação dos nós da rede segundo a área de cobertura.

\begin{tabular}{|c|c|}
\hline Distância & Separação \\
\hline até os $50 \mathrm{~m}$ & $15-20 \mathrm{~m}$ \\
após os $50 \mathrm{~m}$ & $5 \mathrm{~m}-10 \mathrm{~m}$ \\
\hline
\end{tabular}

A determinação deste tipo de parâmetro permitira um melhor comportamento na cobertura das RSSF sobre o padrão ZigBee, sendo que em muitos dos casos os problemas de separação entre os nós da rede pode-se resolver com o incremento da densidade da mesma. 


\subsubsection{Trabalhos Futuros}

- Como um complemento aos estudos realizados neste trabalho é necessário realizar uma análise de mobilidade para referência de implementação do padrão ZigBee em dispositivos que apresentem a mobilidade como uma de suas características. Ao mesmo tempo é necessária uma análise de convivência do padrão ZigBee com outros padrões de comunicação que trabalham na mesma faixa de freqüência como: Bluetooth, Wi-fi etc;

- Realizar uma avaliação de uma RSSF sobre o padrão ZigBee em uma aplicação em ambientes externos como o monitoramento de florestas onde possa ser estudado não só o comportamento da rede através do uso de topologias, mas também o consumo de energia de cada um dos eventos realizados pelos nós sobre estas topologias;

- Desenhar um sistema de processamento em tempo real dos dados coletados pelos nós sensores, através de interfaces sem fio;

- Desenhar uma arquitetura para acesso e gerenciamento de uma rede de sensores através de dispositivos móveis; 


\section{REFERENCIAS}

802.15.4 (2003) IEEE - Institute of Electrical and Electronics Engineers; IEEE 802.15.4

- Wireless Médium Access Control (MAC) and Physical Layer (PHY) Specifications for Low-Rate Wireless Personal Area Networks (LR-WPANs), pp.679. 2003. retirado de www.IEEE.org em Janeiro do 2006.

ANASTASI, G.; CONTI, M.; GREGORI, E.; FALCHI, A.; PASSARELlA, A., Performance measurements of mote sensor networks. Proc. of the ACM/IEEE Int. Symp. on Modeling, Analysis and Simulation of Wireless and Mobile System. 2004.

ALMEIDA; VIEIRA, L.; VITORINO, B.; VIEIRA, M.; NACIF, J.; FERNANDES, A.; SILVA; COELHO, C. Sistema Operacional YATOS para Redes de Sensores sem Fio. Universidade Federal de Minas Gerais. Brasil. 2004.

AL-KARAKI, J. N.; KAMAL, A. E., Routing Techniques in Wireless Sensor networks: A survey, IEEE Wireless Communications., vol. 11, no. 6, December 2004.

ASCAMA, H. (2005) Dissertação de Mestrado: Uma contribuição à implementação de uma infraestrutura de chaves públicas para rede de sensores sem fio com criptografia de curvas elípticas. pp. 1-84. 2005.

BABAK, A.; SEXTON, D.; PING, L.; MAHOMY, M., Interference Effect on IEEE 802.15.4 Performance. INSS06. pp. 1 - 8. 2006.

BERKELEY (2003). Berkeley. Intel website.

Disponível Em: http://www.intelresearch.net/berkeley/index.asp. Acesso em: Janeiro. 2006.

BOUGARD, B.; CATThOOR, F.; DALY, D. C.; CHANDRAKASAN, A.; DEHAEnE, W., Energy Efficiency of the IEEE 802.15.4 Standard in Dense Wireless Microsensor Networks: Modeling and Improvement Perspectives. in Proceedings of Design, Automation and Test in Europe, vol. 1, no. 1, pp. 196 - 201. 2005. 
BHATTI, S.; CARLSON, J.; DAÍ, H.; ROSE, J.; SHETH, A.; SHUCKER, B.; GRUENWAld, C.; TORGEnSON, A.; HAN, R., Mantis Os: An Embedded Multhithreaded Operating System for Wireless Micro Sensor Plataforms. ACM Klumer Mobile Networks \& Applications Jurnal, Special Issue on Wireless Sensor Networks. 2005.

CABRINI, F. H. (2006) Dissertação de Mestrado: Caracterização e Análise de Desempenho de Uma Rede de Sensores Sem Fio. pp. 1-120. 2006.

CORREIA, L. H.; MACEDO, D. F.; SILVA, D. A.; SANTOS, A.; LOUREIRO, A. F.; NOGUEIRA, J. S., Controle de Potência de Transmissão em Protocolos MAC para Redes de Sensores Sem Fio. In: Simpósio Brasileiro de Telecomunicações. Campinas. XXII SIMPOSIO BRASILEIRO DE TELECOMUNICACOES v. 1. p. 709-714. 2005.

CAllaWAY, E.; GORDAY, P.; HeSter, J. A; NAEVE, G.; HeIle, B.; BAHL, V., Home Networking with IEEE 802.15.4: A Developing Standard for Low-Rate Wireless Personal Area Networks. IEEE Communications Magazine, vol. 40, no. 8. pp. 70 - 77. 2002.

CORREIA, L. E. A.; MACEDO, D. F; SANTOS, A. L.; NOGUEIRA, J. M; LOUREIRO, FERREIRA, A., A taxonomy for medium access control protocols in wireless sensor networks. Annales Telecommunications, v. 60, n. 7/8, p. 944 - 969, 2005.

CHIPCON, Radio CC2420 RF Transceiver, Datasheet.

Disponível Em: http://www.chipcon.com. Acesso em: Março. 2006.

CROSSBOW WIRELESS SENSOR NETWORK. TelosB Mote Research. Data sheet. Disponível Em: http://www.xbow.com. Acesso em: Janeiro. 2006.

COX, D.; MILENKOVIC, A.; JOVANOV, E., Time Synchronization for ZigBee Networks, Proceedings of the 37th Southeastern Symposium on System Theory, Tuskegee. Alabama. pp. 135 - 138. 2005. 
DUNKELS, A.; GRÖNVAlL, B. and VOIGT. T., Contiki - a Lightweight and Flexible Operating System for Tiny Networked Sensors, In Proceedings of the First IEEE Workshop on Embedded Networked Sensors 2004 (IEEE EmNetS-I), Tampa, Florida, USA, November 2004.

DRAVES, R.; PADHYE, J., and ZILL, B., Routing in multi-radio, multi-hop wireless mesh networks, in ACM Annual International Conference on Mobile Computing and Networking (MOBICOM), 2004.

ELSON, J.,; GIROD, L. and DEBORAH E. Fine-Grained Network Time Synchronization using Reference Broadcasts, Proceedings of the 5th symposium on Operating systems design and implementation Volume 36 Pages: 147 - 163. 2002.

FERRARI, G.; MEDAGLIANI, P.; DI PIAZZA, S.; MARTALÒ, M., Wireless Sensor Networks: Performance Analysis in Indoor Scenarios, EURASIP Journal onWireless Communications and Networking Volume 2007, Article ID 81864, 14 pages. 2007.

GIACOMIN, J.; VASCONCELOS, F. H., Qualidade da Medição de Intensidade de Sinal nas Comunicaçõs de uma Rede de Sensores Sem Fios: uma abordagem da camada física, Journal Of Computer Science. v. 5. pp. 83 - 94, 2006.

HEINZELMAN, W.; CHANDRAKASAN, A.; BALAKRISHNAN, H., Energy Efficient Communication Protocol for Wireless Microsensor Networks, in Proceedings of the Hawai Conference on System Sciences, January 2000.

HSIN-MU; C., SARAYDAR; TIMOTHY, T.; TALTY, T.; ANES, M.; MACDONALD, A.; TOGUZ, O. ZigBee-Based Intra-Car Wireless Sensor Network, IEEE Commuinications Society Subject Matter Expert, for Publication in the ICC07. pp. 1 - 7. 2007.

HYNCICA, O.; KACZ, P.; BRADAC, Z.; KUCERA, P.; VRBA, R., The ZigBee Experience, In Proceeding of the 2nd International Symposium on Communications, 
Control and Signal Processing (ISCCSO06) Marocco. pp. 1-4. 2006.

KANG, D.; HYUNG-JIK, L.; EUN-JUNG, K.; KYUCHANG, K.; JEUNWOO, L.; A Wearable Context Aware System for Ubiquitous Healthcare, in: Engineering in Medicine and Biology Society, 28th Annual International Conference of the IEEE. 2006

KOHVAKKA, M.; KUORILEHTO, M.; MARKO H.; TIMO D. H., Performance analysis of IEEE 802.15.4 and ZigBee for large-scale wireless sensor network applications, Proceedings of the 3rd ACM international workshop on Performance evaluation of wireless ad hoc, sensor and ubiquitous networks. pp. 48 - 57, 2006.

KWANG K. L.; SEONG H. K.; YONG S. CH.; HONG S. P., A Mesh Routing Protocol using Cluster Label in the ZigBee, Mobile Adhoc and Sensor Systems (MASS), 2006 IEEE International Conference, Vancouver, BC, Canada, pp. 801 - 806, Oct. 2006.

LEE, J. M.; ZHENG, J.; YOUNG-BAR, K.; DEEPESH M., Emerging Standards For Wireless Mesh Technology, IEEE Wireless Commuinications. pp. 1 - 8. 2006.

LEE, J. M., An Experiment on Performance Study of IEEE 802.15.4 Wireless Networks, IEEE International Conference on Emerging Technologies and Factory Automation, Catania, Italy, 19 - 22, 2005.

LEVIS, P.; GAY, D.; HANDZISKI, V.; HAUER, J.; GREENSTEIN, B.; TURON, M., HUI, J., KLUES, K., SHARP, C.; SZEWCZYK, R.; POLASTRE, J.; BUONADONNA, P., NACHMAN, L., TOlle, G.; CUlleR, D.; WOlISZ, A., T2: A Second Generation OS for Embedded Sensor Networks, Technical Report, Telecommunication Network Group, Technische Universitat Berlin. 2005.

MACEDO, D. F.; CORREIA, L. H. ; SANTOS, A.; LOUREIRO, A. F.; NOGUEIRA, J. S. Avaliando aspectos de tolerância a falhas em protocolos de roteamento para redes de sensores sem fio In: VI Workshop de Testes e Tolerância a Falhas, 2005, Fortaleza, 2005. pp. $15-26$. 
MISIC, J. V.; MISIC, V. B.; SHAFI, S. Performance of IEEE 802.15.4 Beacon Enabled PAN with Uplink Transmissions in Non-Saturation Mode - Access Delay for Finite Buffers, First International Conference on Broadband Networks. Broadnets. pp. 416 - 425. 2004.

MOTEIV CORPORATION (2006) TmoteSky Brochure/Datasheet. Disponível Em: http://www.moteiv.com/products/docs/tmote-sky-datasheet.pdf. Acesso em: Março. 2006.

PEREIRA, M. R.; CASTRO, M. C. S.; AMORIM, C. L., Tutorial sobre Redes de Sensores, Cadernos do IME. Série estatística, Rio de Janeiro, v. 14, pp. 3, 2003.

PERRIG, A.; STANKOVIC, J., AND WAGNER, D., Security in wireless sensor networks, ACM 47. pp. 53-57. 2004.

PETROVA, M.; RIIHIJRVI, J.; MHNEN, P.; AND LABELlA, S., Performance study of ieee 802.15.4 using measurements and simulations, In Proceedings of IEEE WCNC, April 2006.

POLASTRE, J.; SZEWCZYK, R.; AND D. CULLER, Telos: Enabling Ultra-low Power Wireless Research, Disponível Em: http://www.moteiv.com

POLlin, S.; ERGEN, M.; COLERI E. S.; BOUGARD, B.; VAN DER PERRE, L.; CATTHOOR, F.; MOERMAN, I.; BAHAI, A.; VARAIYA, P.,Performance Analysis of Slotted IEEE 802.15.4 Medium Access Layer, Research supported by National Semiconductor and ARO-MURI UCSC-W911NF-05-1-0246-VA-09/05 . pp. 1-7 (2005).

PORTER, J.; ARZBERGER, P.; BRAUN, H.; BRYANT, P.; GAGE, S.; HANSEN, T.; HANSON, P.; LIN, CH.; LIN, F.; KRATZ, T.; MICHENER, W.; SHAPIRO, S.; AND THOMAS WILLIAMS, Wireless Sensor Networks for Ecology, BioScience 571, Vol. 55 No. 7, July 2005. 
RAGHUNATHAN, V.; SCHURGERS, C.; PARK, S.; SRIVASTAVA, M. B. Energy aware wireless sensor networks, IEEE Signal Processing Magazine, 19(2). pp. 40 - 50, March 2002.

RASKOVIC, D., Energy-efficient Hierarchical Processing in the Network of Wireless Intelligent Sensors (WISE), Ph.D. Thesis, ECE Dept., University of Alabama in Huntsville. 2004.

RAPPAPORT, T.; MCGILLEM., UHF Fading in Factories, IEEE JSAC, Vol. 7, Nº1, Ene 1989, pp. $40-48$.

RAPPAPORT, T., ireless Communications, Prentice-Hall, New York, 1996

RUIZHONG, L.; ZHI W.; YOUXIAN S., Wireless sensor networks solutions for real time monitoring of nuclear power plant, Intelligent Control and Automation, 2004. WCICA 2004. Fifth World Congress, Volume 4, Issue , 15-19 pp. 3663 - 3667 Vol.4. 2004

SADAGOPAN, N.; KRISHNAMACHARI, B.; HELMY, A., Active query Forwarding in Sensor Networks (ACQUIRE), in Proc. 1st IEEE Intl. Workshop on Sensor Network Protocols and Applications (SNPA), May 2003.

SLIJEPCEVIC, S.; POTKONJAK, M.; TSIATSIS, V.; ZIMBECK, S.; SRIVASTAVA, M. B., On Communication Security inWireless Ad-Hoc Sensor Networks, IEEE International Workshops on Enabling Technologies: Infrastructure for Collaborative Enterprises. pp. 1 - 6. 2002 .

SENE, JR. I. G; BARBOSA, M. G. A; ROCHA, A.; FRANCISCO, A; NASCIMENTO, F.; CARVALHO, H. Monitoração da temperatura corporal baseada em uma rede de sensores sem fios, In: X Congresso Brasileiro De Informática Em Saúde. 2006.

SEIDEL, S. Y.; RAPPAPORT, T. S., 914 MHz Path Loss Prediction Models for Indoor 
Wireless Communications in Multifloored Building, IEEE Trans. Antennas Propagat. Vol. 40. pp. 207 - 214. 1992.

SUKHATME, G. S.; DHARIWAL, A.; ZHANG, B., OBERG, C., STAUFFER, B.; CARON, D. A., Design and Development of a Wireless Robotic Networked Aquatic Microbial Observing System, Environmental Engineering Science, Vol. 24, No. 2. pp. 205 - 215. 2007.

TIMMONS, N. F. and SCANLON, W.G., Analysis of the performance of IEEE 802.15.4 For Medical Sensor Body area Networking, in Proc. IEEE Int. Conf Sensor and Ad Hoc Communications and Networks, Santa Clara, CA. pp. 16 - 24, 2004.

WANG, CH.; JIAN-MING, H.; CHIH-YI, CH.; CHIH-PENG, L. 868/915 MHz ZigBee Receiver for Personal Medical Assistance, Consumer Electronics, ICCE Digest of Technical Papers. pp. 461 - 462. 2006.

WHEELER, A., Commercial Applications Of Wireless Sensor Network Using ZigBee, IEEE Communications Magazine. pp. 1 - 5. 2007.

ZHENG, J.; LEE, J. M., A Comprehensive Performance Study of IEEE 802.15.4, IEEE Press Book, 2004.

Zensys (2007). Home page. http://www.zen-sys.com/.

ZigBee Alliance (2005). ZigBee Public Home Page. http://www.zigbee.org/. 


\section{Apêndice A - Código Fonte do Programa Desenvolvido}

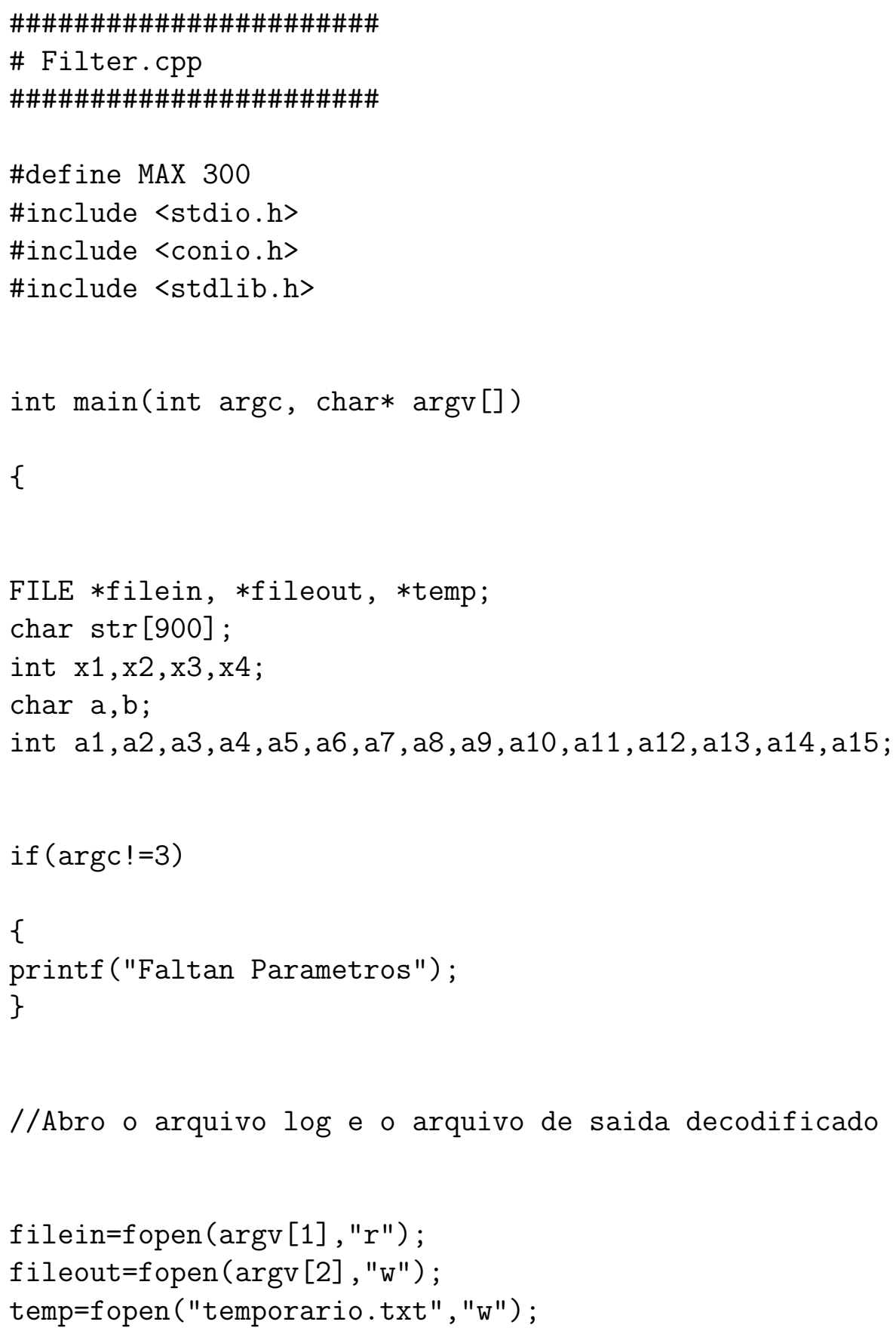


//fprintf (temp, "TOSMsg. lenght TOSMsg.fcf TOSMsg.dsn TOSMsg.destpan TOSMsg.addr TOSMsg.type TOSMsg.group MultihopMsg.sourceaddr MultihopMsg.originaddr MultihopMsg.seqno MultihopMsg.originseqno MultihopMsg.hopcount SurgeMsg.type SurgeMsg.reading SurgeMsg.parentaddr SurgeMsg.seqno $\left.\backslash \mathrm{n}^{\prime \prime}\right)$;

//HEXADECIMAL while(!feof (filein))

\{//Leo linha por linha do arquivo logs //Processo linha por linha fgets (str, MAX,filein);

fprintf (temp, " $\% c \% c \quad \% c \% c \% c \% c \quad \% c \% c \quad \% c \% c \% c \% c \quad \% c \% c \% c \% c$

$\% c \% c \quad \% c \%$ c $\% c \% c \% c \% c \quad \% c \% c \% c \% c \quad \% c \% c \% c \% c \quad \% c \% c \% c \% c$

$\% c \% c \% c \% c \quad \% c \% c \% c \% c \quad \% c \% c \% c \% c \quad \% c \% c \% c \% c \backslash n "$,

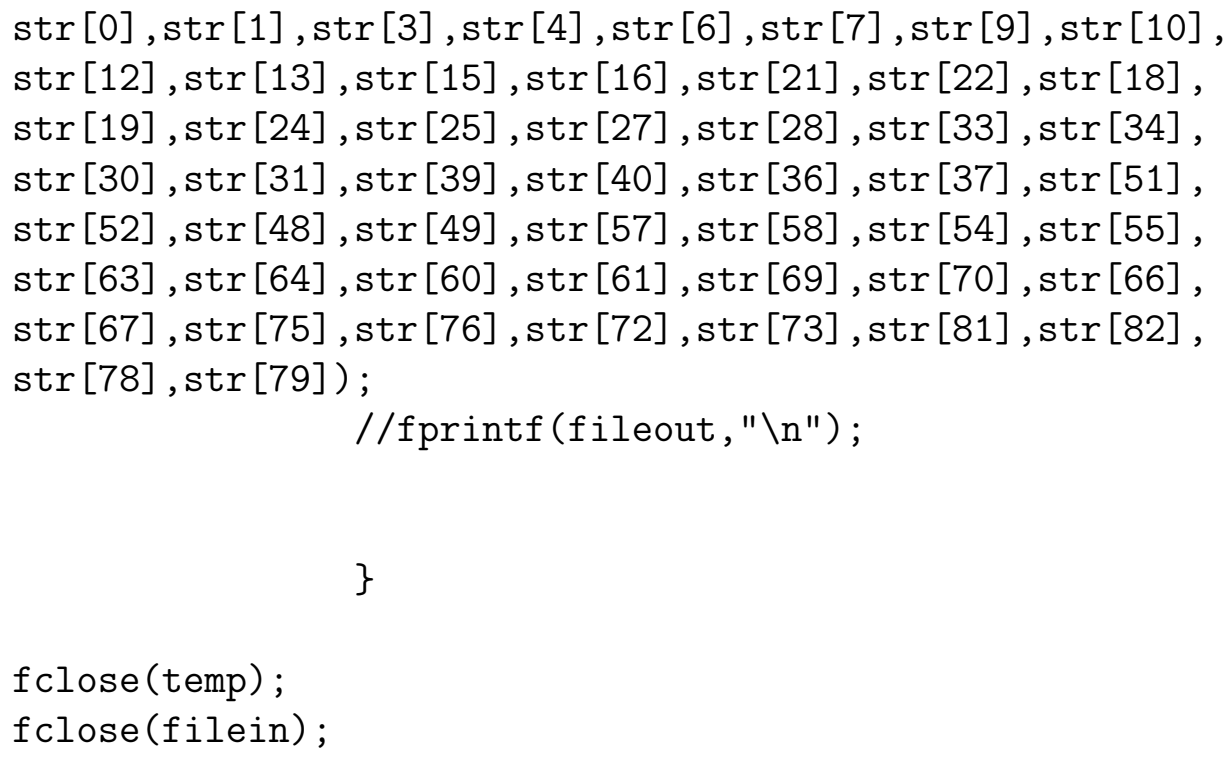

//DECIMAL

fprintf(fileout, "TOSMsg. lenght TOSMsg.fcf TOSMsg.dsn TOSMsg.destpan TOSMsg.addr TOSMsg.type TOSMsg.group MultihopMsg.sourceaddr MultihopMsg.originaddr MultihopMsg.seqno MultihopMsg.originseqno 
MultihopMsg.hopcount SurgeMsg.type SurgeMsg.reading SurgeMsg.parentaddr SurgeMsg.seqno \n");

temp=fopen ("temporario.txt", "r");

while(!feof (temp))

\{ fscanf (temp, $1 \% x \quad \% x \quad \% x \quad \% x \quad \% x \quad \% x \quad \% x \quad \% x \quad \% x \quad \% x \quad \% x \quad \% x$

" , \&a1 , \&a2 , \&a3 , \&a4 , \&a5 , \&a6 , \&a7 , \&a8, \&a9 , \&a10, \&a11 , \&a12 , \&a13, \&a14 , \&a15) ;

fprintf(fileout, $1 \% \mathrm{~d} \% \mathrm{~d} \% \mathrm{~d} \% \mathrm{~d} \% \mathrm{~d} \% \mathrm{~d} \% \mathrm{~d} \% \mathrm{~d} \% \mathrm{~d} \% \mathrm{~d} \% \mathrm{~d} \% \mathrm{~d} \% \mathrm{~d} \% \mathrm{~d} \% \mathrm{~d}$

$\backslash n ", a 1, a 2, a 3, a 4, a 5, a 6, a 7, a 8, a 9, a 10, a 11, a 12, a 13, a 14, a 15)$;

\}

$/ / / / / / / / /$

fclose(fileout);

fclose (temp);

return 0;

\} 


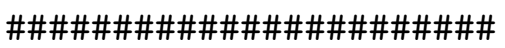 \\ \# Filter-ACK.cpp

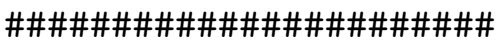

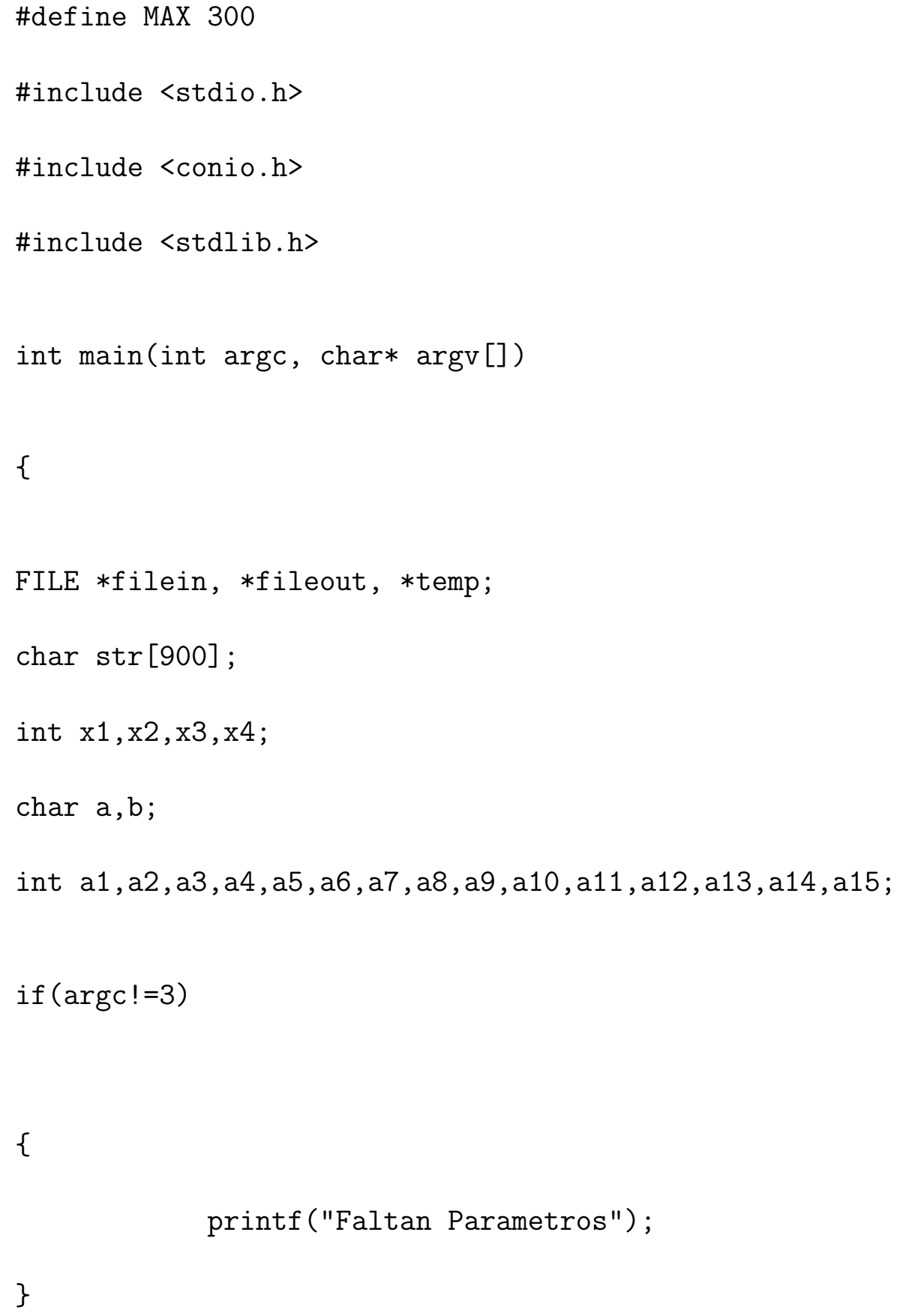




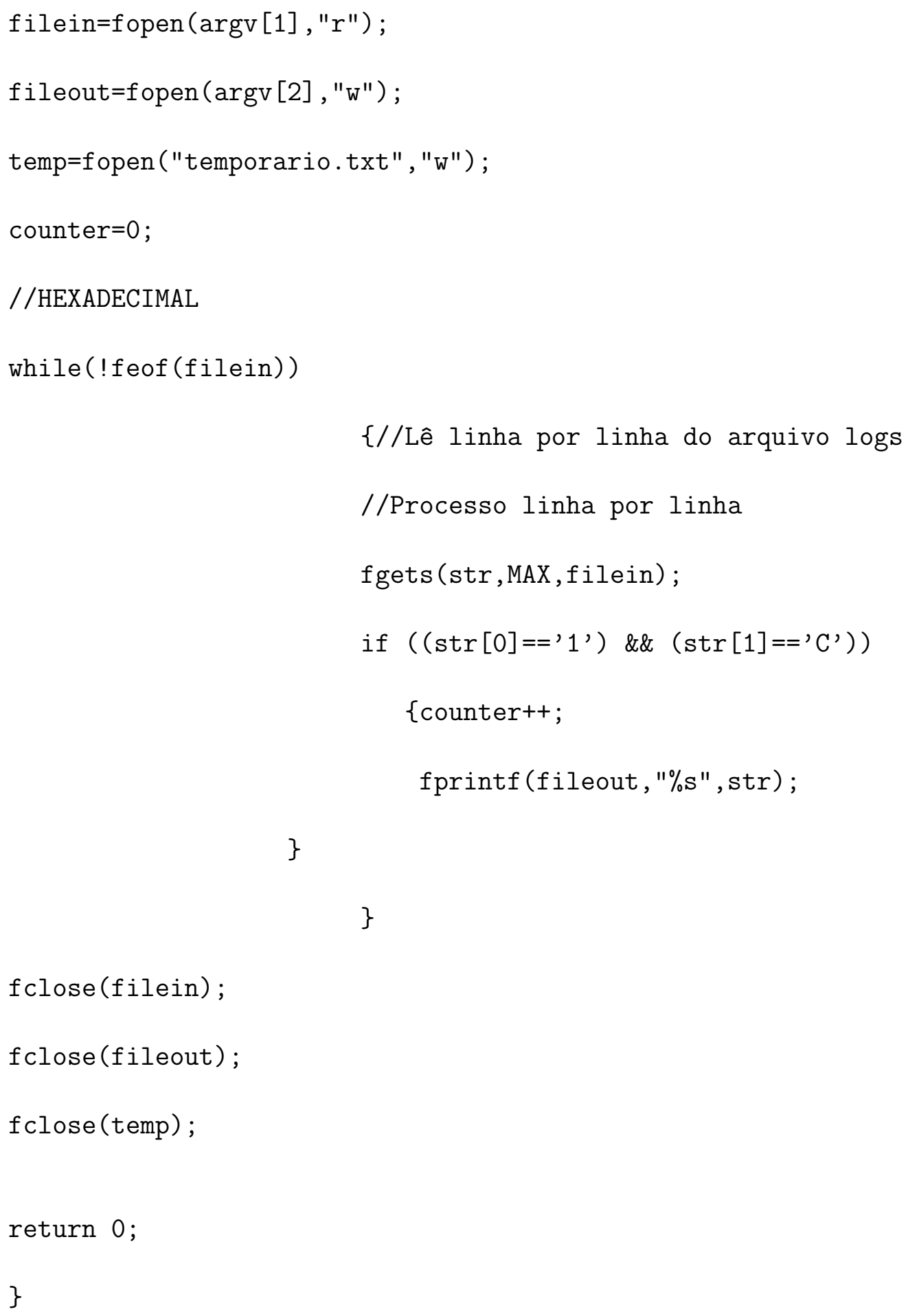




\section{Apêndice B - Código Fonte do Vi Desenvolvido}

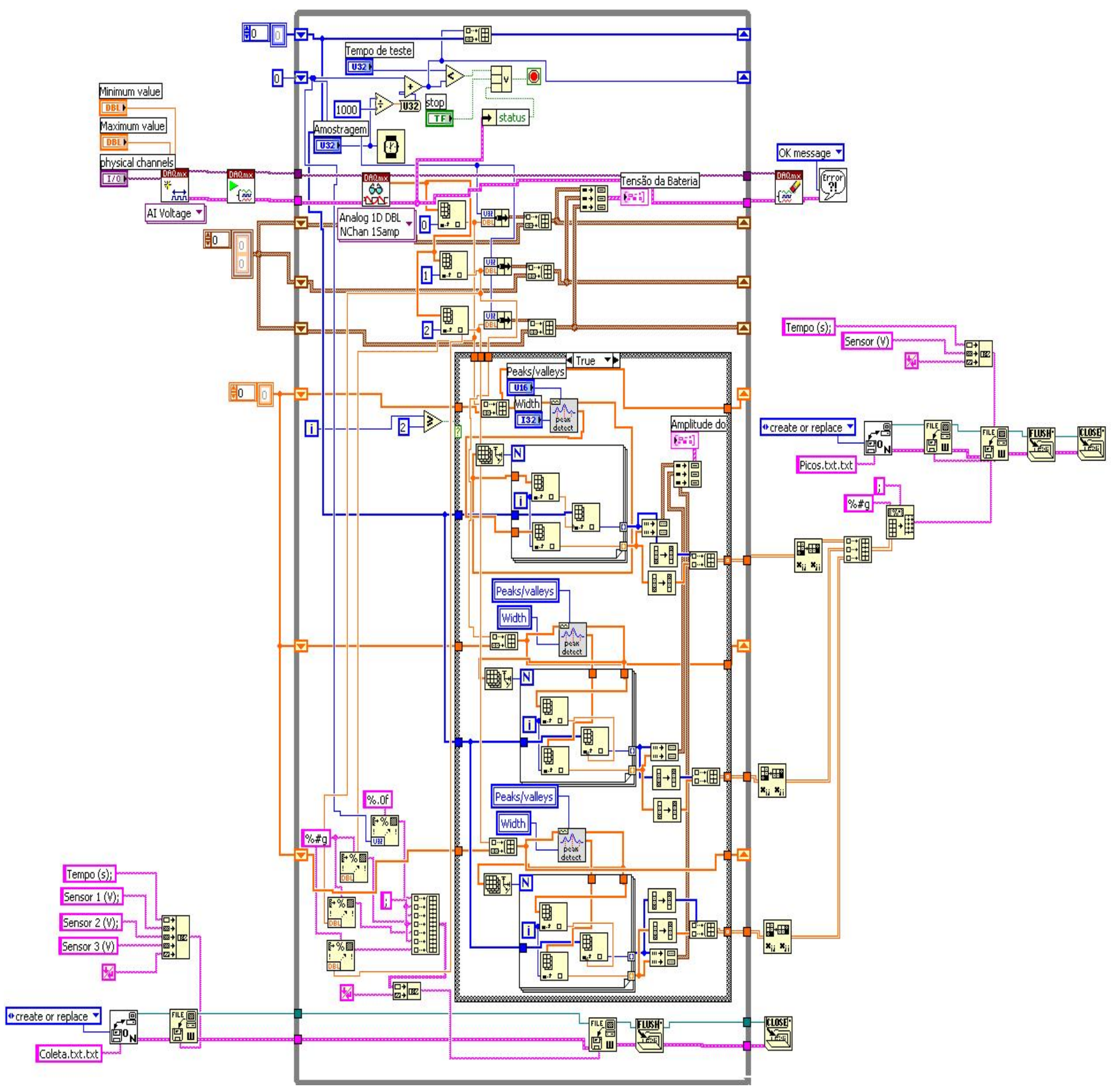

